Portland State University

PDXScholar

1978

\title{
A technique to calculate complex electromagnetic fields by using the finite element method
}

Davood Asgharian

Portland State University

Follow this and additional works at: https://pdxscholar.library.pdx.edu/open_access_etds

Part of the Computer Sciences Commons

Let us know how access to this document benefits you.

\section{Recommended Citation}

Asgharian, Davood, "A technique to calculate complex electromagnetic fields by using the finite element method" (1978). Dissertations and Theses. Paper 2863.

https://doi.org/10.15760/etd.2859

This Thesis is brought to you for free and open access. It has been accepted for inclusion in Dissertations and Theses by an authorized administrator of PDXScholar. Please contact us if we can make this document more accessible: pdxscholar@pdx.edu. 
AN ABSTRACT OF THE THESIS OF Davood Asgharian for the Master of Science in Applied Science presented May 16, 1978.

Title: A Technique to Calculate Complex Electromagnetic Fields by Using the Finite Element Method.

APPROVED BY MEMBERS OF THE THESIS COMMITTEE:

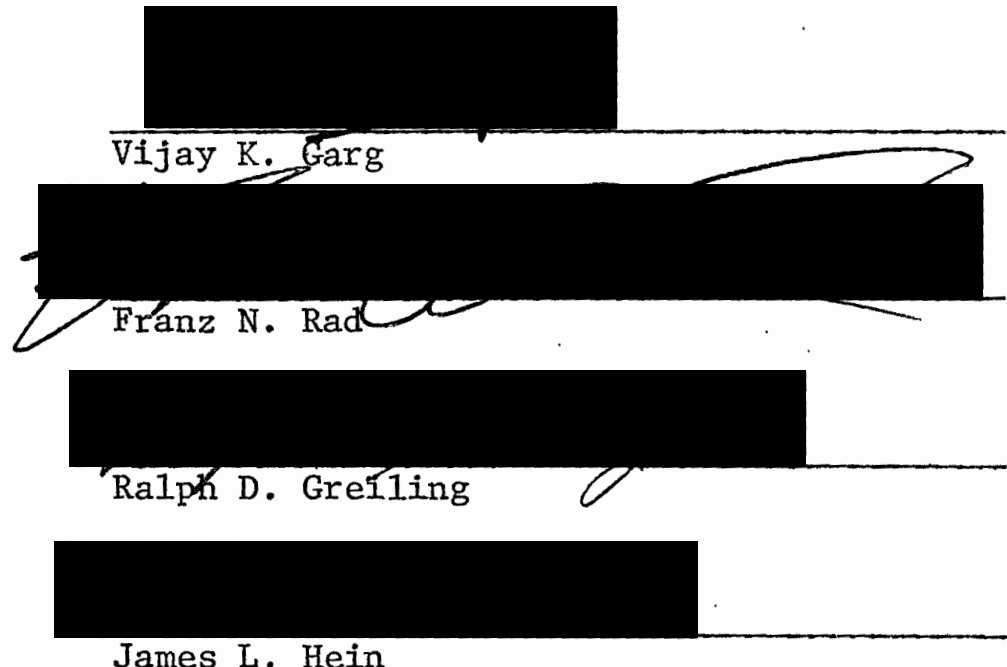

A computer program based on Maxwel1's equations is developed to calculate two-dimensional complex potentials by the Finite Element Method. This study offers a solution to a complex continuum problem by allowing a subdivision into a series of simple interrelated problems. The region of interest is divided into triangular elements. For each node in the grid, the Finite Element Method is used to set up an equation for the potential as a function of those of the surrounding nodes. All these equations are solved by the Gaussian Elimination Method. For increased accuracy this method requires a high degree of division of the region of interest. This could cause a storage problem on the computer. To eleviate this problem a half-banded scheme is used. A comparison is 
provided between the data obtained from the developed algorithm and an actual experiment. In this experiment two-types of sunken swimming pools, reinforced and non-reinforced, were used to hold three different waters of conductivities $29 \mu \mathrm{r} / \mathrm{cm}, 1500 \mu \mathrm{r} / \mathrm{cm}$ and $3000 \mu \mathrm{r} / \mathrm{cm}$. In order to test the accuracy of the computer program developed, the results of another solved problem are also compared to another computer program's results which was based on capacitive and resistive distribution of potentials. The result of this study shows the hazard may exist on the edges of the swimming pool when the resistivity of the surrounding soil is high. 
A TECHNIQUE TO CALCULATE COMPLEX ELECTROMAGNETIC

FIELDS BY USING THE FINITE ELEMENT METHOD

by

DAVOOD ASGHARIAN

A thesis submitted in partial fulfillment of the requirements for the degree of

\author{
MASTER OF SCIENCE \\ in \\ APPLIED SCIENCE
}

Portland State University

1978 
TO THE OFFICE OF GRADUATE STUDIES AND RESEARCH:

The members of the Committee approve the thesis of Davood Asgharian presented May 16, 1978.
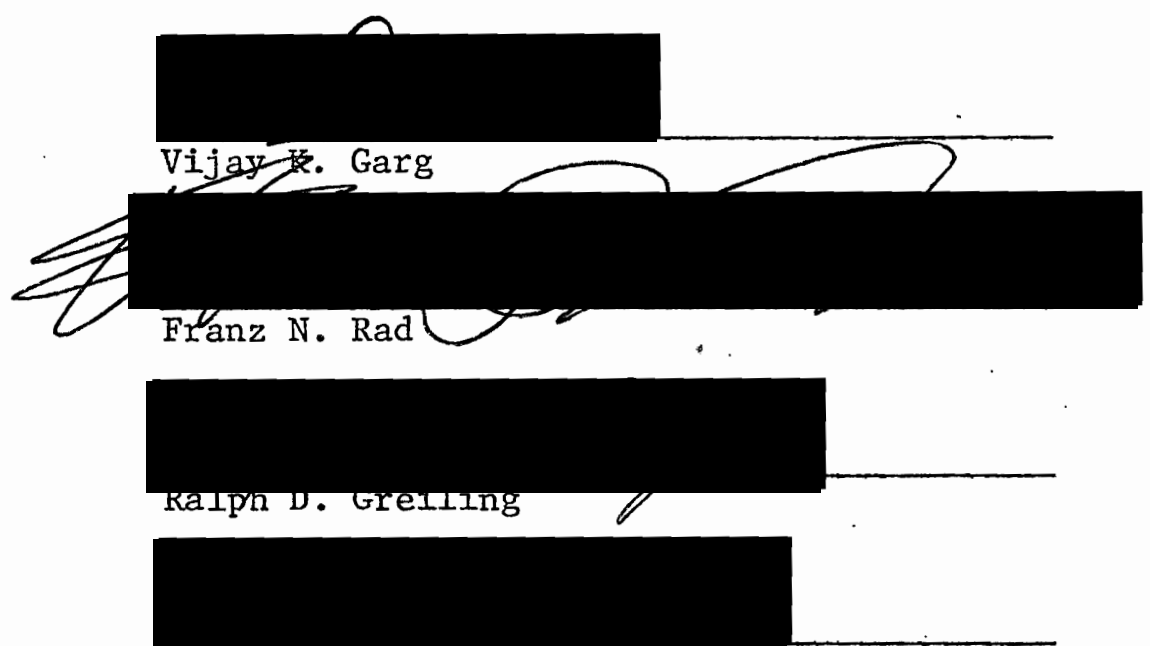

James L. Hein

\section{APPRQVED :}

Frof M. Young, Department Hezd Enqineering and Applied Science

Stănley E. Rauch, Dean

Graduate Studies and Research 
DEDICATED

TO MY

LOVING

WIFE 


\section{ACKNOWLEDGMENTS}

The author gratefully acknowledges indebtedness to Dr. V. J. Garg for his suggestion of the problem, criticisms, and suggestions during the course of this study and his sacrifice of time and energy during the writing of this thesis.

The author wishes to express his gratitude to Dr. F. Rad for his advice and reviewing this thesis. I would also like to express my appreciation to Professor R. Greiling for making many constructive comments.

Consultation with Dr. W. Mueller was also a great aid in the writing of the computer portion of this study.

The author wishes to thank Ms. Donna Mikulic for the excellent and efficient typing of this thesis.

I am especially indebted to my dear wife for her encouragement, understanding and unfailing patience. 
TABLE OF CONTENTS

ACKNOWLEDGMENTS

Page

ACKNOHLEGMENS

LIST OF TABLES

vii

LIST OF FIGURES

viii

CHAPTER

I INTRODUCTION

1.1 REVIEW OF LITERATURE 1

1.2 STATEMENT OF THE PROBLEM 3

II FINITE ELEMENT METHOD $\quad 4$

2.1 DEFINITION 4

2.2 FORMULATION OF FINITE - ELEMENT METHOD 4

2.3 FORMULATION OF POTENTIAL PROBLEMS WITH SPATIAL
FINITE ELEMENT SUBDIVISIONS

2.4 FINITE ELEMENT SOLUTION OF COMPLEX POTENTIAL
ELECTRIC FIELDS

III COMPUTER PROGRAM 18

3.1 SOLUTION TECHNIQUE FOR THE FINITE ELEMENT METHOD 18

3.2 RESULTS OF THE COMPUTER SOLUTION 29

3.3 COMPARISON OF RESULTS WITH OTHER COMPUTER

IV EXPERIMEN'AAL PROGRAM $\quad 38$

$\begin{array}{lll}V & \text { RESULTS } & 42\end{array}$

5.1 COMPARISON OF CALCULATED VALUES WITH EXPERIMENTAL RESULTS

5.2 POTENTIAL HAZARD TO THE HUMAN BODY 52

5.3 THE LIMITATIONS AND ACCURACY OF THE
THEORETICAL TECHNIQUE

$\begin{array}{ll}\text { VI CONCLUSION } & 60\end{array}$

$\begin{array}{ll}\text { BIBLIOGRAPHY } & 61\end{array}$ 
Page

APPENDIX A EULER'S THEOREM OF VARIATIONAL CALCULUS

APPENDIX B THE GAUSSIAN METHOD

66

APPENDIX C CALCULATION OF CURRENT DENSITY

72

APPENDIX D LISTING OF PROGRAMS AND SUBROUTINES

76

APPENDIX E COMPUTER RESULTS

87

APPENDIX F EXPERIMENTAL RESULTS 


\section{LIST OF TABLES}

Table

Page

3.1

Comparison of Results of a Specific Problem

$5.1-5.4$

Calculated Current Travelling Through the Human Body Standing on the Soil

5.5

Calculated Current Travelling Through the Human Body Inside the Swimming Pool

C. $1-C .3$

Calculated Current Densities on the Surface of the Earth

E.1 - E. 9

Current Densities Calculated in Soil

$88-96$

E.10 - E. 12

Current Densities Calculated in Water

$97-99$

F.1 - F.9

Current Densities Measured in Soil

101-109

F.10 - F.12

Current Densities Measured in Water

110 


\section{LIST OF FIGURES}

Figure

Page

2.1

Triangular Division of the Area

2.2

One Triangle

2.3

Typical Triangle with Vertices Marked

2.4

Area Coordinates

3.1

Region ' $s$ ' is Divided in 18 Triangular Elements

Banded Form of a Symmetrical Matrix

Flow Chart, Subroutine "BANDWIDTH"

Flow Chart, Subroutine "FIND"

The Finite Element Model

Regional Division of the Experimental Model

Flow Chart, Subroutine "Good"

3.8

Flow Chart, Program "TES"

3.9

Resistive and Complex Admittance Networks

Two Materials in Series

4.1

Schematic Diagram of the Experimental Model

Schematic Diagram of the Electrical Circuit

$5.1-5.8$ Calculated Current Densities Levels of Current Hazards to the Human
Body 
CHAPTER I

INTRODUCTION

\subsection{REVIEW OF LITERATURE}

A considerable amount of work has been done in the past in calculating the self and mutual impedance of two parallel ground return wires. The following paragraphs summarize these attempts in chronological order.

The first attempt was made by Carson (1). He investigated the problem of wave propagation along a transmission system composed of an overhead wire parallel to the surface of the earth. However a complete solution of determining the actual impedance is impossible because of the non-homogeneity of the earth. The solution to the problem, where the actual earth is replaced by a plane homogeneous semi-infinite solid has promoted considerable theoretical and practical interest.

In 1951, Lacey and Wasley (2) at the Hydro-Electro Power Commission of Ontario, Canada, developed an equation for the mutual impedance of two finite length earth-return circuits, either parallel or at an angle. The equation developed by them is to be a generalization of Carson's work.

In 1965, Wedepoh1 (3) published a paper on wave propagation in multiconductor overhead lines which would permit the earth-return path to have a relative permeability other than unity, which was not permissi- 
ble in the analysis by Carson. In this paper, the new approach is applied to the case of a two-layer earth, including the effects of displacement currents. The results were in agreement with those obtained for the case of a homogeneous earth.

In 1966, Krakowski (4) developed equations for the mutual impedances of overhead lines with the earth as a return path. In this paper the problem deals with two different lines which cross each other at an angle, $\alpha$, different from zero. A particular case of this problem is the same as Carson's solution for $\alpha=0$. The general solution of this problem is considered, assuming that the earth is uniformly conducting and that both overhead conductors are parallel to the surface of the earth.

In 1973, Nakagawa (5) published a paper in this area. This solution permits the earth-return path to be considered as three layers of different resistivities, permitivities and permeabilities. A stratified earth causes marked differences in the earth impedances and the resultant wave deformations from the homogeneous case. The depth of a layer is a significant factor to the value of the stratified-earth impedance. The displacement currents can influence earth-return impedances. This is only at very high frequencies and under the conditions of high earth resistivity and low conductor height.

All these papers prove that there are several ways of calculating the distributed impedance of ground return transmission lines.

Magnusson (6) developed a method of calculating the mutual and self-impedance of overhead lines with the earth as a return path. He also calculated the mutual and self-impedance of the line under the 
following conditions:
A. A conductor height of 35 feet
B. A line-to-ground short-circuit current of 2000 amperes.
C. A ground conductivity of 0.01 mho per meter

By the calculated value of the mutual and self-impedance of overhead lines with the earth as a return path and the use of the developed formula, he calculated the current densities in a typical below grade swimming pool.

The densities change with respect to the distance of the swimming pool from the vertical plane of the transmission line. The calculated current densities in the pool were found to be hazardous to the swimmer in the swimming pool.

\subsection{STATEMENT OF THE PROBLEM}

The purpose of this investigation is to develop a computer code based on Maxwell's equations to calculate potentials between points of interest on the surface of the earth and swimming pool by knowing at least two boundary conditions, using the Finite Element Method. In order to check the validity of this study, the results are compared to experimental values. 
CHAPTER II

FINITE ELEMENT METHOD

\subsection{DEFINITION}

The Finite Element Method is a numerical technique for obtaining approximate solutions to a wide variety of engineering problems. The ability to use elements of various types and sizes and to model a system of arbitrary geometry, are the main advantages of the Finite Element Method.

Other approximate methods, for example the Finite Difference Method, lacks these advantages. Using these approximate methods, a specific numerical result may be obtained for a specific problem, but a general computer solution applicable to all cases is not possible.

The Finite Element Method offers a way to solve a complex continuum problem by subdividing the continuum into a series of simpler interrelated problems. It gives a consistent technique for modeling the system as an assemblage of discrete parts or finite elements.

\subsection{FORMULATION OF FINITE ELEMENT METHOD}

It is desirable to obtain results in a general form applicable to any situation. For this purpose a division of the region into triangular shape elements is used as shown in Fig. 2.1.

The problem is to calculate the values of $\mathrm{H}_{\mathrm{N}}^{(e)}$ (i.e., voltage) at each node, $(\mathrm{N}=1,2, \ldots, \mathrm{n})$ by knowing values of $\mathrm{H}_{\mathrm{N}}^{(\mathrm{e})}$ at some node 


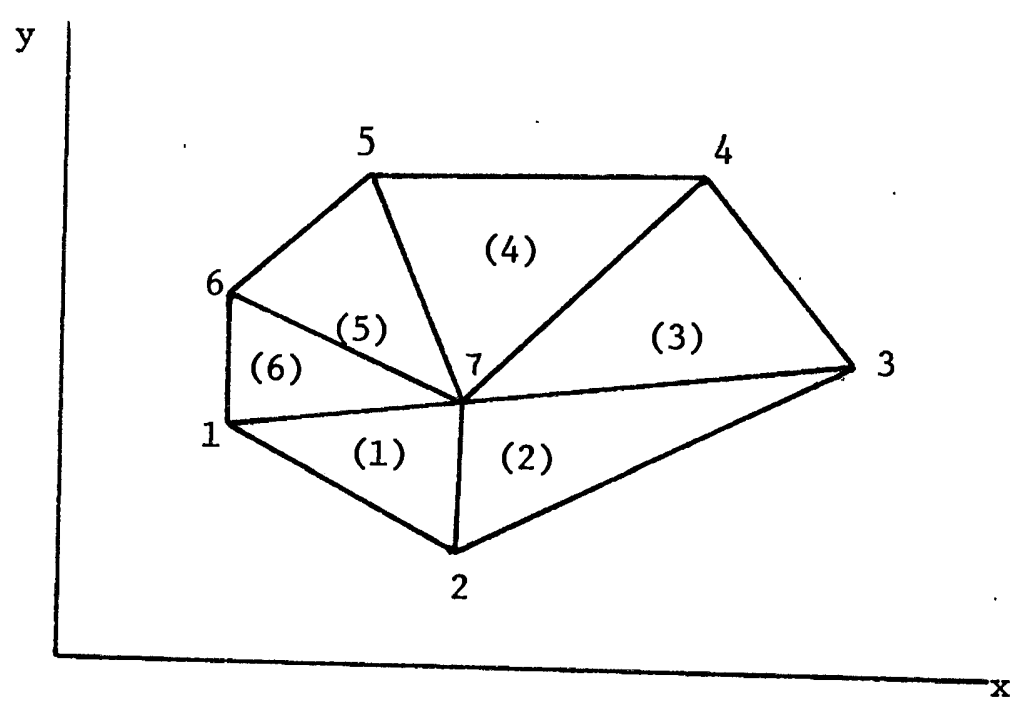

Figure 2.1 Triangular division of the area.

as boundary conditions.

The integer numbers of $1,2, \ldots, \mathrm{n}$ represent the number of the particular node and value of $\mathrm{H}$ at node 5 which is written as $\mathrm{H}_{5}$. The integer numbers written inside parenthesis, for example, (3) represents the element's number.

Each element has three nodes and each node has its own coordinate values. For example, element (1) has nodes $1,2,7$ and coordinate values of $\left(x_{1}, y_{1}\right),\left(x_{2}, y_{2}\right),\left(x_{7}, y_{7}\right)$, and element (5) has nodes $6,7,5$ and coordinate values of $\left(x_{6}, y_{6}\right),\left(x_{y_{7}}, y_{7}\right),\left(x_{5}, y_{5}\right)$.

Fig. 2.2 shows a typical triangle from the whole area of Fig. 2.1. The assumption is that the value of $h$ (i.e., voltage) at any point inside the triangle is a linear function of $\mathrm{H}$ at the triangle's three nodes, or simply: 
$h^{(e)}=\left[N_{l}^{(e)} N_{m}^{(e)} N_{m}^{(e)}\right]\left[\begin{array}{c}H_{\ell} \\ H_{m} \\ H_{m}\end{array}\right]=[N][H]$

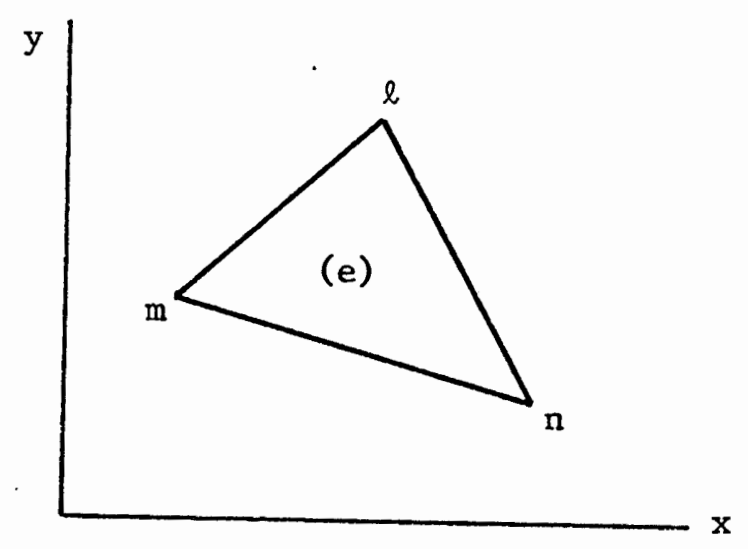

Figure 2.2 One triangle element.

Therefore, for the area of Fig. 2.1, the values of $h$ in each element are:

$$
\begin{aligned}
& h^{(1)}=\mathrm{N}_{1}^{(1)} \mathrm{H}_{1}+\mathrm{N}_{2}^{(1)} \mathrm{H}_{2}+\mathrm{N}_{7}^{(1)} \mathrm{H}_{7} \\
& \mathrm{~h}^{(2)}=\mathrm{N}_{2}^{(2)} \mathrm{H}_{2}+\mathrm{N}_{3}^{(2)} \mathrm{H}_{3}+\mathrm{N}_{7}^{(2)} \mathrm{H}_{7} \\
& \mathrm{~h}^{(3)}=\mathrm{N}_{3}^{(3)} \mathrm{H}_{3}+\mathrm{N}_{4}^{(3)} \mathrm{H}_{4}+\mathrm{N}_{7}^{(3)} \mathrm{H}_{7} \\
& \mathrm{~h}^{(4)}=\mathrm{N}_{4}^{(4)} \mathrm{H}_{4}+\mathrm{N}_{5}^{(4)} \mathrm{H}_{5}+\mathrm{N}_{7}^{(4)} \mathrm{H}_{7} \\
& \mathrm{~h}^{(5)}=\mathrm{N}_{5}^{(5)} \mathrm{H}_{5}+\mathrm{N}_{6}^{(5)} \mathrm{H}_{6}+\mathrm{N}_{7}^{(5)} \mathrm{H}_{7} \\
& \mathrm{~h}^{(6)}=\mathrm{N}_{6}^{(6)} \mathrm{H}_{6}+\mathrm{N}_{1}^{(6)} \mathrm{H}_{1}+\mathrm{N}_{7}^{(6)} \mathrm{H}_{7}
\end{aligned}
$$

Where [N] is called a shape function and will be seen later to play a paramount role in the Finite Element Method. The shape function is a function of area coordinates: 


$$
N_{n}^{(e)}=1 / 2 A(e)\left[a_{n}^{(e)}+b_{n}^{(e)} X+c_{n}^{(e)} Y\right]
$$

Where $A=$ area of the triangle:

$$
\begin{aligned}
& a_{n}=x_{\ell} y_{m}-x_{m} y_{\ell} \\
& b_{n}=y_{\ell}-y_{m} \\
& c_{n}=x_{m}-x_{\ell}
\end{aligned}
$$

For example $\mathrm{N}_{7}$ for element (4) is:

$$
\mathrm{N}_{7}^{(4)}=1 / 2 \mathrm{~A}^{(4)}\left[\mathrm{a}_{7}^{(4)}+\mathrm{b}_{7}^{(4)} \mathrm{X}+\mathrm{c}_{7}^{(4)} \mathrm{Y}\right]
$$

Where:

$$
\begin{aligned}
& a_{7}=x_{4} y_{5}-x_{5} y_{4} \\
& b_{7}=y_{4}-y_{5} \\
& c_{7}=x_{5}-x_{4}
\end{aligned}
$$

and so on.

The total $\mathrm{h}$ in this area is equal to the summation of $\mathrm{hS}$ in the elements.

$$
h=\sum_{e=1}^{E} h^{(e)}
$$

Where $\mathrm{E}$ is the number of the last node. Eq. 2-9 could be written in matrix form as well as in summation form.

$$
\left[\begin{array}{l}
h^{(1)} \\
h^{(2)} \\
h^{(3)} \\
h^{(4)} \\
h^{(5)} \\
h^{(6)}
\end{array}\right]=\left[\begin{array}{lllllll}
N_{1}^{(1)} & N_{2}^{(1)} & 0 & 0 & 0 & 0 & N_{7}^{(1)} \\
0 & N_{2}^{(2)} & N_{3}^{(2)} & 0 & 0 & 0 & N_{7}^{(2)} \\
0 & 0 & N_{3}^{(3)} & N_{4}^{(3)} & 0 & 0 & N_{7}^{(3)} \\
0 & 0 & 0 & N_{4}^{(4)} & N_{5}^{(4)} & 0 & N_{7}^{(4)} \\
0 & 0 & 0 & 0 & N_{5}^{(5)} & N_{6}^{(5)} & N_{7}^{(5)} \\
N_{1}^{(6)} & 0 & 0 & 0 & 0 & N_{6}^{(6)} & N_{7}^{(6)}
\end{array}\right]\left[\begin{array}{c}
\mathrm{H}_{1} \\
H_{2} \\
H_{3} \\
H_{4} \\
H_{5} \\
H_{6}
\end{array}\right]{ }^{2-10}
$$




\subsection{FORMULATION OF POTENTIAL PROBLEMS WITH SPATIAL FINITE ELEMENT SUBDIVISIONS}

The current density $\mathrm{J}_{\mathrm{T}}$ consists of both conduction and displacement components, respectively:

$$
\mathrm{J}_{\mathrm{T}}=\sigma_{\mathrm{E}}+(\partial / \partial \mathrm{t}) \mathrm{D}
$$

where

$$
D=j t^{\omega} \varepsilon E
$$

After substitution of Eq. 2-12 into Eq. 2-11 one may obtain this result:

$$
\mathrm{J}_{\mathrm{T}}=(\sigma+j \omega \varepsilon) \mathrm{E}
$$

Equation 2-13 by Kirchoff's law must satisfy the continuity equation.

$$
\nabla \cdot \mathrm{J}_{\mathrm{T}}=0
$$

or

$$
\nabla \cdot(\sigma+j \omega \varepsilon) E=0
$$

but

$$
\begin{aligned}
& E=-\nabla V=0 \\
& \nabla \cdot(\sigma+j \omega \varepsilon) \nabla V=0
\end{aligned}
$$

where

$$
\nabla V=\left[(\partial / \partial x) V a_{x}+(\partial / \partial y) V a_{y}+(\partial / \partial z) V a_{z}\right]
$$

Substitute Eq. 2-18 back in Eq. 2-16:

$$
\begin{array}{ll}
\nabla \cdot(\sigma+j \omega \varepsilon)\left[(\partial / \partial \mathrm{x}) \mathrm{Va}_{\mathrm{x}}+(\partial / \partial \mathrm{y}) \mathrm{Va}_{\mathrm{y}}+(\partial / \partial z) \mathrm{Va}_{\mathrm{z}}\right]=0 & 2-19 \\
\nabla \cdot \mathrm{A}=(\partial / \partial \mathrm{x}) \mathrm{A}+(\partial / \partial \mathrm{y}) \mathrm{A}+(\partial / \partial \mathrm{z}) \mathrm{A} & 2-20
\end{array}
$$

Therefore the resultant equation is:

$$
(\partial / \partial x)(\sigma+j \omega \varepsilon)(\partial / \partial x) V+(\partial / \partial y)(\sigma+j \omega \varepsilon)(\partial / \partial y) v+
$$

$$
(\partial / \partial z)(\sigma+j \omega \varepsilon)(\partial / \partial z) V=0
$$


In order to solve Eq. 2-21 one may need to know Euler's theorem of variational calculus, as outlined in Appendix A. By the help of variational calculus, a function $I(V)$ could be found where $\delta I(V)=0$ everywhere.

$$
\begin{aligned}
& I(V)=1 / 2 \int_{\Omega}\left[(\sigma+j \omega \varepsilon)(\partial V / \partial x)^{2}+(\sigma+j \omega \varepsilon)(\partial V / \partial y)^{2}+\right. \\
& \left.(\sigma+j \omega \varepsilon)(\partial V / \partial z)^{2}\right] d x d y d z
\end{aligned}
$$

but

$$
v^{(e)}=\sum_{i=1}^{3} N_{i} v_{i}=[N][V]{ }^{(e)}
$$

The derivative of $I(V)$ with respect to the $V_{1}$ is equal to zero.

$$
\begin{aligned}
& \partial I(V)(e) / \partial V_{i}= 0 \\
&=\int_{\Omega}\left\{\left[(\sigma+j \omega \varepsilon)\left(\partial V^{(e)} / \partial x\right)\left(\partial / \partial V_{i}\right)\left(\partial V^{(e)} / \partial x\right)\right]+\right. \\
& {\left.\left[(\sigma+j \omega \varepsilon)\left(\partial V^{(e)} / \partial y\right)\left(\partial / \partial V_{i}\right) \partial v^{(e)} / \partial y\right)\right]+ } \\
& {\left.\left[(\sigma+j \omega \varepsilon)\left(\partial V^{(e)} / \partial z\right)\left(\partial / \partial V_{i}\right)\left(\partial V^{(e)} / \partial z\right)\right]\right\} d x d y d z \quad 2-24 }
\end{aligned}
$$

But from Eq. 2-23 it is obvious that the derivative of $v^{(e)}$ with respect to $\mathrm{x}$ is:

$$
\begin{array}{r}
\partial v^{(e)} / \partial x=\sum_{i=1}^{3}\left(\partial N_{i} / \partial x\right) v_{i}=[\partial N / \partial x][V] \\
(e) \\
\left(\partial / \partial v_{i}\right)\left(\partial v^{(e)} / \partial x\right)=\left(\partial / \partial v_{i}\right)\left[\left(\partial N_{i} / \partial x\right) v_{i}\right]=\partial N_{i} / \partial x
\end{array}
$$

where

$$
\partial V^{(e)} / \partial V_{i}=N_{i}
$$

The result of the substitution of Eq. 2-25, 2-26 and 2-27 back in Eq. $2-24$ is : 


$$
\begin{aligned}
\partial I(V)(e) / \partial V_{i}=0= & \int_{\Omega}\left\{(\sigma+j \omega \varepsilon)[\partial N / \partial \mathbf{x}][V]\left(\partial N_{i} / \partial x\right)+\right. \\
& (\sigma+j \omega \varepsilon)[\partial N / \partial y][V]\left(\partial N_{i} / \partial y\right)+ \\
& \left.(\sigma+j \omega \varepsilon)[\partial N / \partial z][V]\left[\partial N_{i} / \partial z\right]\right\} d x d y d z
\end{aligned}
$$

Equation 2-28 could be written in general form as:

$$
[\mathrm{K}][\mathrm{V}]=[0]
$$

Where:

$$
\begin{aligned}
\mathrm{K}_{i, j}= & \int_{\Omega}\left\{(\sigma+j \omega \varepsilon)\left(\partial \mathrm{N}_{i} / \partial x\right)\left(\partial \mathrm{N}_{j} / \partial x\right)+(\sigma+j \omega \varepsilon)\left(\partial \mathrm{N}_{i} / \partial y\right)\right. \\
& \left.\left(\partial \mathrm{N}_{j} / \partial y\right)+(\sigma+j \omega \varepsilon)\left(\partial \mathrm{N}_{i} / \partial z\right)\left(\partial \mathrm{N}_{j} / \partial z\right)\right\} d x d y d z
\end{aligned}
$$

\subsection{FINITE ELEMENT SOLUTION OF COMPLEX POTENTIAL ELECTRIC FIELDS}

The region of the problem can be subdivided into triangles in any desired manner, insuring only that all different material interfaces coincide with triangle sides. Figure 2.3 shows a typical region divided into triangles.

It is assumed that there is a linear variation of potential within each triangular element with respect to the nodal potentials.

A convenient set of coordinates $\mathrm{L}_{1}, \mathrm{~L}_{2}, \mathrm{~L}_{3}$ for a triangle $\ell, \mathrm{m}, \mathrm{n}$, Fig. 2.4, is defined by the following linear relation between these and the Cartesian system: 


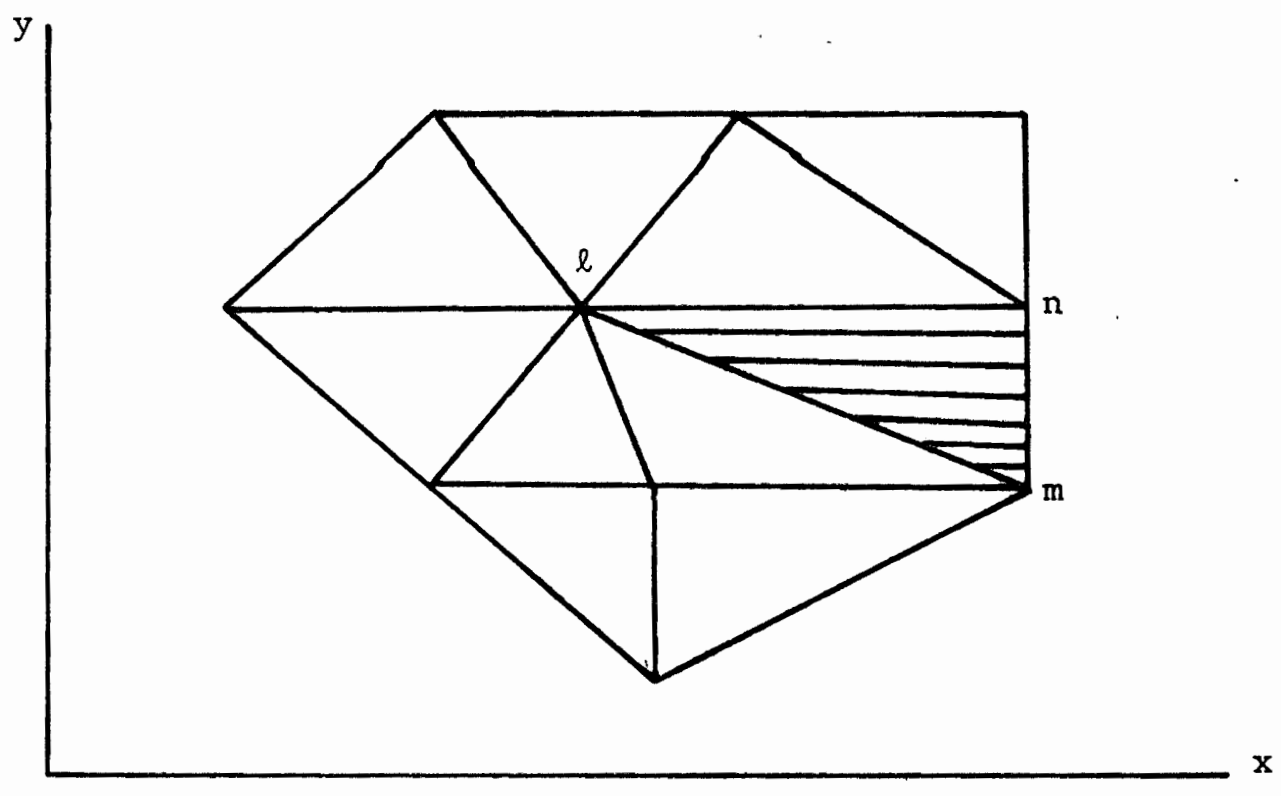

Figure 2.3 Typical trlangle with vertices marked.

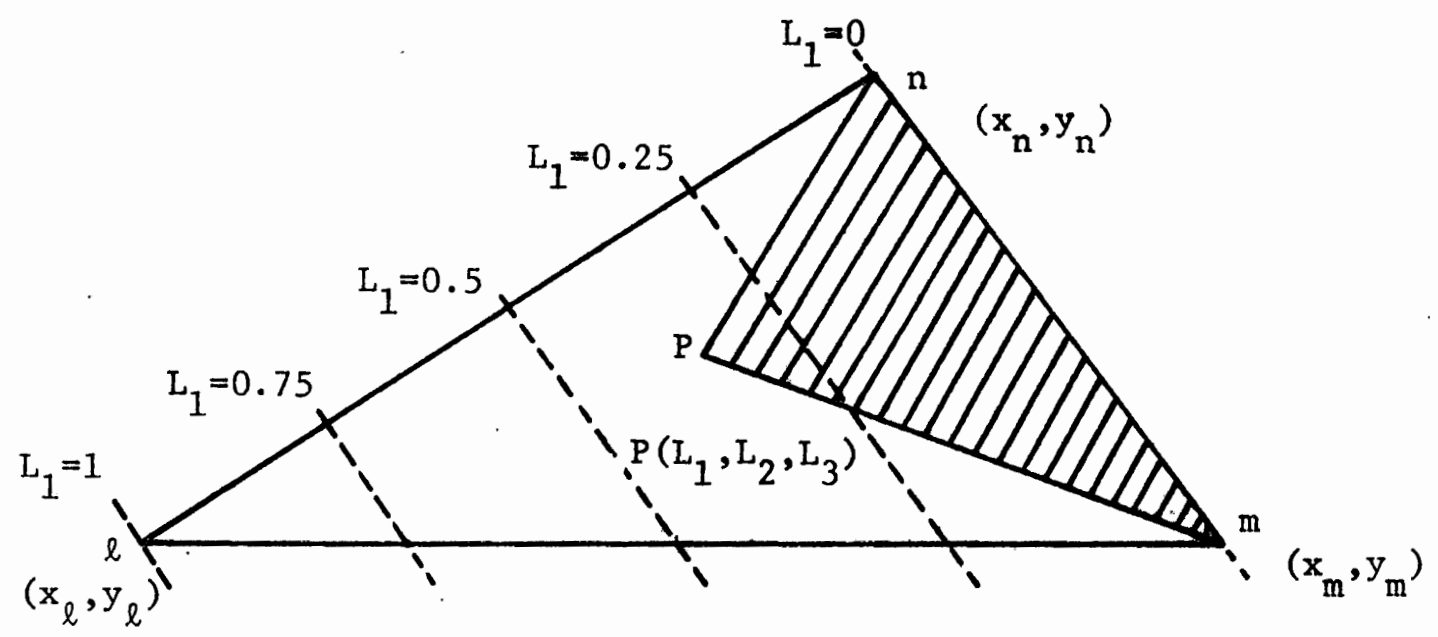

Figure 2.4 Area coordinates. 


$$
\begin{aligned}
& x=L_{1} x_{\ell}+L_{2} x_{m}+L_{3} x_{n} \\
& y=L_{1} y_{\ell}+L_{2} y_{m}+L_{3} y_{n} \\
& 1=L_{1}+L_{2}+L_{3}
\end{aligned}
$$

To every set, $\mathrm{L}_{1}, \mathrm{~L}_{2}, \mathrm{~L}_{3}$ (which are not independent, but are related by the third equation) corresponds a unique set of Cartesian coordinates. At point $1, \mathrm{~L}_{1}=1$ and $\mathrm{L}_{2}=\mathrm{L}_{3}=0$, etc. A linear relation between the area coordinates and Cartesian coordinates implies that contours of $\mathrm{L}_{1}$ are equally placed straight lines parallel to side 2-3 on which $L_{1}=0$ etc. It is easy to see that an alternative definition of the coordinate $L_{1}$ of a point $P$ is by a ratio of the area of the shaded triangle to that of the total triangle.

$$
\mathrm{L}_{1}=\frac{\text { area } P \mathrm{mn}}{\text { area } \ell \mathrm{mn}}
$$

One may write Equations 2-31 through 2-33 in matrix form and solve it for $L_{1}, L_{2}, L_{3}$.

$$
\left[\begin{array}{ccc}
x_{\ell} & x_{m} & x_{n} \\
y_{\ell} & y_{m} & y_{n} \\
1 & 1 & 1
\end{array}\right]\left[\begin{array}{c}
L_{1} \\
L_{2} \\
L_{3}
\end{array}\right]=\left[\begin{array}{l}
x \\
y \\
1
\end{array}\right]
$$




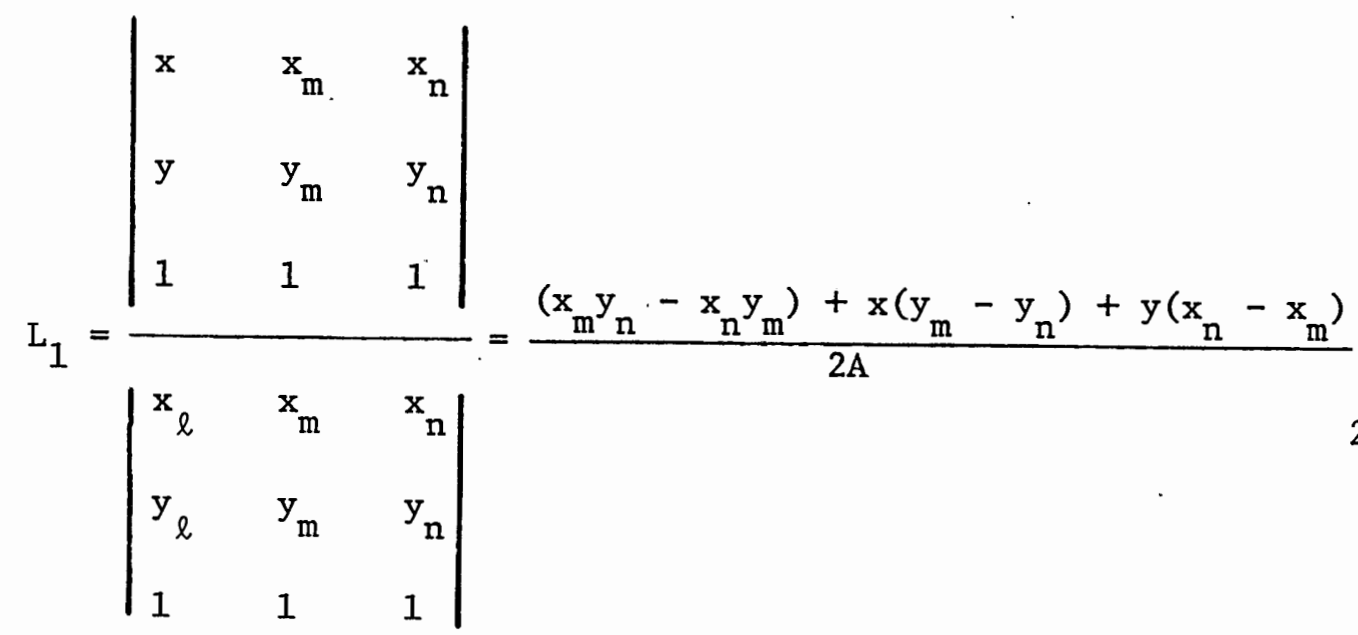

$L_{2}=\frac{\left|\begin{array}{ccc}x_{\ell} & x & x_{n} \\ y_{\ell} & y & y_{n} \\ 1 & 1 & 1\end{array}\right|}{\left|\begin{array}{ccc}x_{\ell} & x_{m} & x_{n} \\ y_{\ell} & y_{m} & y_{n} \\ 1 & 1 & 1\end{array}\right|}$

$\left|\begin{array}{ccc}\mathrm{x}_{\ell} & \mathrm{x}_{\mathrm{m}} & \mathrm{x} \\ \mathrm{y}_{\ell} & \mathrm{y}_{\mathrm{m}} & \mathrm{y} \\ 1 & 1 & 1\end{array}\right|$

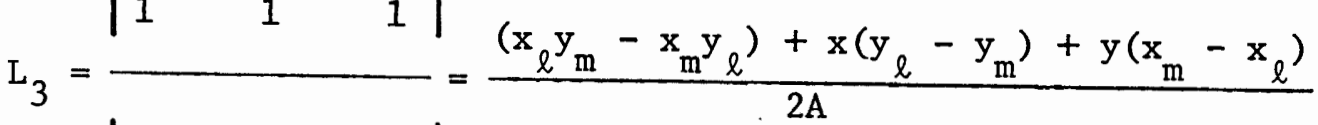
$\left|\begin{array}{ccc}x_{\ell} & x_{m} & x_{n} \\ y_{\ell} & y_{m} & y_{n} \\ 1 & 1 & 1\end{array}\right|$ 
Where:

$$
\begin{aligned}
2 \mathrm{~A}=2 *(\text { area of the triangle })= & \left(\mathrm{x}_{\mathrm{m}} \mathrm{y}_{\mathrm{n}}-\mathrm{x}_{\mathrm{n}} \mathrm{y}_{\mathrm{m}}\right)+\left(\mathrm{x}_{\mathrm{n}} \mathrm{y}_{\ell}-\mathrm{x}_{\ell} \mathrm{y}_{\mathrm{m}}\right)+ \\
& \left(\mathrm{x}_{\ell} \mathrm{y}_{\mathrm{m}}-\mathrm{x}_{\mathrm{m}} \mathrm{y}_{\ell}\right)
\end{aligned}
$$

The area coordinates are the shape functions: $\mathrm{N}_{1}=\mathrm{L}_{1}, \mathrm{~N}_{2}=\mathrm{L}_{2}$ and $\mathrm{N}_{3}=\mathrm{L}_{3}$

The potential inside the triangular element is a linear function of the nodal's potentials:

$$
\mathrm{v}^{(\mathrm{e})}=\mathrm{I}_{1} \mathrm{~V}_{\ell}+\mathrm{I}_{2} \mathrm{~V}_{\mathrm{m}}+\mathrm{L}_{3} \mathrm{~V}_{\mathrm{n}}
$$

After substituting Equations $2-36,2-37$ and 2-38 into Equation 2-40 one obtains:

$$
\begin{aligned}
v^{(e)}= & 1 / 2 A\left[\left[\left(x_{m} y_{n}-x_{n} y_{m}\right)+x\left(y_{m}-y_{n}\right)+y\left(x_{n}-x_{m}\right)\right] v_{\ell}+\right. \\
& {\left[\left(x_{n} y_{\ell}-x_{\ell} y_{n}\right)+x\left(y_{n}-y_{\ell}\right)+y\left(x_{\ell}-x_{n}\right)\right] v_{m}+} \\
& {\left.\left[\left(x_{\ell} y_{m}-x_{m} y_{\ell}\right)+x\left(y_{\ell}-y_{m}\right)+y\left(x_{m}-x_{\ell}\right)\right] v_{n}\right] }
\end{aligned}
$$

In order to solve Equation 2-28 the shape functions must be known. When they are determined they can be substituted in Equation 2-42.

$$
[\mathrm{K}][\mathrm{V}]=[0]
$$

Matrix $\mathrm{K}$ is calculated for a two dimensional problem.

$$
\left.\mathrm{K}_{i j}=\int_{\Omega}\left[(\sigma+j \omega \varepsilon)\left(\partial \mathrm{N}_{i} / \partial \mathrm{x}\right)\left(\partial \mathrm{N}_{j} / \partial \mathrm{x}\right)+(\sigma \mathrm{y})\right] \mathrm{j} \mathbf{\mathrm { j }} \mathrm{dy \varepsilon}\right)\left(\partial \mathrm{N}_{i} / \partial \mathrm{y}\right)
$$


For each element $(\sigma+j \omega \varepsilon)$ may be taken outside the integration sign. Therefore:

$$
\begin{aligned}
& \mathrm{K}_{1,1}=\left[\left(\mathrm{dN}_{1} / \mathrm{dx}\right)^{2}+\left(\mathrm{dN}_{1} / \mathrm{dy}\right)^{2}\right] \mathrm{dx} \mathrm{dy} \\
& =\left[\frac{\left(y_{m}-y_{n}\right)^{2}}{4 * A^{2}}+\frac{\left(x_{n}-x_{m}\right)^{2}}{4 * A^{2}}\right] d x d y=\frac{\left(y_{m}-y_{n}\right)^{2}+\left(x_{n}-x_{m}\right)^{2}}{4 * A} \\
& \mathrm{~K}_{1,2}=\left[\frac{\left(\mathrm{y}_{\mathrm{m}}-\mathrm{y}_{\mathrm{n}}\right)\left(\mathrm{y}_{\mathrm{n}}-\mathrm{y}_{\ell}\right)}{4 * \mathrm{~A}^{2}}+\frac{\left(\mathrm{x}_{\mathrm{n}}-\mathrm{x}_{\mathrm{m}}\right)\left(\mathrm{x}_{\ell}-\mathrm{x}_{\mathrm{m}}\right)}{4 * \mathrm{~A}^{2}}\right] \mathrm{dx} d \mathrm{y}= \\
& \frac{\left(y_{m}-y_{n}\right)\left(y_{n}-y_{\ell}\right)+\left(x_{n}-x_{m}\right)\left(x_{\ell}-x_{n}\right)}{4 * A} \\
& \mathrm{k}_{1,3}=\frac{\left(\mathrm{y}_{\mathrm{m}}-\mathrm{y}_{\mathrm{n}}\right)\left(\mathrm{y}_{\ell} \mathrm{e}_{\mathrm{m}}\right)+\left(\mathrm{x}_{\mathrm{n}}-\mathrm{x}_{\mathrm{m}}\right)\left(\mathrm{x}_{\mathrm{m}}-\mathrm{x}_{\ell}\right)}{4 * \mathrm{~A}} \\
& \mathrm{~K}_{2,1}=\mathrm{K}_{1,2}
\end{aligned}
$$

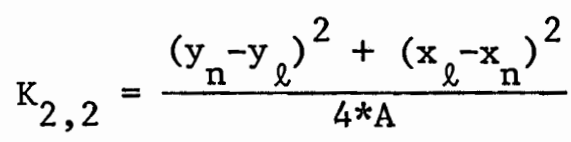

$$
\begin{aligned}
& \mathrm{K}_{2,3}=\left[\frac{\left(\mathrm{y}_{\mathrm{n}}-\mathrm{y}_{\ell}\right)\left(\mathrm{y}_{\ell} \ell_{\mathrm{m}}^{-\mathrm{y}_{\mathrm{m}}}\right.}{4 * \mathrm{~A}^{2}}+\frac{\left(\mathrm{x}_{\ell} \mathrm{x}_{\mathrm{n}}\right)\left(\mathrm{x}_{\mathrm{m}}-\mathrm{x}_{\ell}\right)}{4 * \mathrm{~A}^{2}}\right] \mathrm{dx} \mathrm{dy}= \\
& \frac{\left(y_{n}-y_{\ell}\right)\left(y_{\ell}-y_{m}\right)+\left(x_{\ell}-x_{n}\right)\left(x_{m}-x_{\ell}\right)}{4 * A} \\
& \mathrm{~K}_{3,1}=\mathrm{K}_{1,3}
\end{aligned}
$$




$$
\begin{aligned}
& \mathrm{k}_{3,2}=\mathrm{k}_{2,3} \\
& \mathrm{k}_{3,3}=\frac{\left(\mathrm{y}_{\ell}-\mathrm{y}_{\mathrm{m}}\right)^{2}+\left(\mathrm{x}_{\mathrm{m}}-\mathrm{x}_{\ell}\right)^{2}}{4 *_{\mathrm{A}}}
\end{aligned}
$$

Substituting Equations 2-44 thru 2-51 into Equation 2-42 and writing the result in matrix form: 

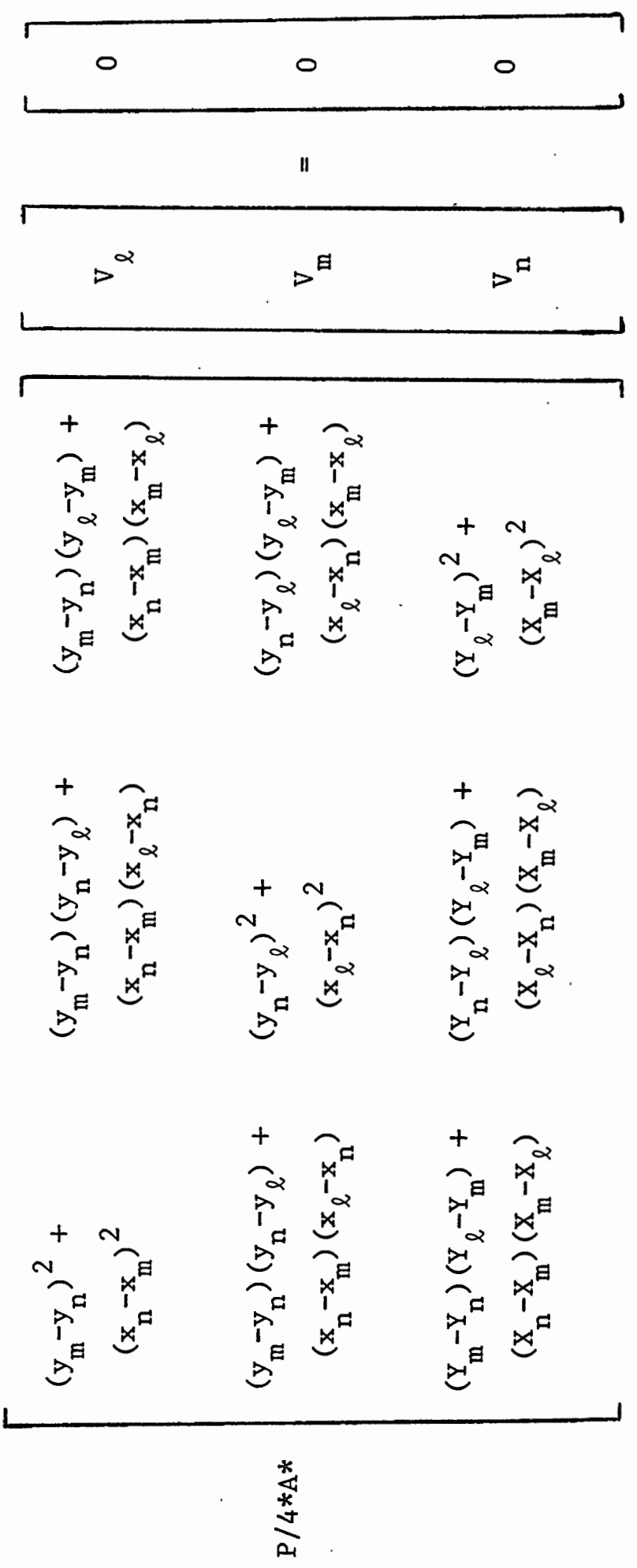


\section{COMPUTER PROGRAM}

\subsection{SOLUTION TECHNIQUE FOR THE FINITE ELEMENT METHOD}

A computer program is written to solve Eq. 2-53 for the region of interest which consists of n-type of materfals and at least two boundary conditions. This equation in the short form is given by:

$$
[\mathrm{K}][\mathrm{V}]=[0]
$$

Matrix [K] is the coefficient matrix and consists of all the properties of the materials in the region. Each element in the region could have a different property from the others. Matrix [K] is calculated for each element with its own properties and then transferred to the final coefficient matrix $[F]$. One example is given below.

Region S, Fig. 3.1, is divided into 18 triangular elements and each element has been numbered from 1 to 18 .

Also all nodes are numbered in a fashion to create a sparse [F] matrix to reduce the band-width of the [F] matrix. To do so, the side which has less nodes than the other is determined. Then the nodes are numbered from one end to the other and returned to the original side, as shown in Fig. 3.1. This method insures the smallest possible bandwidth for the $[F]$ matrix. 


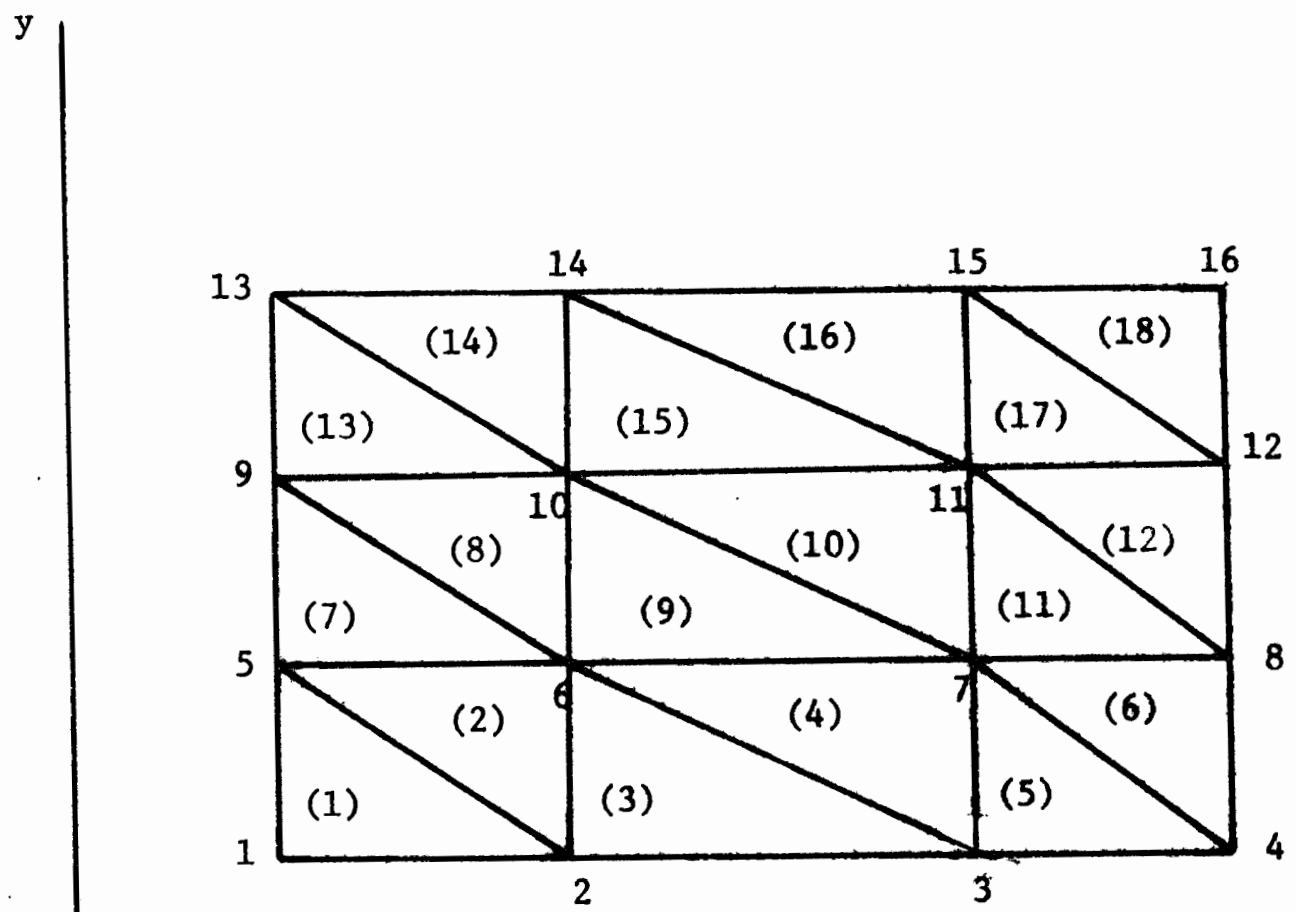

Figure 3.1 Region $S$ is divided in 18 triangular elements. 
The arbitrary element $\mathrm{Z}$ has nodes $\ell, \mathrm{m}, \mathrm{n}$ and coordinates of $(\mathrm{xN}$, YN ), ( $\mathrm{xNm}, \mathrm{YNm}),(\mathrm{xNn}, \mathrm{YNn})$ and material property of $\mathrm{P}$. By using Eq. 2-53 we can solve for matrix $\mathrm{K}$ :

$$
\mathrm{K}=\left[\begin{array}{ccc}
\mathrm{K}_{\ell, \ell} & \mathrm{K}_{\ell, \mathrm{m}} & \mathrm{K}_{\ell, \mathrm{n}} \\
\mathrm{K}_{\mathrm{m}, \ell} & \mathrm{K}_{\mathrm{m}, \mathrm{m}} & \mathrm{K}_{\mathrm{m}, \mathrm{n}} \\
\mathrm{K}_{\mathrm{n}, \ell} & \mathrm{K}_{\mathrm{n}, \mathrm{m}} & \mathrm{K}_{\mathrm{n}, \mathrm{n}}
\end{array}\right]
$$

By transformation, $k_{\ell, \ell}$ goes to the [F] matrix in row $l$ and column $\ell$ and then added to the previous value of $F_{\ell, l}$. Similarly, $K_{\ell, m}$ goes into the row $\ell$ and column $m$ of the matrix $[F]$ and then added to the previous values of $\mathrm{F}_{\ell, \mathrm{m}}$, and so on.

After completing the matrix $[F]$, Equation 3-1 becomes:

$$
[\mathrm{F}][\mathrm{V}]=[0]
$$

where it has the dimension of (No. of nodes by No. of nodes) and $K$ is a 3 by 3 matrix. Since Equation $3-3$ is equal to zero, it requires the boundary conditions for solution. The boundary conditions are used to create values on the other side of the equation.

For instance, region $\mathrm{S}$ in Fig. 3.1 has two boundaries, one at each end. Nodes 1,5,9 and 13 from one end and nodes 4,8,12 and 16 from the other end are the boundary nodals and have known values of voltage. Therefore we can leave these nodes out of our calculations. For example: element (7) has nodes 5,6,9 where nodes 5,9 have known values and node 6 is an unknown.

The matrix notation for this element after calculating the $\mathrm{K}$ matrix is : 


$$
\left[\begin{array}{ccc}
\mathrm{K}_{5,5} & \mathrm{k}_{5,6} & \mathrm{k}_{5,9} \\
\mathrm{~K}_{6,5} & \mathrm{~K}_{6,6} & \mathrm{~K}_{6,9} \\
\mathrm{k}_{9,5} & \mathrm{k}_{9,6} & \mathrm{k}_{9,9}
\end{array}\right]\left[\begin{array}{c}
\mathrm{v}_{5} \\
\mathrm{v}_{6} \\
\mathrm{v}_{9}
\end{array}\right]=\left[\begin{array}{l}
0 \\
0 \\
0
\end{array}\right]
$$

Therefore there is just one equation and one unknown and it is easy to transfer the known values to the other side of the equation. The result is:

$$
\left[\mathrm{K}_{6,6}\right]\left[\mathrm{v}_{6}\right]=\left[-\mathrm{K}_{6,5} * \mathrm{v}_{5}-\mathrm{K}_{6,9} * \mathrm{v}_{9}\right]=\left[\mathrm{B}_{6}\right]
$$

Now this equation is transferred to the [F] matrix:

$$
[\mathrm{F}][\mathrm{V}]=[\mathrm{B}]
$$

For the small size of matrix [F] we can find the inverse of the [F] matrix and multiply it with the [B] matrix to find the values of the nodes.

A11 finite element solutions require a high subdivision of the region for the utmost accuracy. This makes matrix [F] so large that it becomes useless to solve by the invertion of the [F] matrix.

Due to the nature of the problem, provided that the nodes are numbered in a careful manner, the non-zero terms in matrix [F] will be concentrated in a narrow band situated adjacent to the leading diagonal. This fact, combined with the symmetrical nature of matrix [F] indicates that only a relatively small portion of the matrix is of real interest. If advantage is taken of these observations, demands on the computer storage may be considerably reduced. Moreover, if the solution procedure is so arranged that many of the operations involving the zero terms are eliminated, the speed of the solution can be increased.' Methods which 
take advantage of the banded nature of matrix [F] are often called 'banded methods'.

Methods which offer potentially greater economies are the so-called 'half-banded schemes'. The upper half of the diagonal band of the matrix is stored as a rectangular matrix as shown in Figure 3.2.

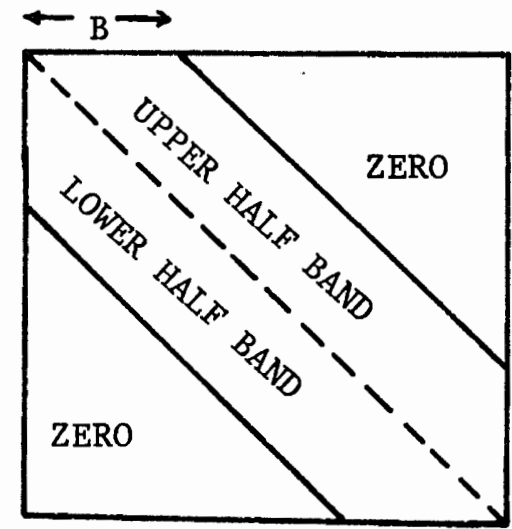

MATRIX F

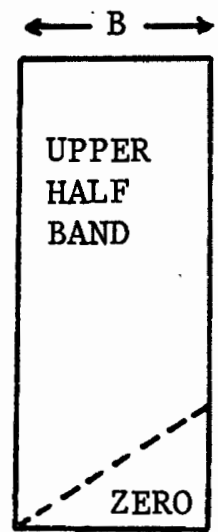

MATRIX A

Figure 3.2 Banded form of a symmetrical matrix.

The upper half band part of matrix [F] is stored in matrix [A]

which is much smaller than matrix [F]. Matrix [A] has a number of columns equal to the bandwidth and rows equal to the number of nodes. Each row of matrix [F] is transferred to matrix [A].

To calculate the band-width of a finite element problem, one must know the number of all elements and their node numbers, because bandwidth is equal to the largest difference between two nodes in one element; that is compared to the rest of elements +1 .

Figure 3.3 is a flow chart of the computer program which finds the bandwidth of matrix [F] or any other symmetrical matrix. Figure 3.4 is a flow chart which determines the coefficient matrix and transfers the upper half part of matrix [F] to matrix [A].

Equation 3-6 takes the form: 


$$
[\mathrm{A}][\mathrm{V}]=[\mathrm{B}]
$$

It is impossible to find the inverse of [A] because it is no longer a square matrix. Therefore, the Gaussian Elimination Technique is used to solve Equation 3-7. Another step to save memory space is to eliminate matrix [V] from the equation. To do so, the problem between [A] and [B] is solved and the result is stored in matrix [B]. Matrix [B] has the same dimension as matrix [V].

For more understanding of the Gaussian Elimination Technique an example is solved in Appendix $B$ along with the flow chart. Appendix $D$ includes a listing of the main program as well as all subroutines discussed in this chapter. 


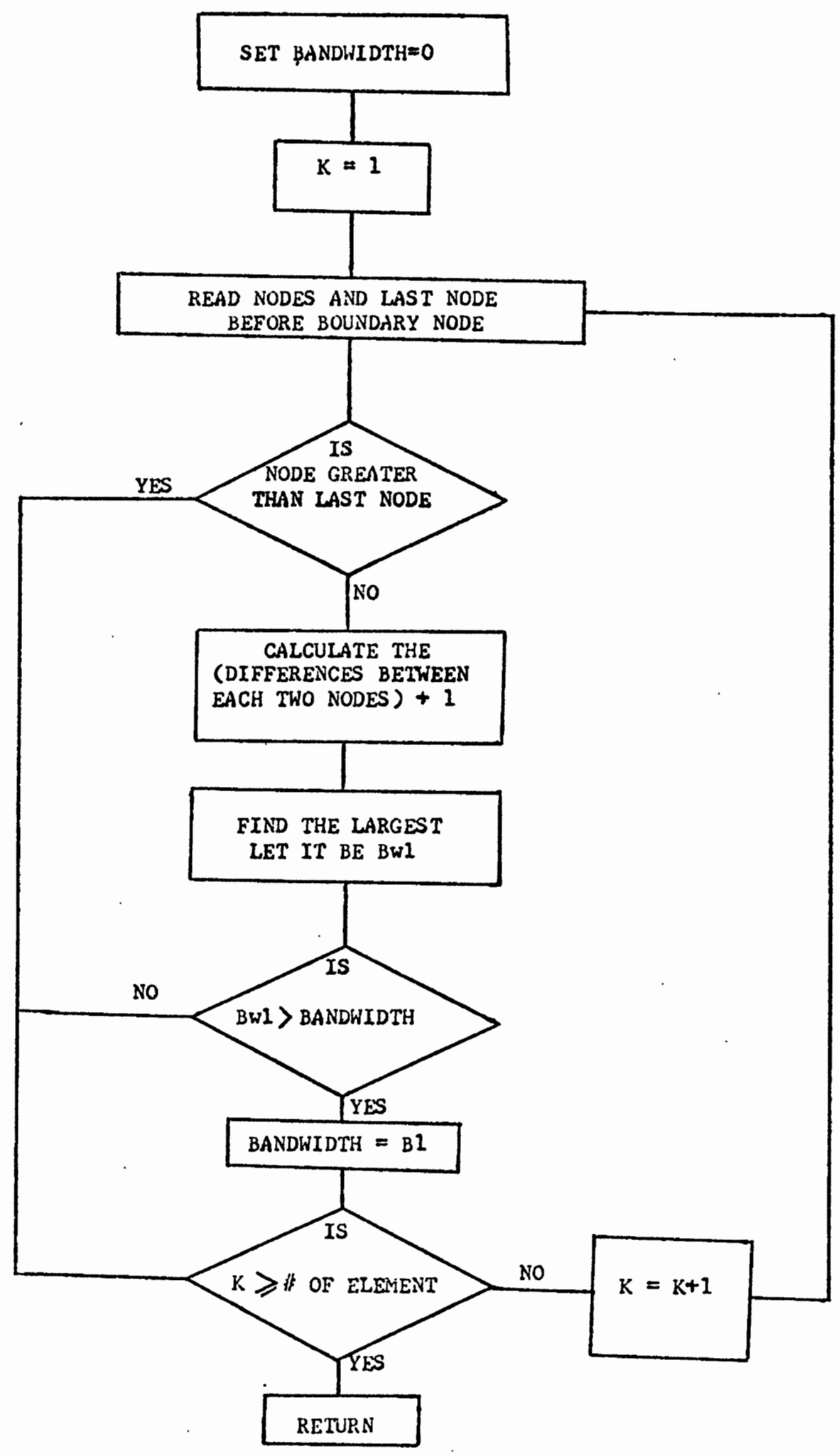

Figure 3.3 Flow chart, subroutine "BANDWIDTH". 


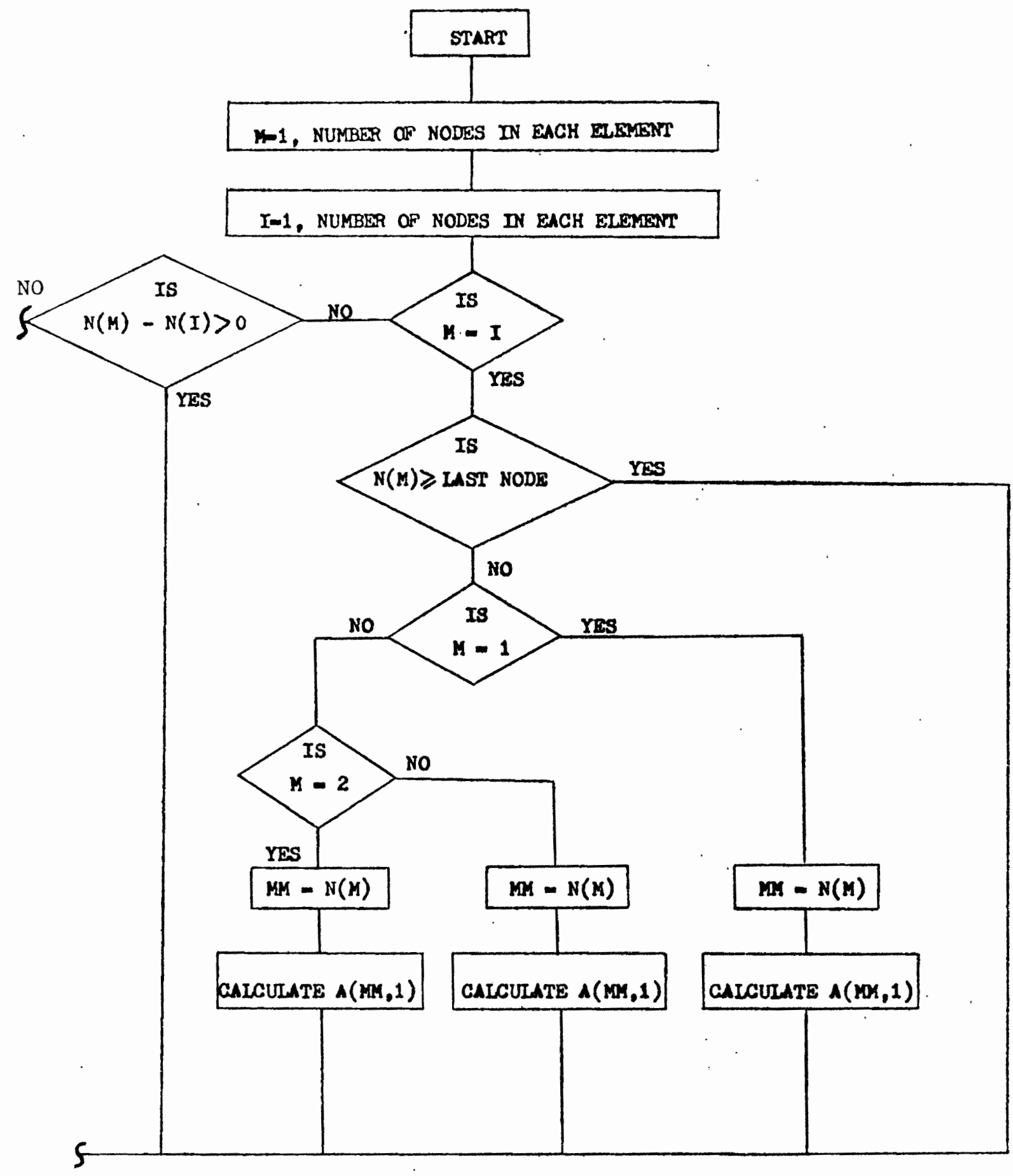

Figure 3.4 Flow chart, subroutine "FIND". 


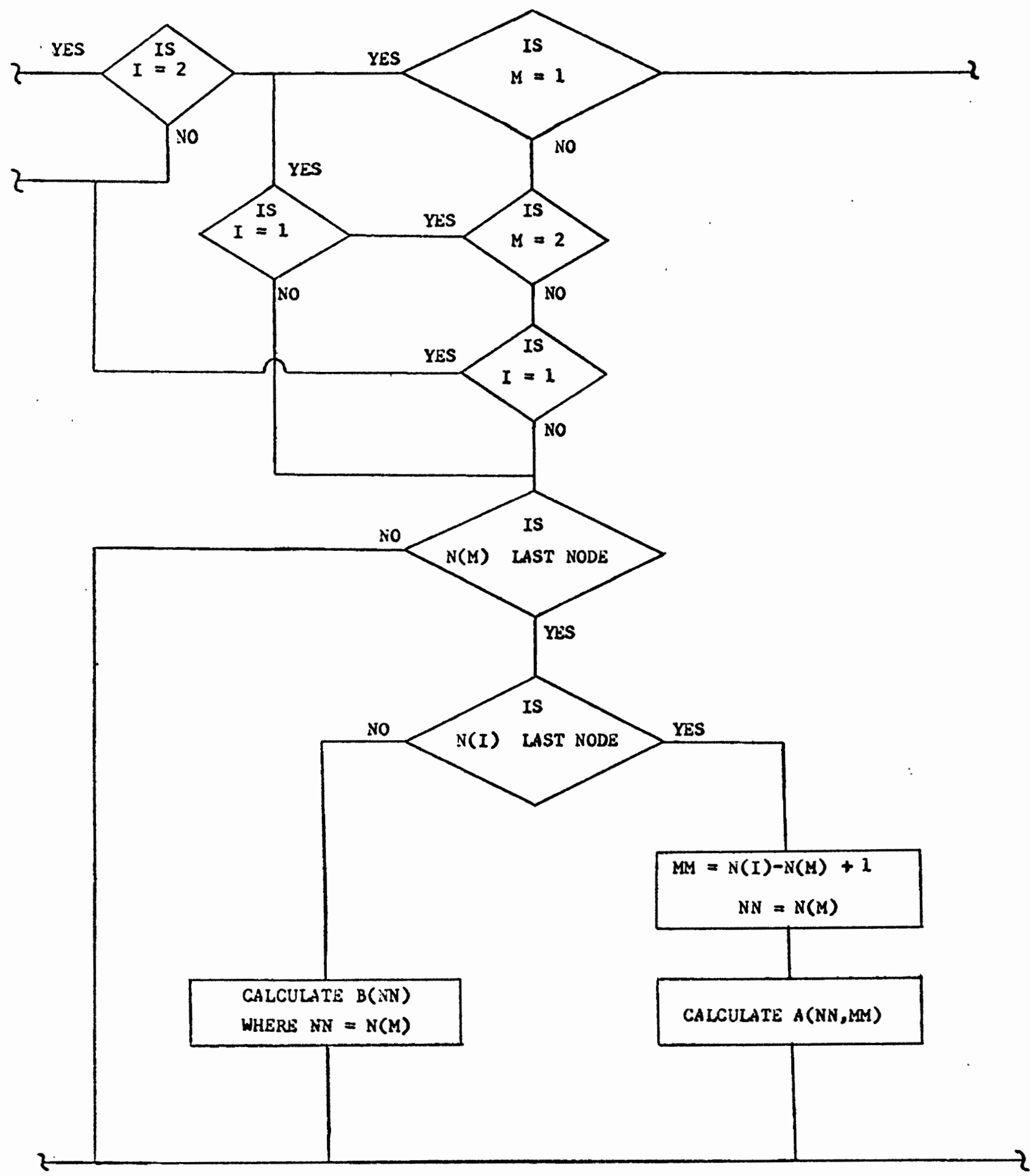

Figure 3.4 (Continued) 


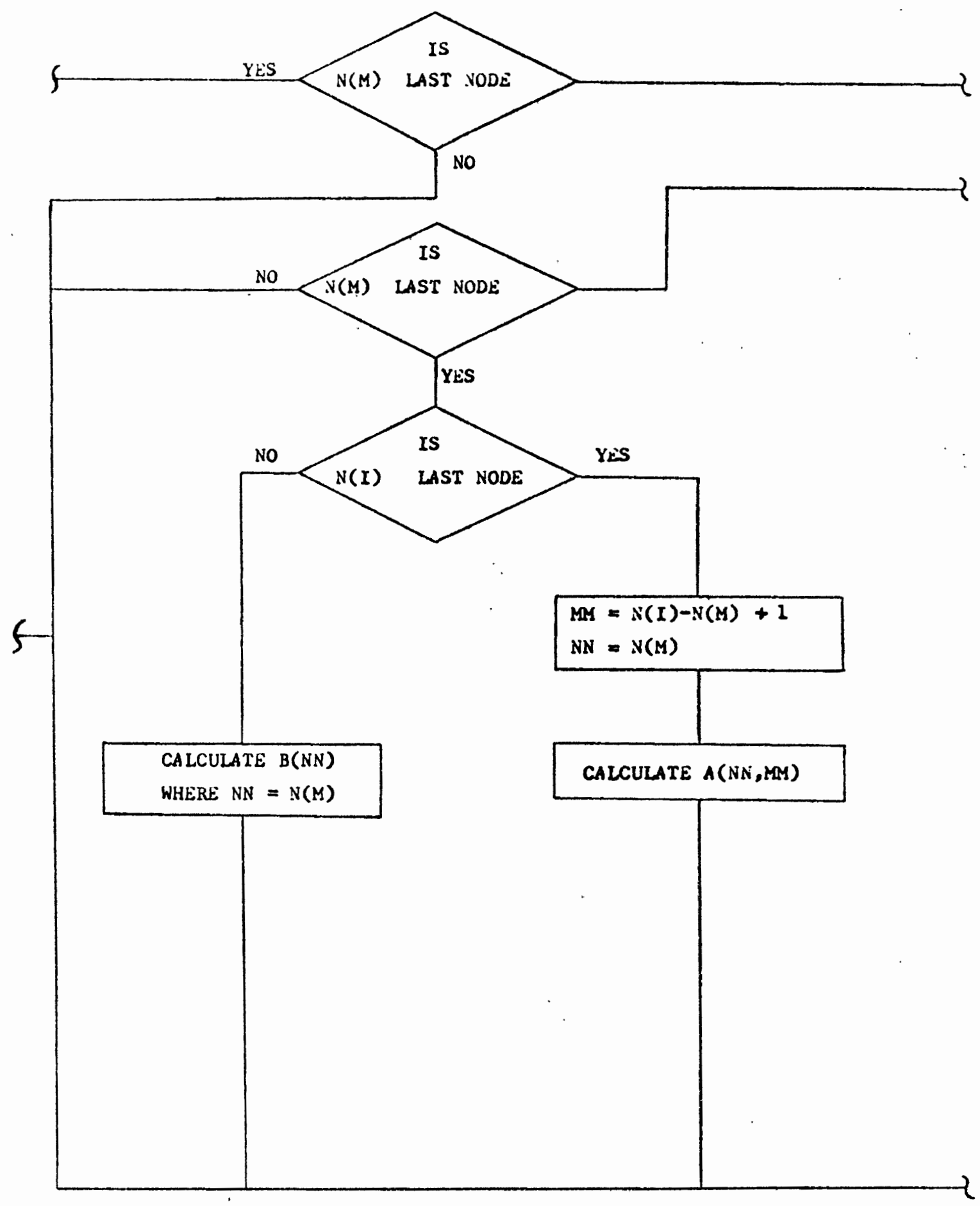

Figure 3.4 (Continued) 


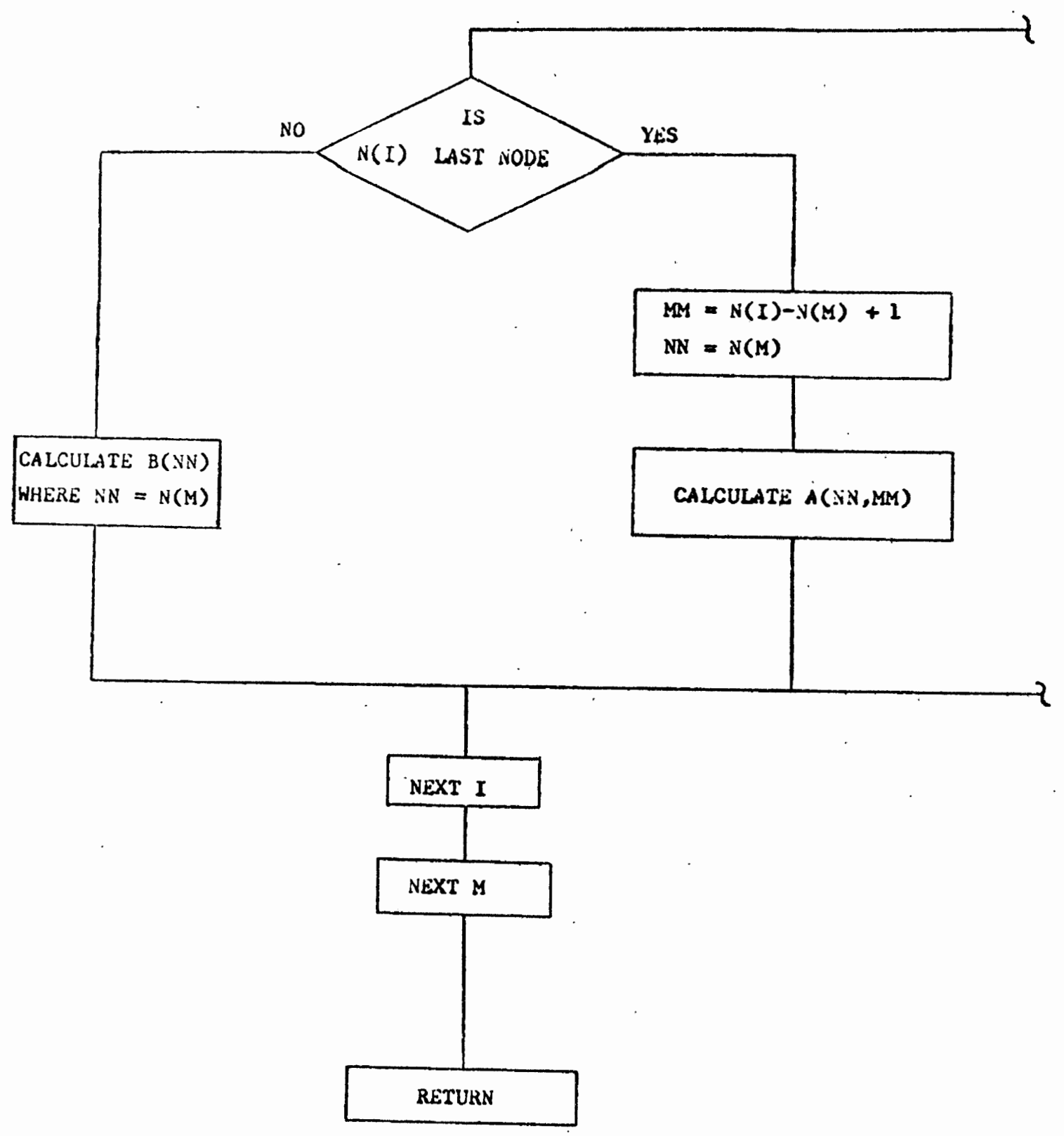

Figure 3.4 (Continued) 


\subsection{RESULTS OF THE COMPUTER SOLUTION}

The problem was to calculate current densities everywhere in the region S. Region $\mathrm{S}$ was a large area of soil with a sunken swimning pool in the center of the region. The region was divided into 760 elements with three types of materials and two boundary conditions. Figure 3.5 shows the subdivided region of ' $s$ '.

For large problems such as this involving many elements, it is useful to possess a routine which generates the complete set of data for the finite element program.

Region 'S' was subdivided into five regions. Region one was below the swimming pool, region two and four were the swimming pool ends and the soil; region three was the swimming pool and surrounding soil; and region five was above the swimming pool. Figure 3.6 shows these five regions.

The reason for dividing region ' $S$ ' into five regions was to make data preparation easier. Regions 2,3,4 were divided in a different fashion than 1 and 5. Region 1,5 and 2,4 are identical in values of $x$ and $\mathrm{y}$ with some constant. Also the results of each region can be stored in a different matrix and recalled when needed. All nodes on each boundary are given the same number for simplification purposes.

A subroutine was written to find the coordinates of all nodes. Figure 3.7 shows a flow chart of such a subroutine.

Figure 3.5 shows that nodes $1,10,19,28$ and 37 have the same value of $\mathrm{x}$ and nodes $1,2,3,4,5,6,7,8$ and 9 have the same values of $\mathrm{y}$. Therefore coordinates of nodes are calculated and stored in a matrix for later use. 
Another data file $1 \mathrm{~s}$ generated which consists of all elements with their nodal numbers. Figure 3.8 shows a flow chart of this program (called "TES") which can read the element's number and their nodal numbers from the file and find the corresponding coordinate values and store them In a separate file, which lacks the Information about the first and last row of the region ' $S$ '. This information could be added to the file eastiy.

This data file is ready to be given to the maln program for calculation of voltages at each node. A program is written to calculate the current densities in the region In the y-direction. Results of computer program, in tabular form are given in Appendix $\mathrm{E}$.

A comparison of the computer results with experimental results is given in Chapter V. 
Figure 3.5 The finite element model. 


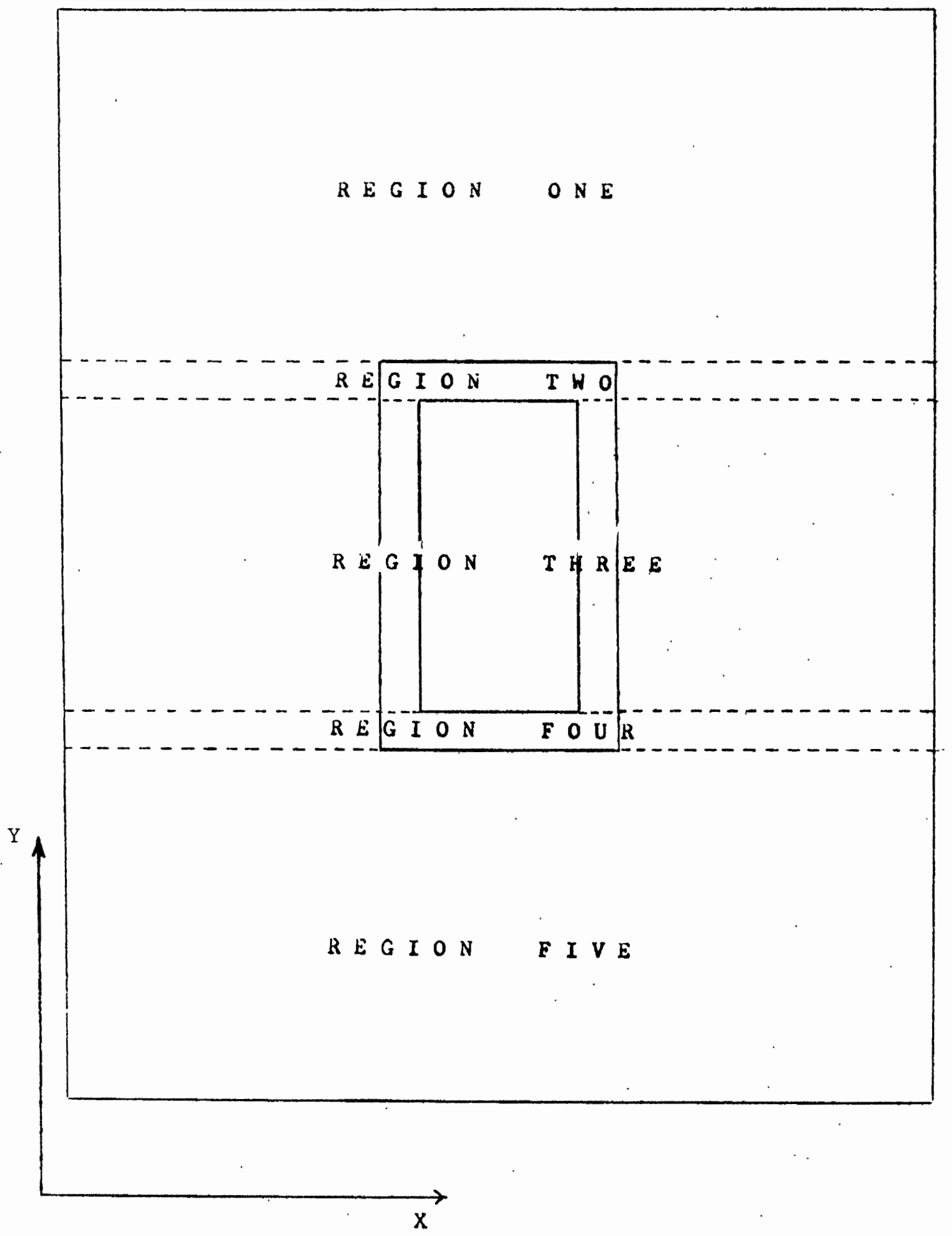

Figure 3.6 Regional division of the experimental model. 


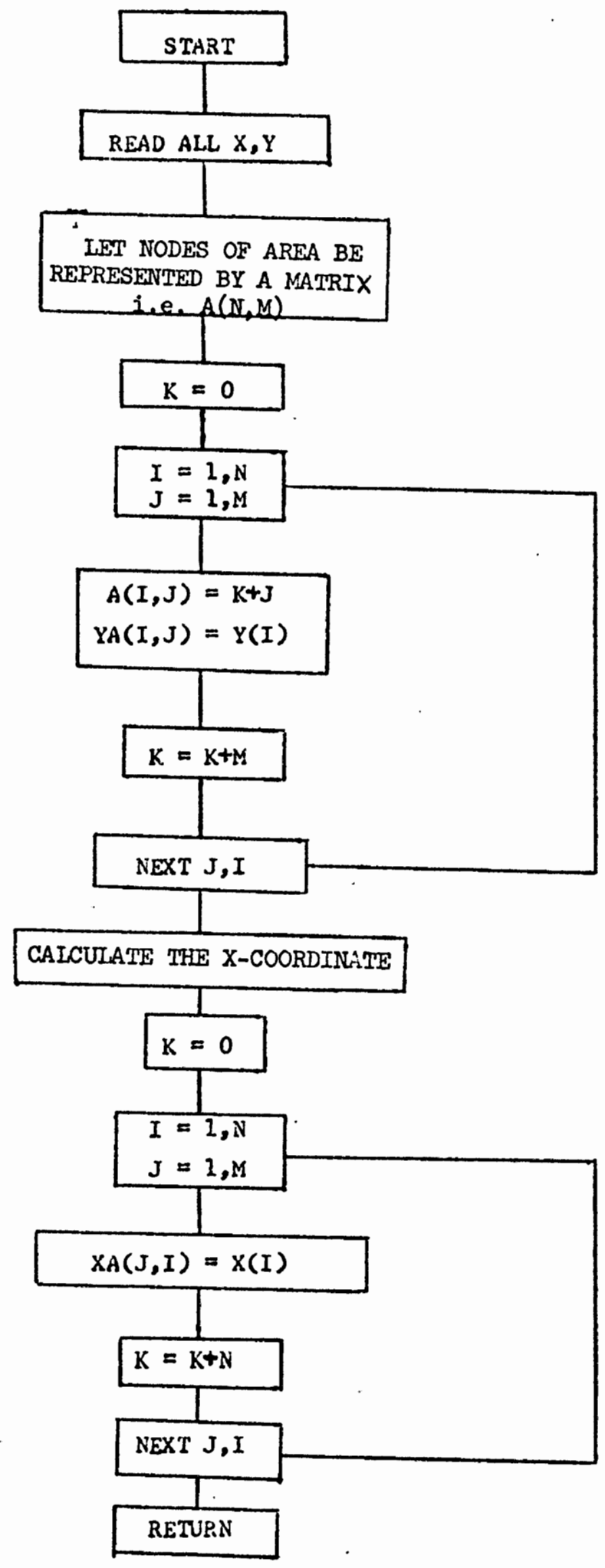

Figure 3.7 Flow chart, subroutine "GOOD". 


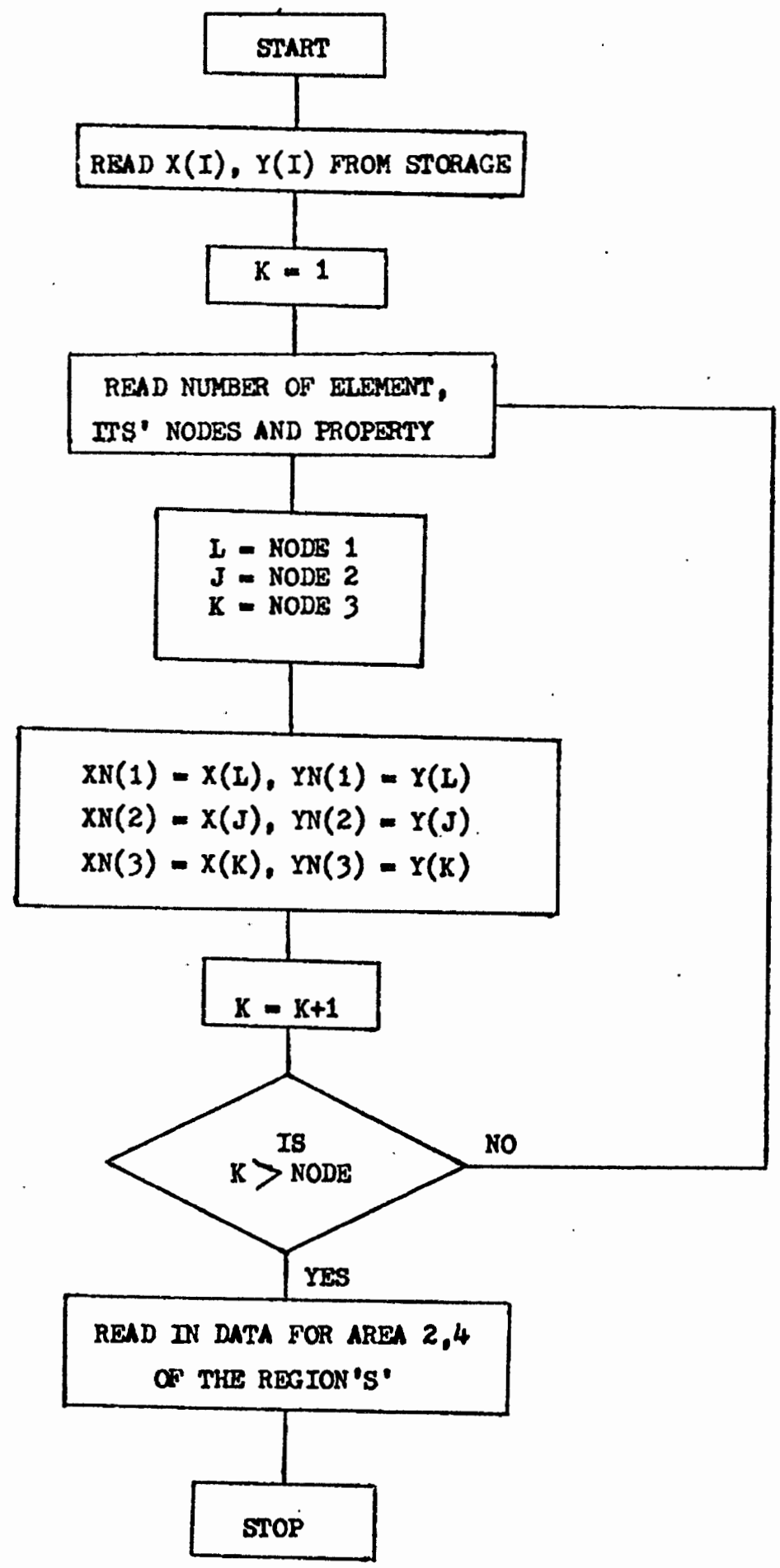

Figure 3.8 Flow chart, program "TES". 


\subsection{COMPARISON OF RESULTS WITH OTHER COMPUTER TECHNIQUES}

In order to check the accuracy of the proposed theoretical technique which is based on Maxwell's equations, solutions to selected problems were compared to results obtained using another computer program, which calculates electric fields in configurations with both capacitive and resistive distribution of potentials (Anderson, 1976, Ref. No. 16).
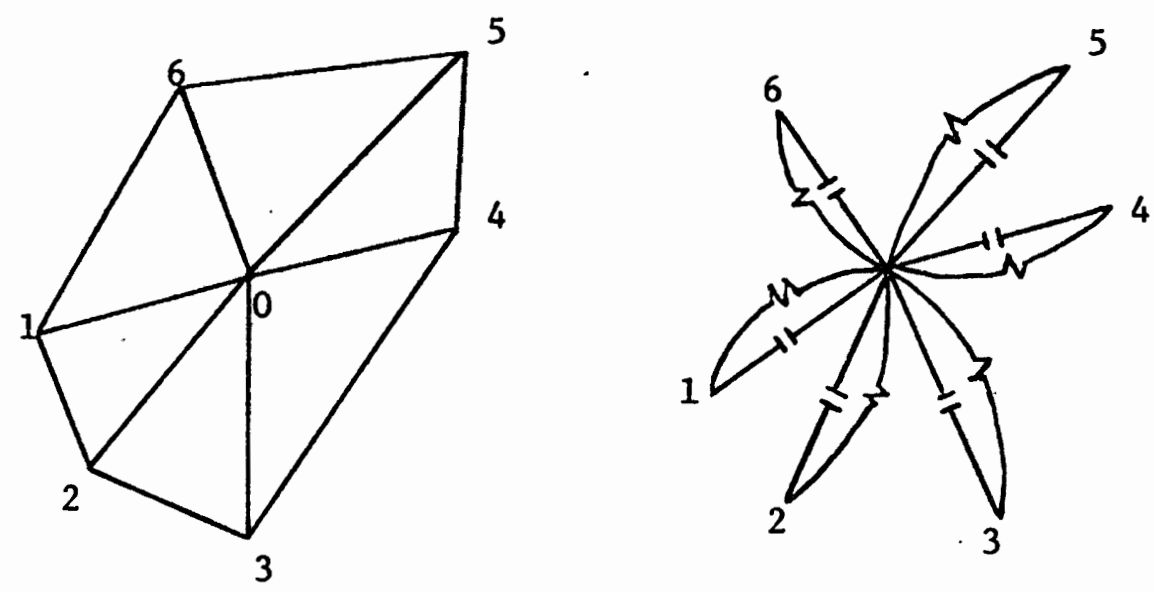

Figure 3.9 Resistive and complex admittance networks.

Figure 3.9 shows triangular elements and their complex admittance network. The resultant equation for the complex potential at the center node is:

$$
v_{0}=\frac{1}{\sum_{n=1}^{6}(G+j B)_{n}} \sum_{n=1}^{6}(G+j B)_{n} v_{n}
$$

To check the accuracy of the program, results of a specific problem are compared. 
A square of $100 \times 100 \mathrm{~mm}$ is divided up into two series connected halves, one where the capacitive distribution dominates, and one where the resistive distribution dominates. Permittivities and conductivities are chosen in such a way that the voltage across each half has the same magnitude (Fig. 3.10). A very coarse subdivision of only 16 triangular elements is used.

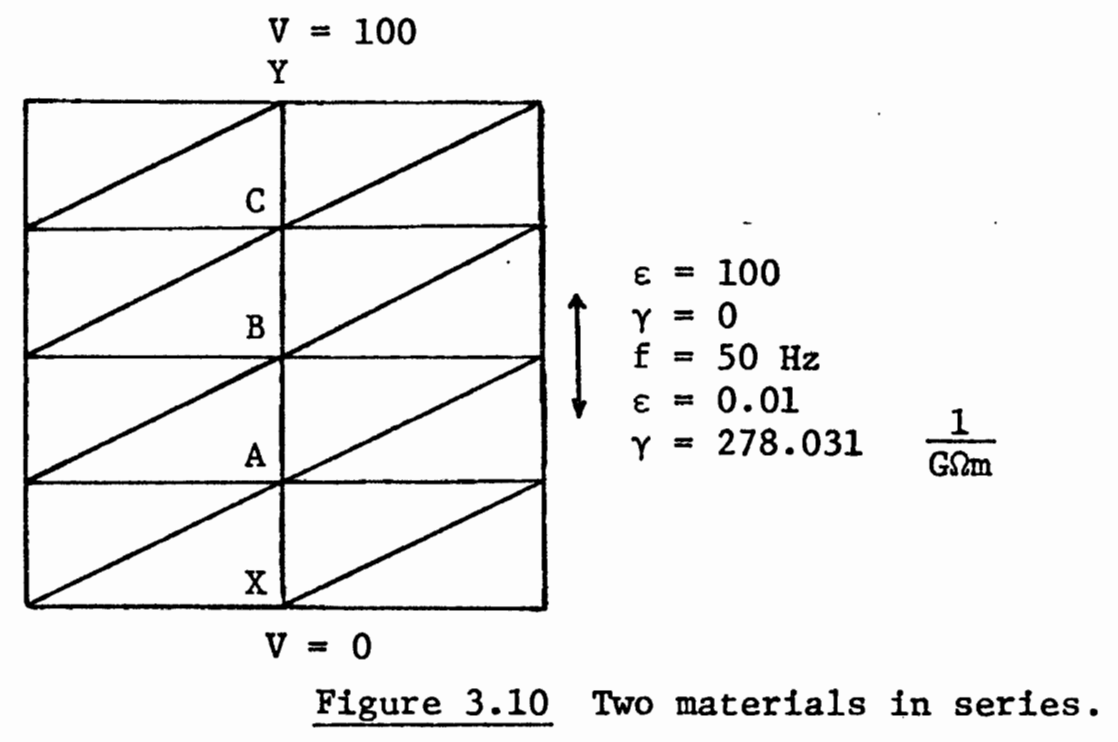

Table 3.1 shows the comparison of results using Andersen's solution and the proposed solution, to the actual values. As evident from Table 3.1 , agreement between the proposed solution and the actual values is very close. 
TABLE 3.1

\begin{tabular}{|c|l|l|l|}
\hline Sta. & Actual Values & $\begin{array}{l}\text { Andersen's } \\
\text { Solution }\end{array}$ & Proposed Solution \\
\hline$Y$ & $100+j 0$ & $100+j 0$ & $100+j 0$ \\
$C$ & $75+j 25$ & $74.99+j 24.97$ & $74.9999+j 24.9695$ \\
B & $50+j 50$ & $49.98+j 50.02$ & $49.9999+j 50.0001$ \\
$A$ & $25+j 25$ & $24.99+j 24.99$ & $24.9999+j 24.9999$ \\
$X$ & $0+j 0$ & $0+j 0$ & $0+j 0$ \\
\hline
\end{tabular}

Also, the accuracy of the proposed theoretical solution was verified by comparing the results of the theoretical solution to known actual values. In a11 cases very close agreement was observed. 


\section{EXPERIMENTAL PROGRAM}

In conjunction with the theoretical analysis, an experimental program was set up. This experiment was based on an average current density of 0.07 amp per square meter in the unfform ground under the transmission line. (See Appendix C.)

In order to create a similar situation for the experiment, a large box with conductors at two ends was chosen to hold the soil and the swimming pool. Figure 4.1 shows a schematic diagram of the box.

To create a uniform current density throughout the soil a known voltage calculated from Equation 4-1 was applied across the conductors.

$$
J=E \sigma=E / \rho
$$

where $\mathrm{J}=$ current density

$$
\begin{aligned}
& \rho=\text { resistivity of soil } \\
& \sigma=\text { conductivity of soil } \\
& E=\text { applied voltage }
\end{aligned}
$$

Resistivity of the soil was calculated from Equation 4-2.

$$
R=V / I=\rho \ell / s=\ell / \sigma s
$$

The experiment was done for three different resistivity values for the soil, each soil type with two different types of swimming pools, reinforced and non-reinforced swimming pool; and each swimming pool 
containing three different types of water.

Three resistivity values for soil and conductivity values for water were:

For Soil

a: 1000 ohm-meter

b: $\quad 55$ ohm-meter

c: 10 ohm-meter
For Water

30 micro-mho/cm

1500 micro-mho/cm

3000 micro-mho/cm

To determine the current densities, first potentials at predetermined points were measured and then current densities were calculated from potential measurements.

current densities $=\frac{\text { difference in two potentials }}{\begin{array}{l}\text { (distance between two potentials }) * \text { conductivity of } \\ \text { the material }\end{array}}$ Figure 4.2 shows a schematic diagram of the circuit used to measure the potentials at each point.

Reference 18 contains a detailed description of the experimental program and results. Selected results of this experimental program are presented in tabular form in Appendix $\mathrm{F}$. 

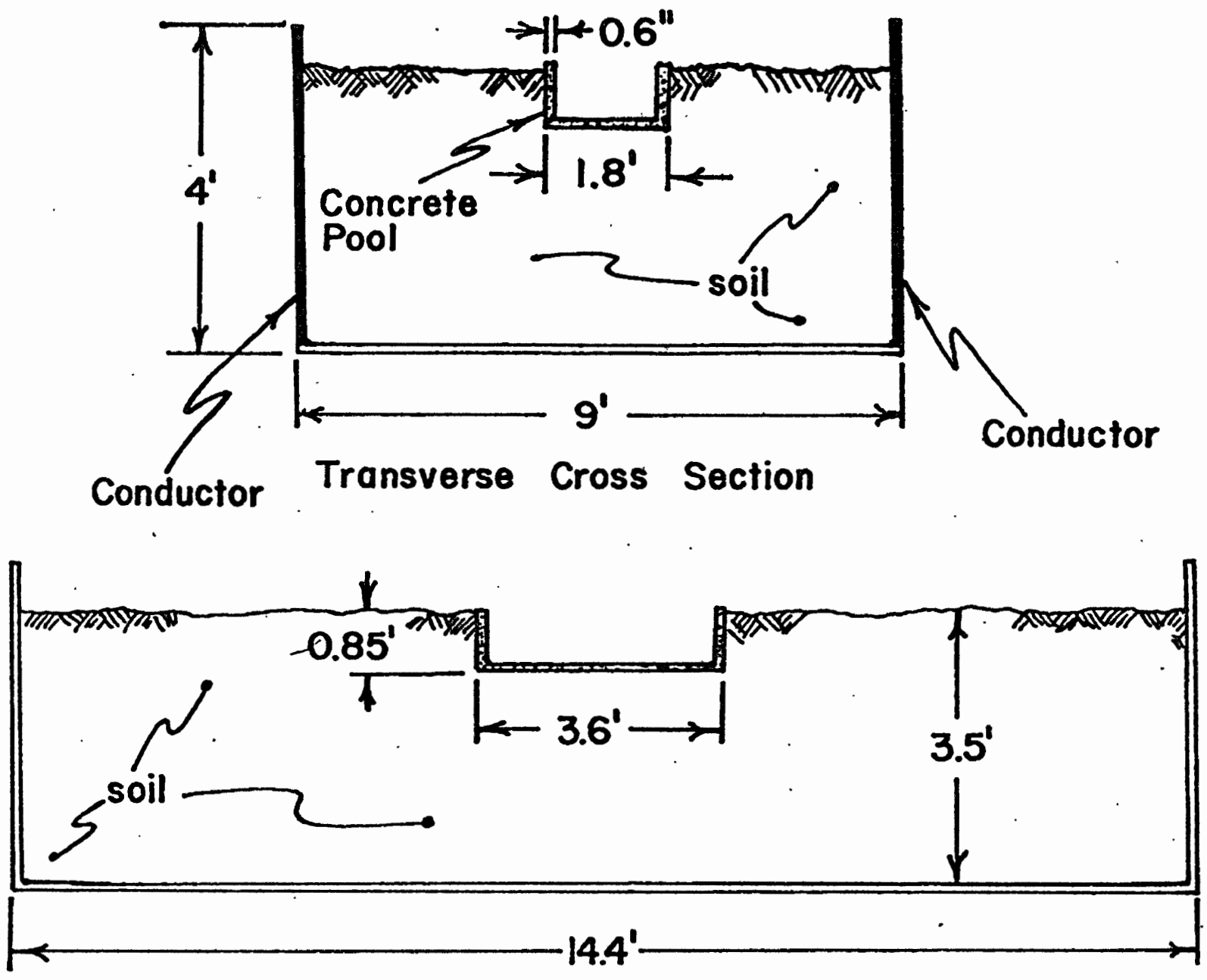

Longitudinal Cross Section

Figure 4.1 Schematic diagram of the experimental model. 


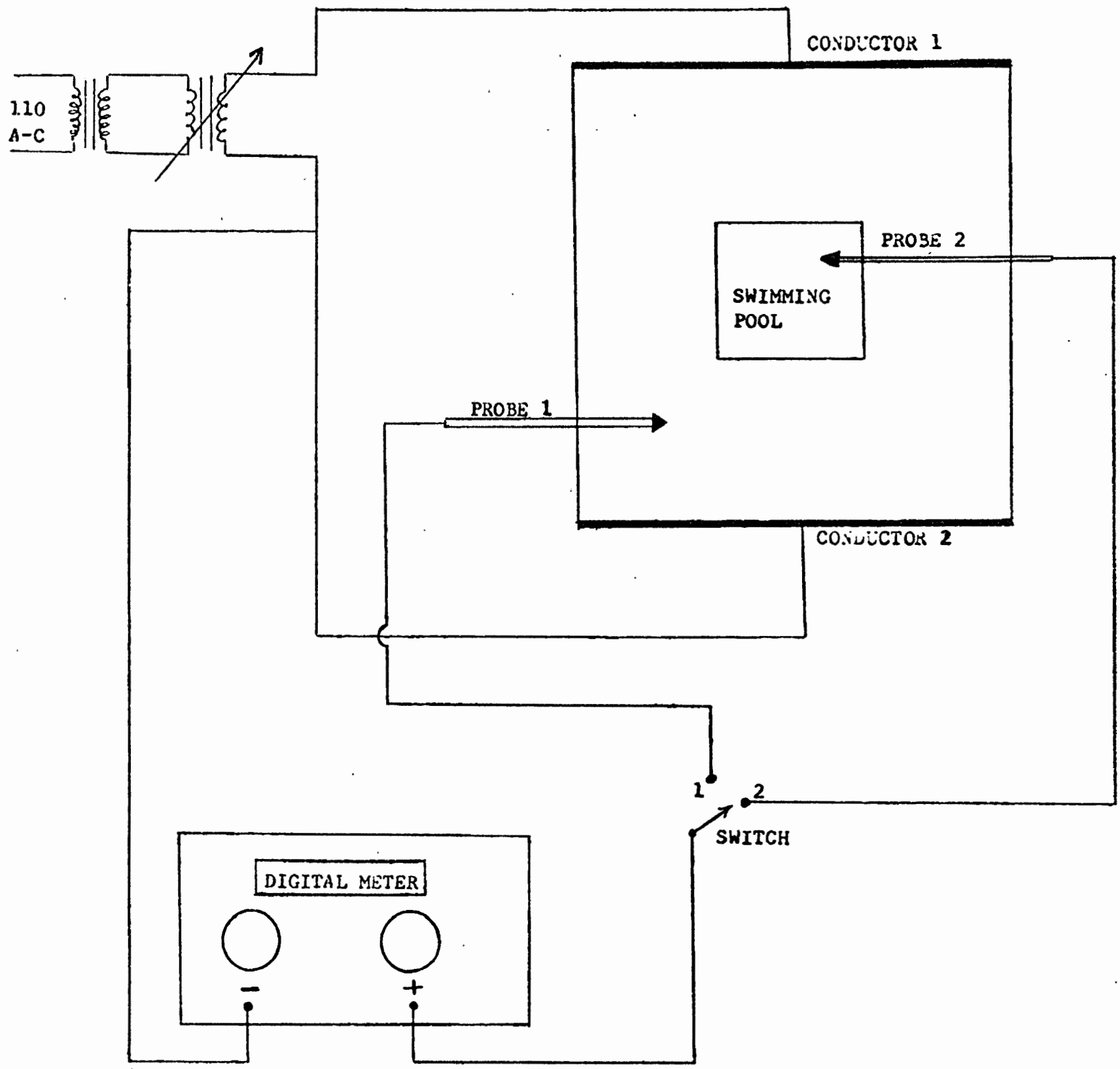

SWITCH 1 TO MEASURE VOLTAGES IN THE SOIL. SWITCH 2 TO MEASURE VOLTAGES IN THE WATER.

Figure 4.2 Schematic diagram of the electrical circuit. 


\section{CHAPTER V}

RESULTS

\subsection{COMPARISON OF CALCULATED VALUES WITH EXPERIMENTAL RESULTS}

In order to compare the calculated results with the measured values, current densities of medium case (resistivity of the soil $=55$ ohm-meter) are plotted in Figures 5.1 to 5.8 .

In these figures, current densities are plotted versus distance. Each figure represents calculated and measured current densities in the soil as well as the swimming pool.

The calculated current densities in these figures show the expected symmetry of the system about the center line, Figures 5.1-5.8. This is one verification of the accuracy of the computer program.

The measured values of current densities do not show the same exact symmetry. This could be explained in terms of the accuracy of the instruments. Also the conductivity of the soil is not uniform everywhere and the given value of conductivity is only an average measured value. Another reason for the discrepancy between the theoretical and measured values is the two dimensional computer modeling, which assumes the swimming pool walls to be infinitely long in the $z$-direction (depth). The calculated values of the current densities between stations 1 to 6 and 12 to 17, Figures 5.1-5.2, In the soil are higher than measured values. The measured values of current densities inside and outside the swimming pool between stations 6 to 12 are higher than 
calculated values. Between stations 6 to 12 the theoretical model assumes a plate of iron bars of infinite depth. Due to this plate of high conductivity, the potential gradients along the plate are zero, resulting in zero current densities along the line 'C'. Furthermore, the current flowing along the paths ' $A$ ' and ' $B$ ' are attracted toward the infinite iron plate resulting in lower values of current densities along ' $A$ ' and ' $B$ ' as compared to the experimental case, where only finite plates of iron bars exist.

Along the line ' $D$ ', the calculated current densities must-go through the infinite iron plate, while in the measured case the current paths go through the bottom surface bars of the swimming pool. Results in tabular form are shown in Appendices $\mathrm{D}$ and $\mathrm{E}$.

The reason for higher current densities and potential gradients along the line ' $\mathrm{C}$ ' between stations $6-8$ and 10-12 is the sharp change in material conductivities at these stations (soil conductivity $=1.8 \times 10^{-1}$ $\mathrm{mho} / \mathrm{m}$; iron conductivity $\left.=1.1 \times 10^{6} \mathrm{mho} / \mathrm{m}\right)$. Due to high conductivity of iron bars the current is attracted toward the pool walls and thus increasing the field (potential gradient) around the corners. 
CURRENT DENSITIES IN SOIL AND POOL WATER $\left(m-A m p s / m^{2}\right)$ SOIL RESISTIVITY $=55$ ohm-meters POOL TYPE: $\otimes R$ Reiniorced WATER CONDUCTIVITY $=1500$ micro-mho $/ \mathrm{cm}$. DNon-reinforced LINE C Calculated - Measured - - -

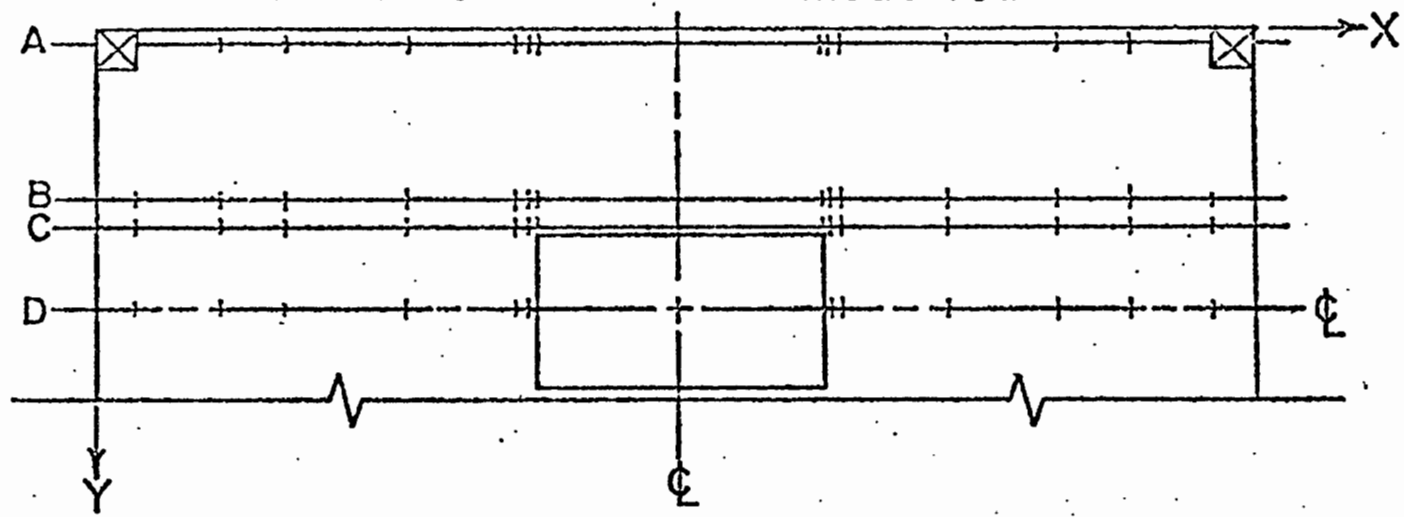

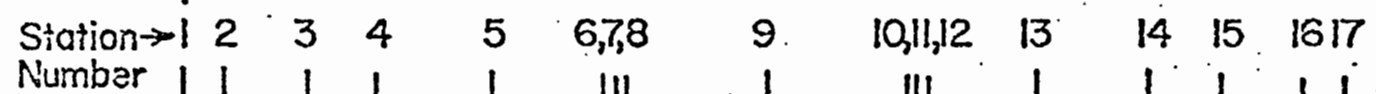

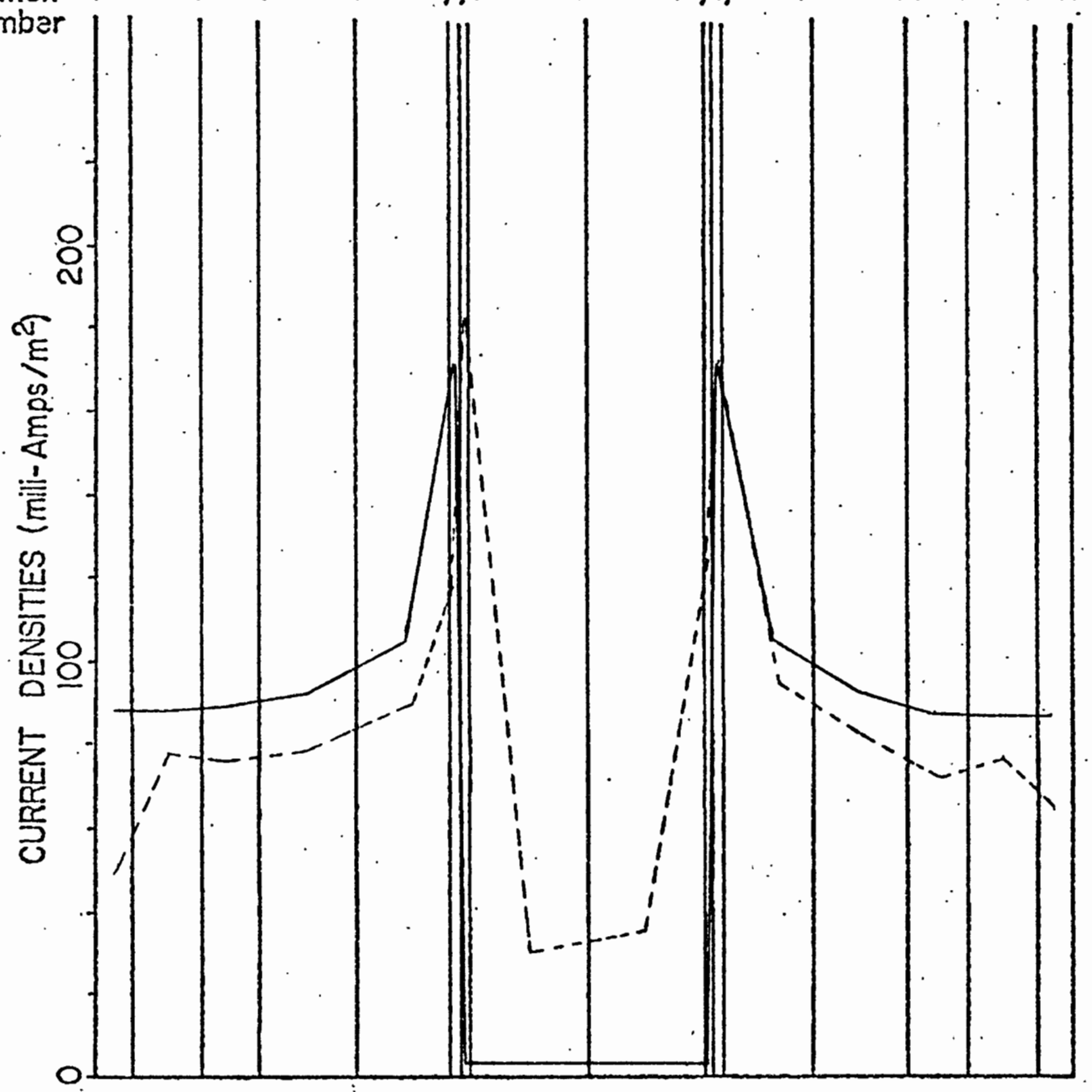

Figure 5.1 Calculated current densities. 
CURRENT DENSITIES IN SOIL AND POOL WATER $\left(m-A m p s / m^{2}\right)$ SOIL RESISTIVITY $=55$ ohm-maters POOL TYPE: $\triangle$ Reiniorced WATER CONDUCTIVITY $=1500$ micro-mio/cm. DNon-reiniorced LINE D Calculated - Measured-D-

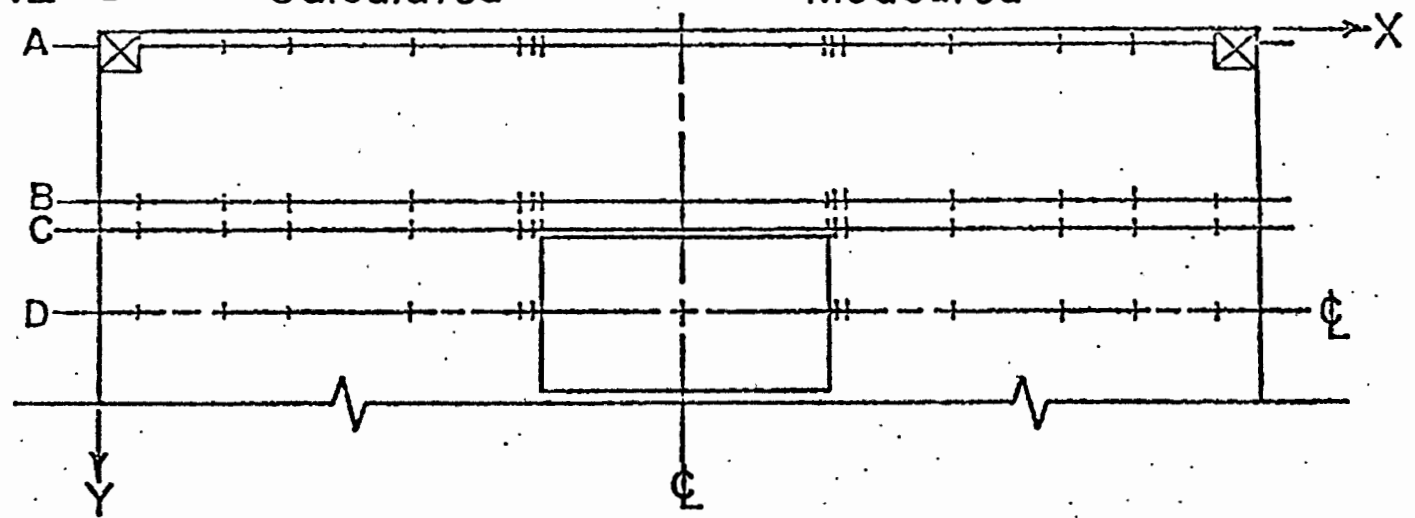

$\begin{array}{llllll}\text { Station } \rightarrow 1 & 2 & 3 & 4 & 5 & 6,7,8\end{array}$

Number

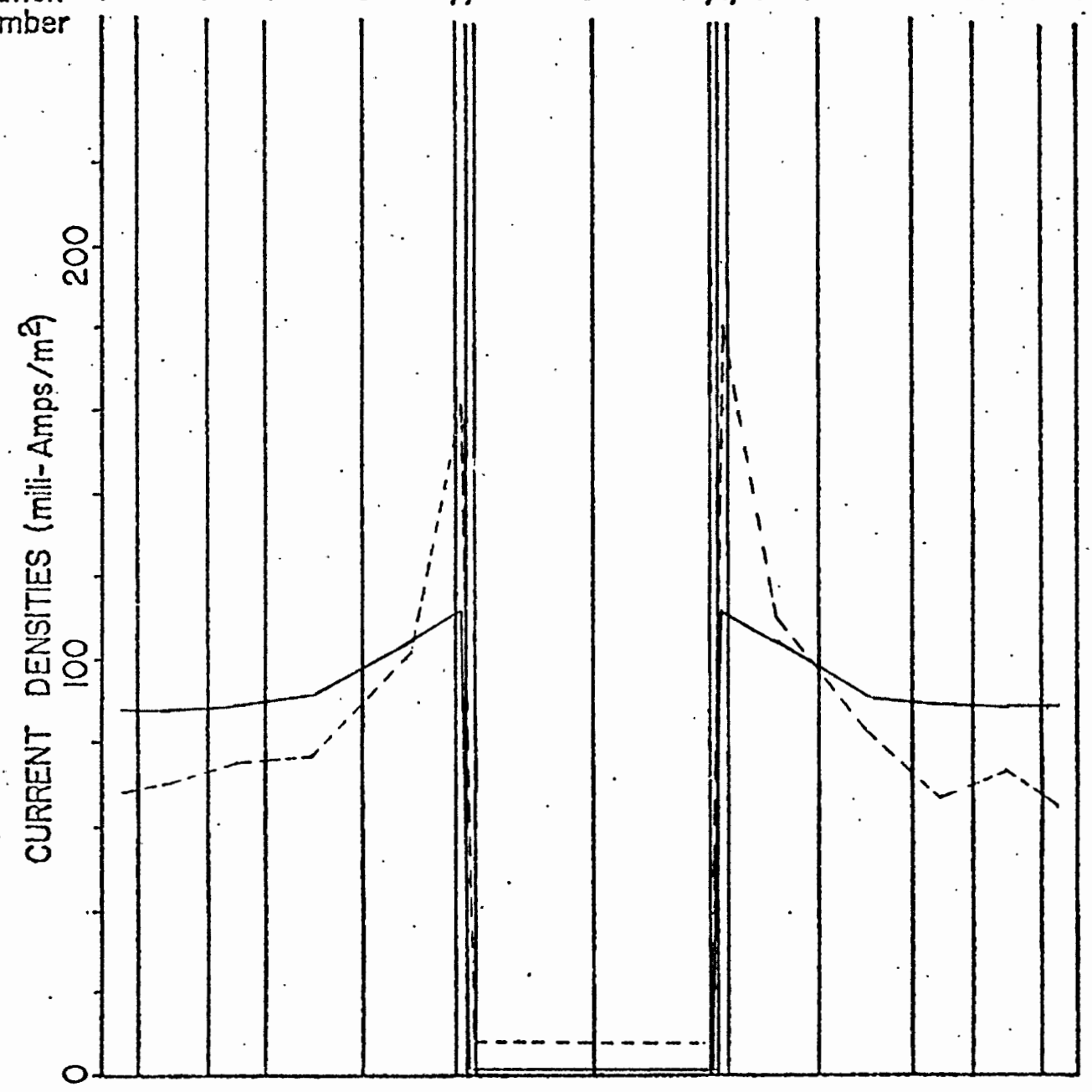

Figure 5.2 Calculated current densities. 
CURRENT DENSITIES IN SOIL AND POOL WATER (m-Amps/m $\mathrm{m}^{2}$ ) SOIL RESISTIVITY $=55$ ohm-meters POOL TYPE: Reinforced WATER CONDUCTIVITY $=3000$ micro-mho $/ \mathrm{cm}$. $\square$ Non-reinforced

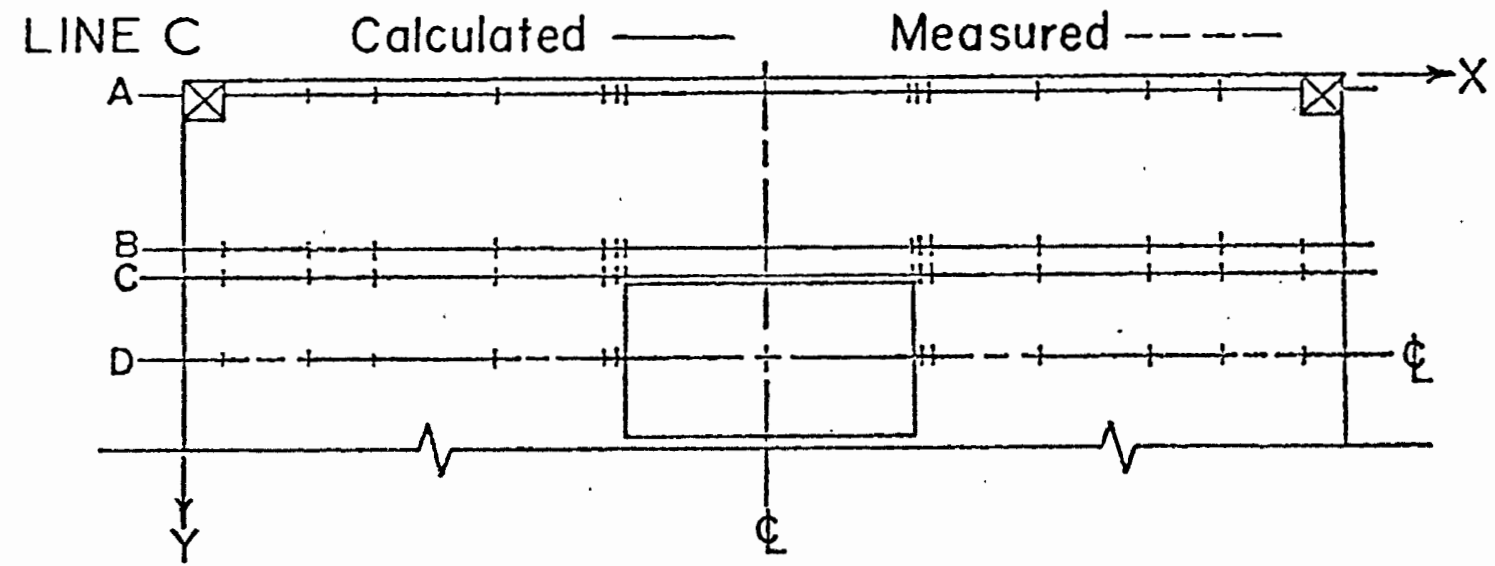

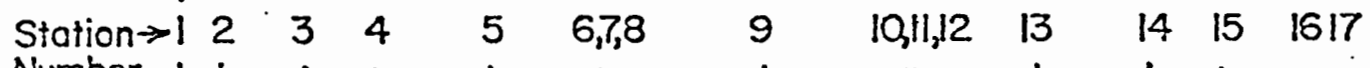

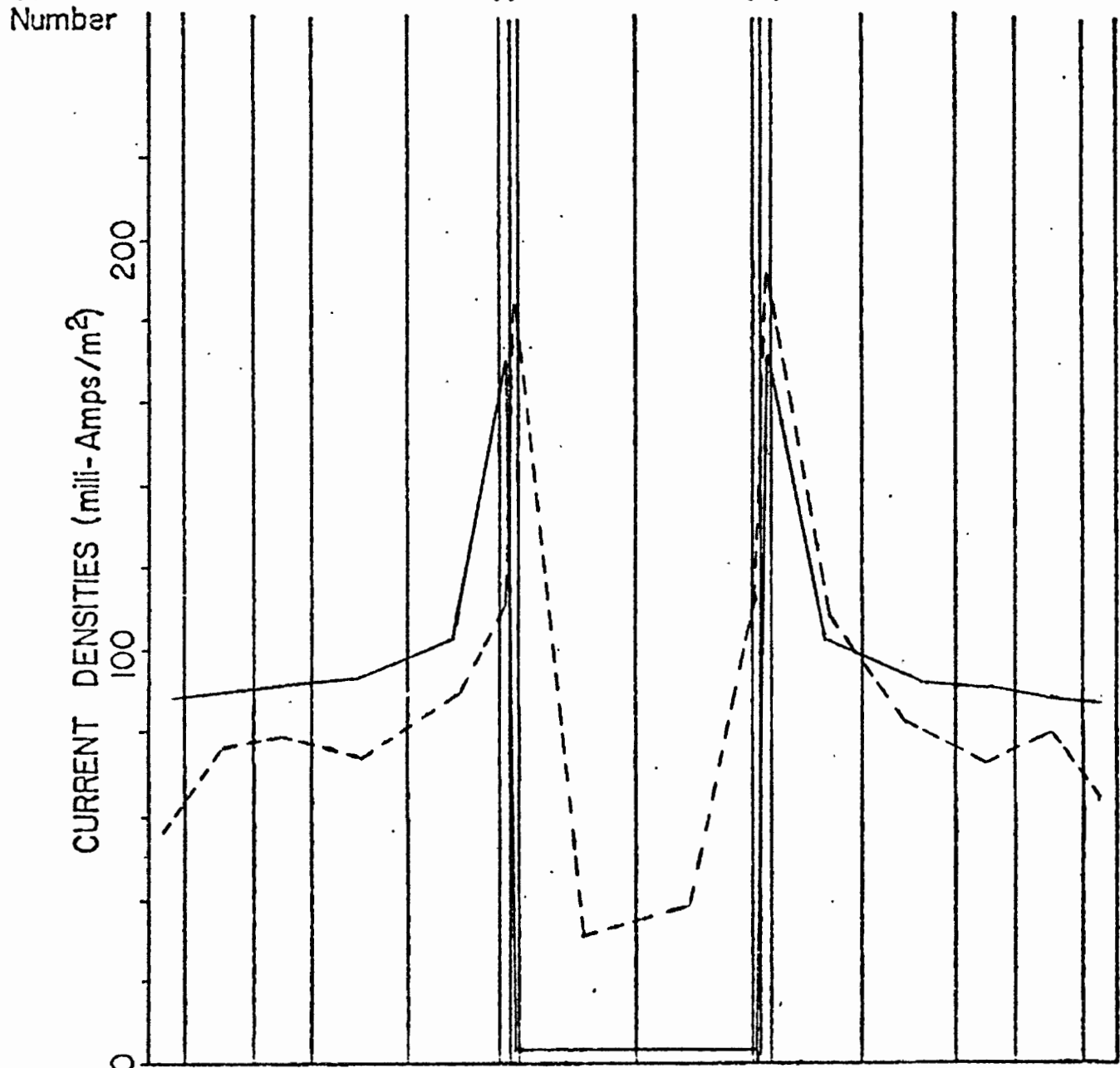

Figure 5.3 Calculated current densities. 
CURRENT DENSITIES IN SOIL AND POOL WATER $\left(m-A m p s / m^{2}\right)$ SOIL RESISTIVITY $=55$ ohm-maters POOL TYPE: $\triangle$ Reiniorced WATER CONDUCTIVITY $=3000$ micro-mho $/ \mathrm{cm}$. DNon-reiniorced

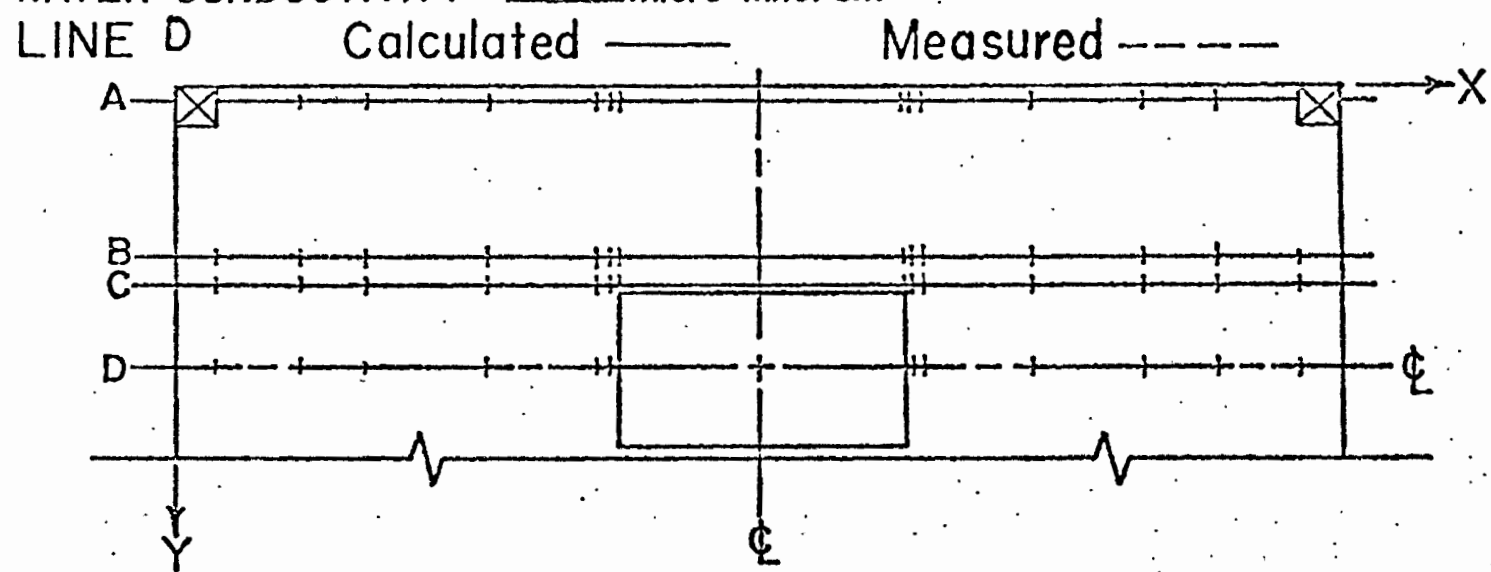

Station $\rightarrow$

Number

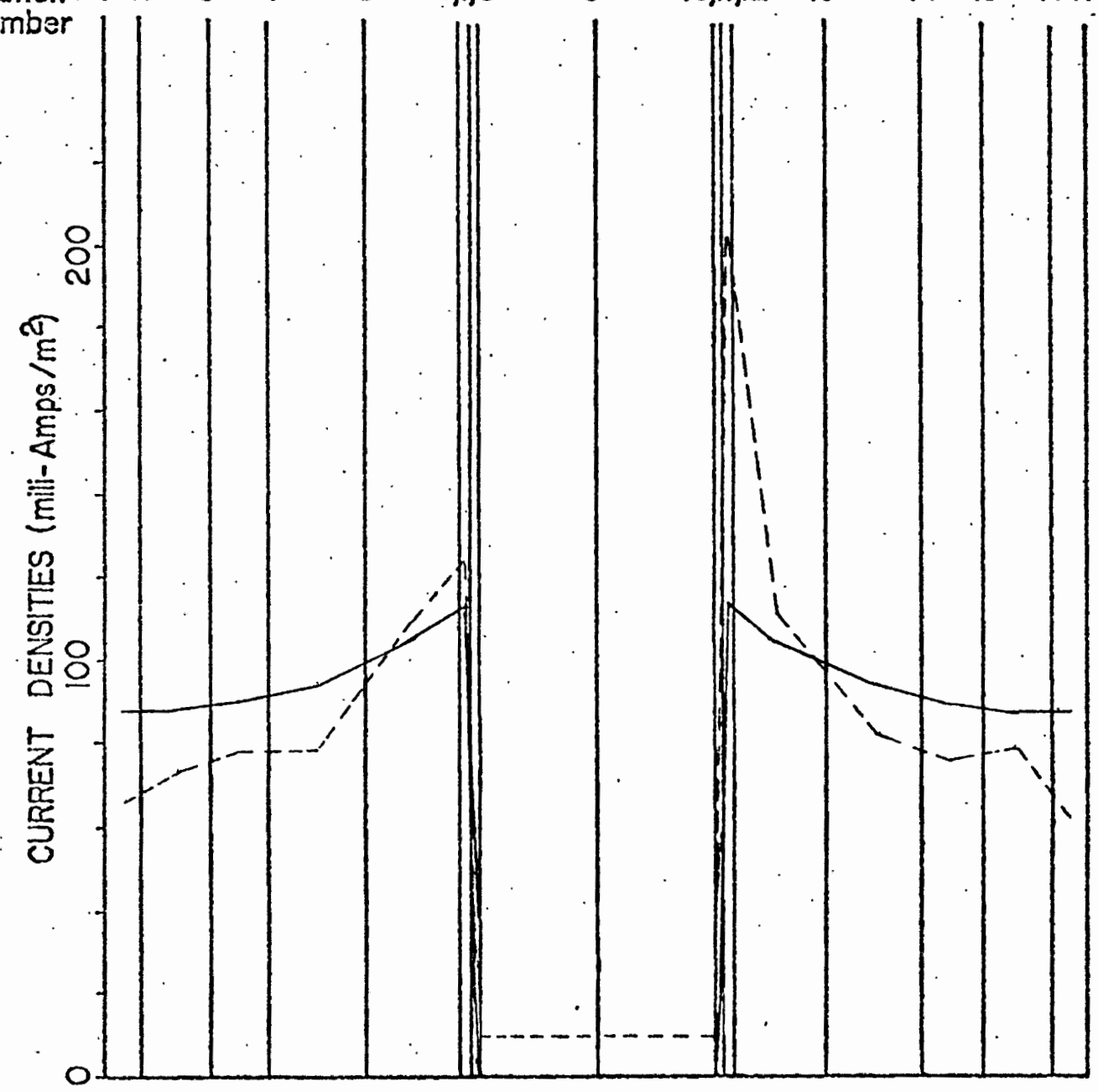

Figure 5.4 Calculated current densities. 
CURRENT DENSITIES IN SOIL AND POOL WATER $\left(m-A m p s / m^{2}\right)$ SOIL RESISTIVITY $=59.5$ oinm-meters POOL TYPE: $\square$ Reinforcad WATER CONDUCTIVITY $=1600$ micro-mino $/ \mathrm{cm}$. QNon-rainiorced LINE C Calculated - Measured-_-

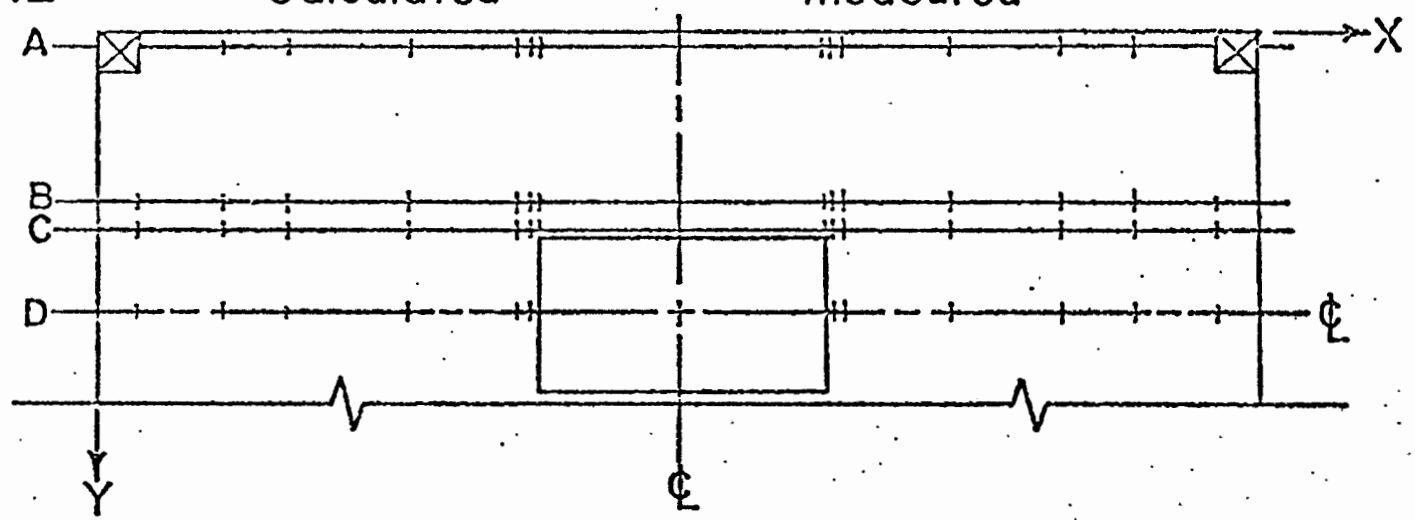

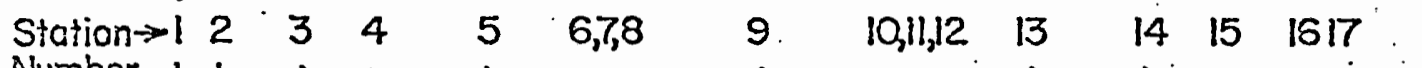

Number

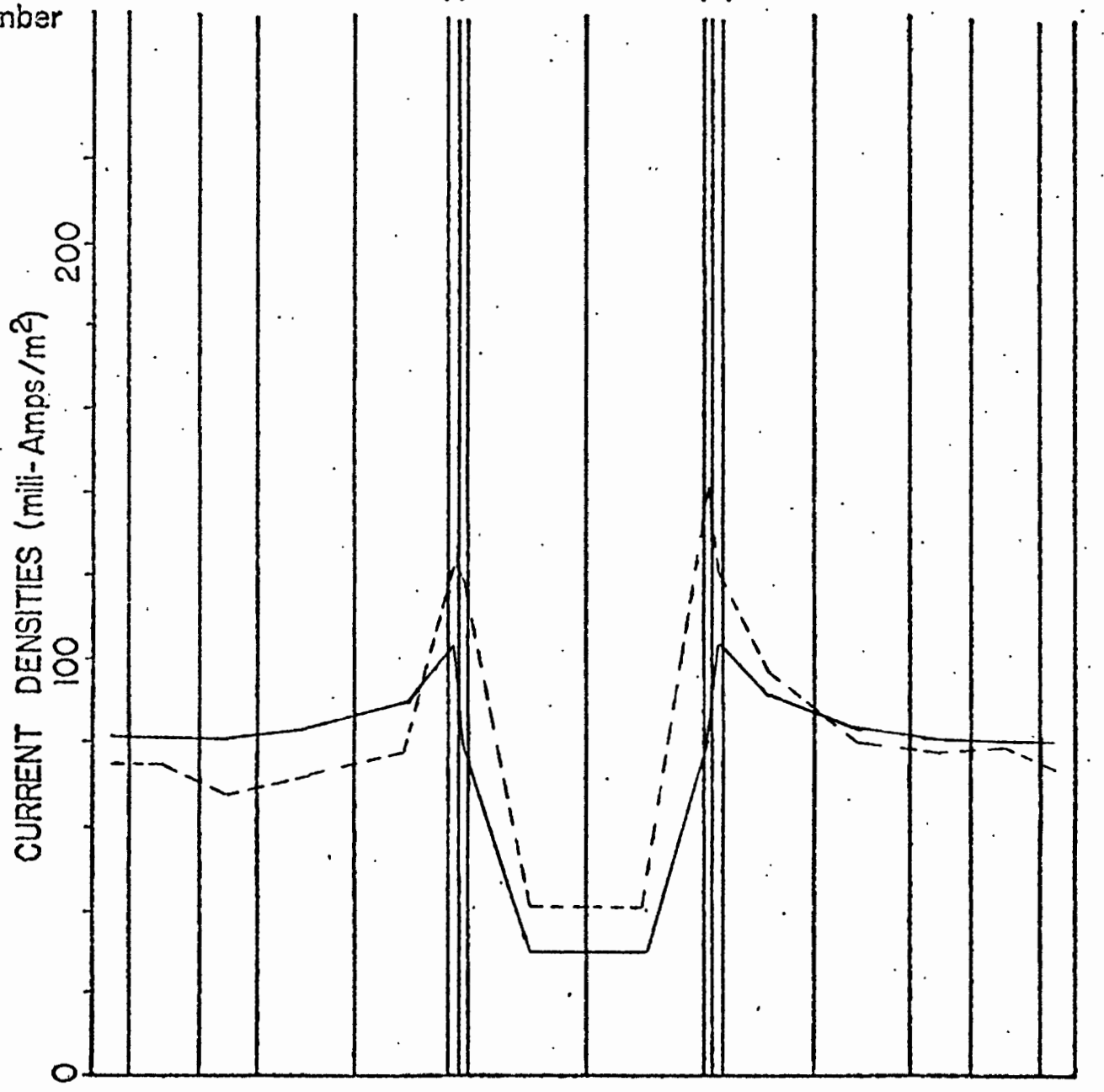

Figure 5.5 Calculated current densities. 
CURRENT DENSITIES IN SOIL AND POOL WATER $\left(m-A m p s / m^{2}\right)$ SOIL RESISTIVITY $=59.5$ ohm-meters POOL TYPE: $\square$ Reinforced WATER CONDUCTIVITY $=1600$ micro-mho $/ \mathrm{cm}$. $\triangle$ Non-reinforced LINE D Calculated - Measured -- -

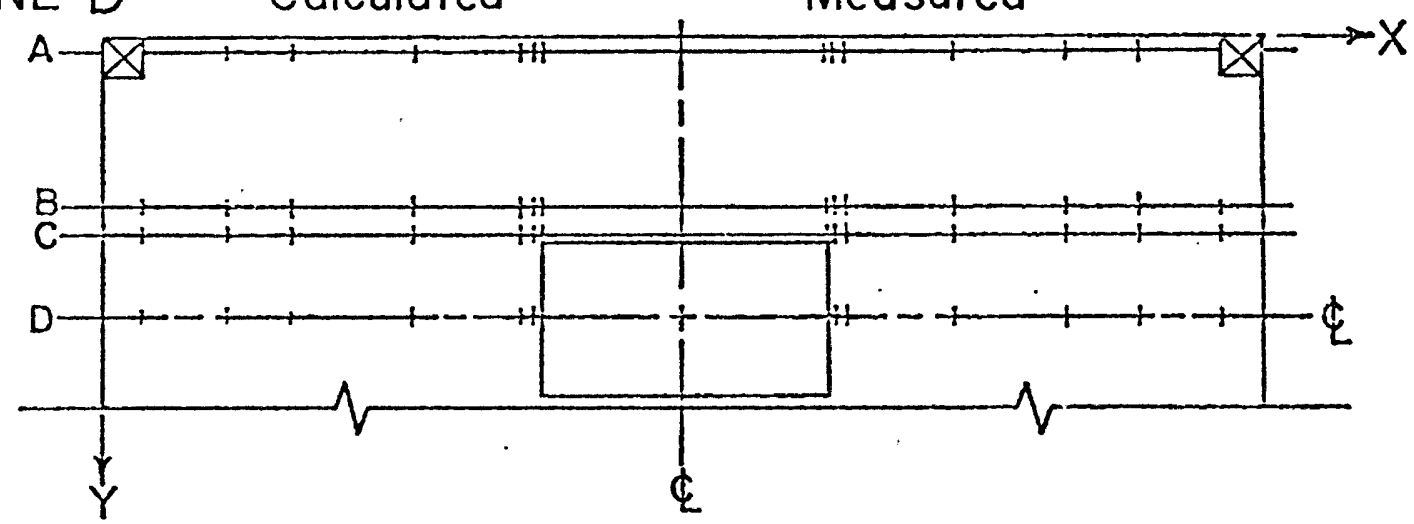

$\begin{array}{llllllllllll}\text { Station } \rightarrow 1 & 2 & 3 & 4 & 5 & 6,7,8 & 9 & 10,11,12 & 13 & 14 & 15 & 1617 \\ \text { Numbar } & 1 & & & & & & & & \end{array}$

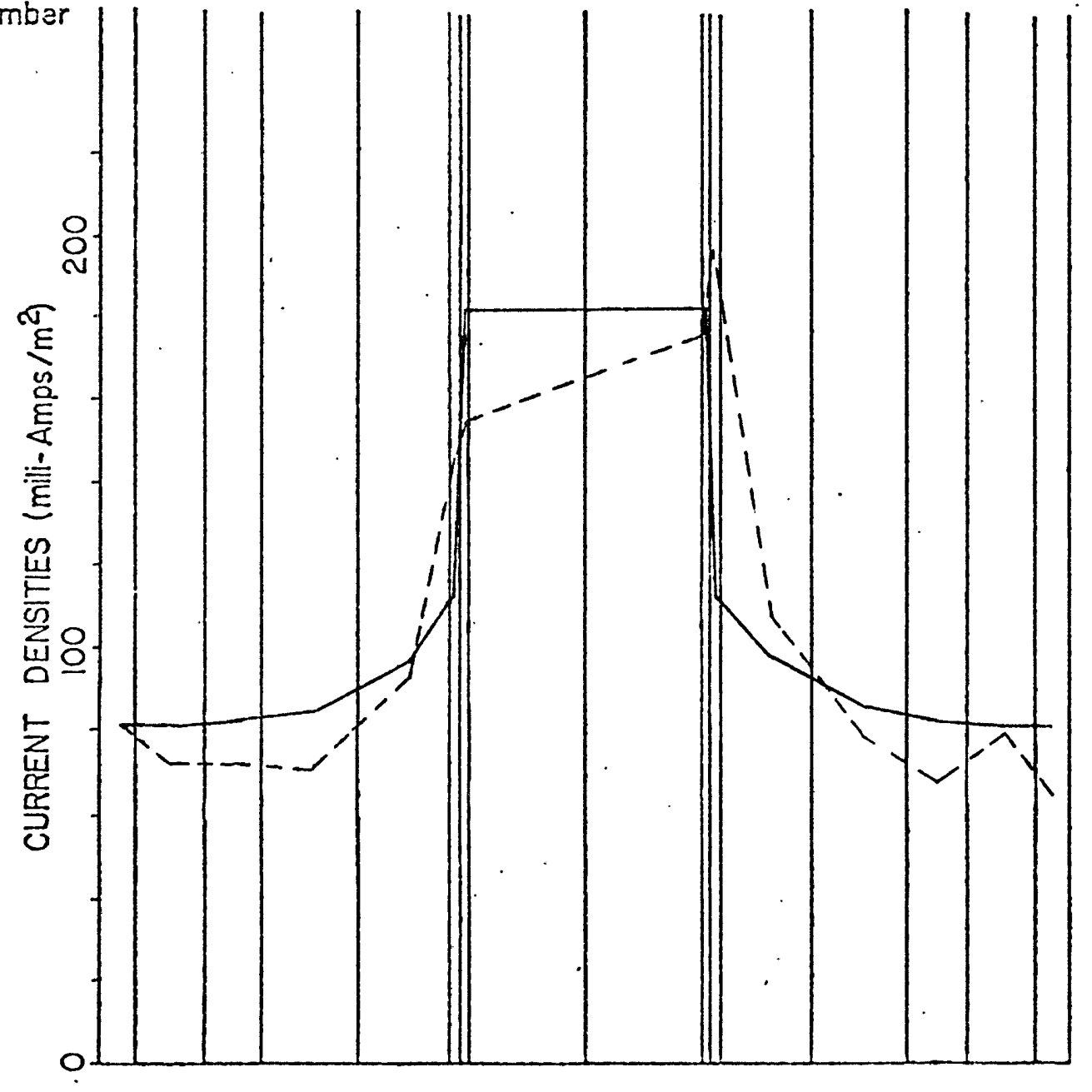

Figure 5.6 Calculated current densities. 
CURRENT DENSITIES IN SOIL AND POOL WATER $\left(m-A m p s / m^{2}\right)$ SOIL RESISTIVITY $=52.5$ ohm-maters POOL TYPE: $\square$ Reinforced WATER CONDUCTIVITY $=3200$ micro-mio $/ \mathrm{cm}$. QNon-reiniorced LINE C Calculated __. Measured-_-

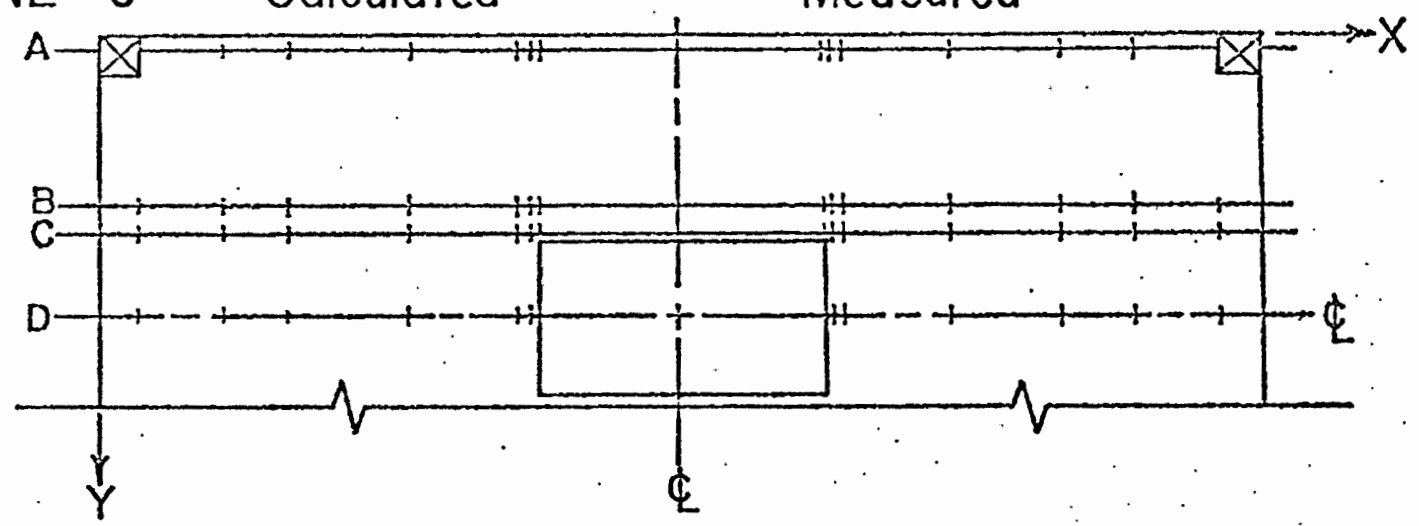

Station $\rightarrow$

Numbar

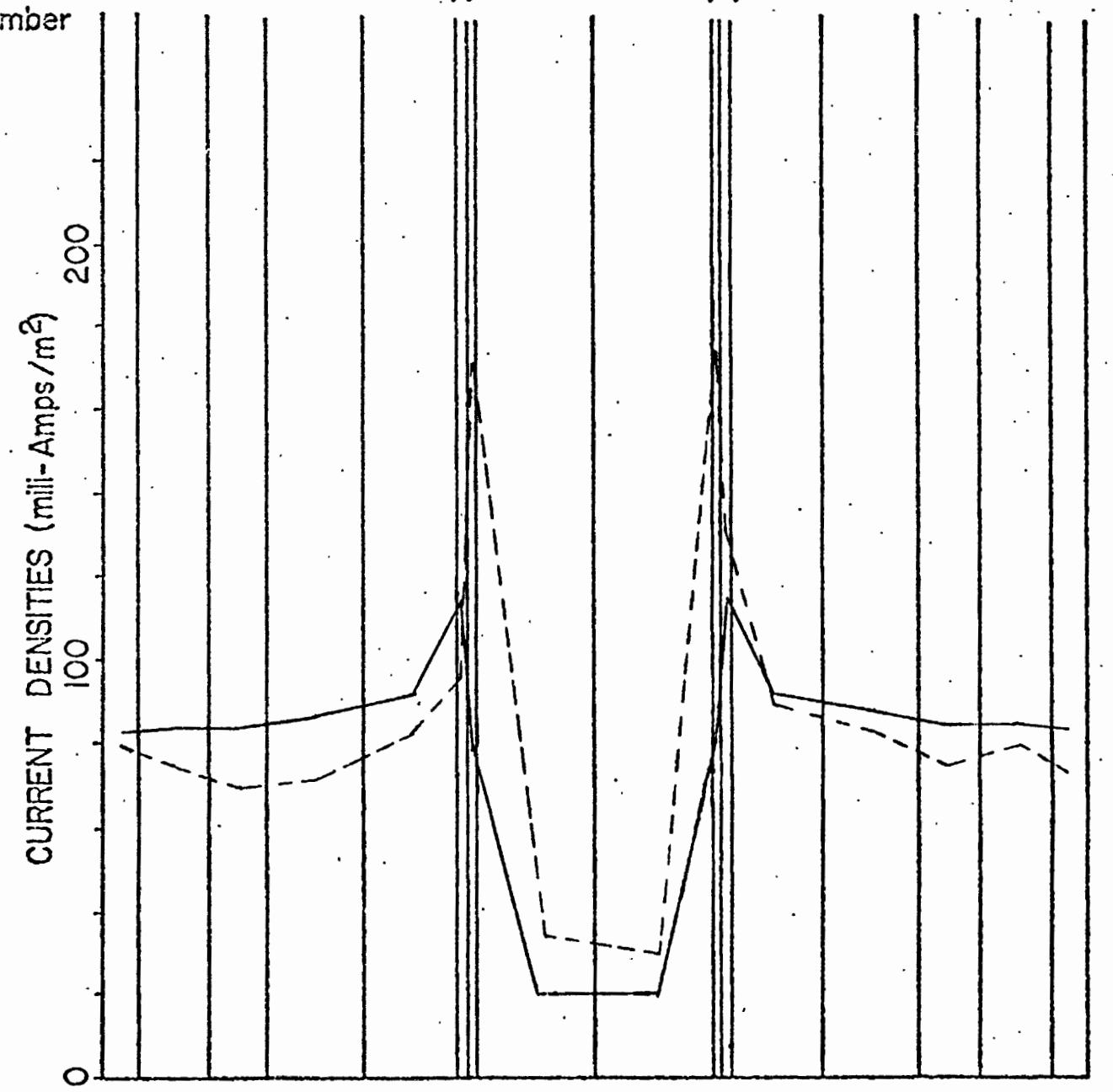

Figure 5.7 Calculated current densities. 
CURRENT DENSITIES IN SOIL AND POOL WATER $\left(m-A m p s / m^{2}\right)$ SOIL RESISTIVITY $=50.50 \mathrm{om}-$ meters POOL TYPE: $\square$ Reinforced WATER CONDUCTIVITY $=3000 \mathrm{micro}-\mathrm{mho} / \mathrm{cm}$. Non-reinforced LINE D Calculated — Measured-- - -

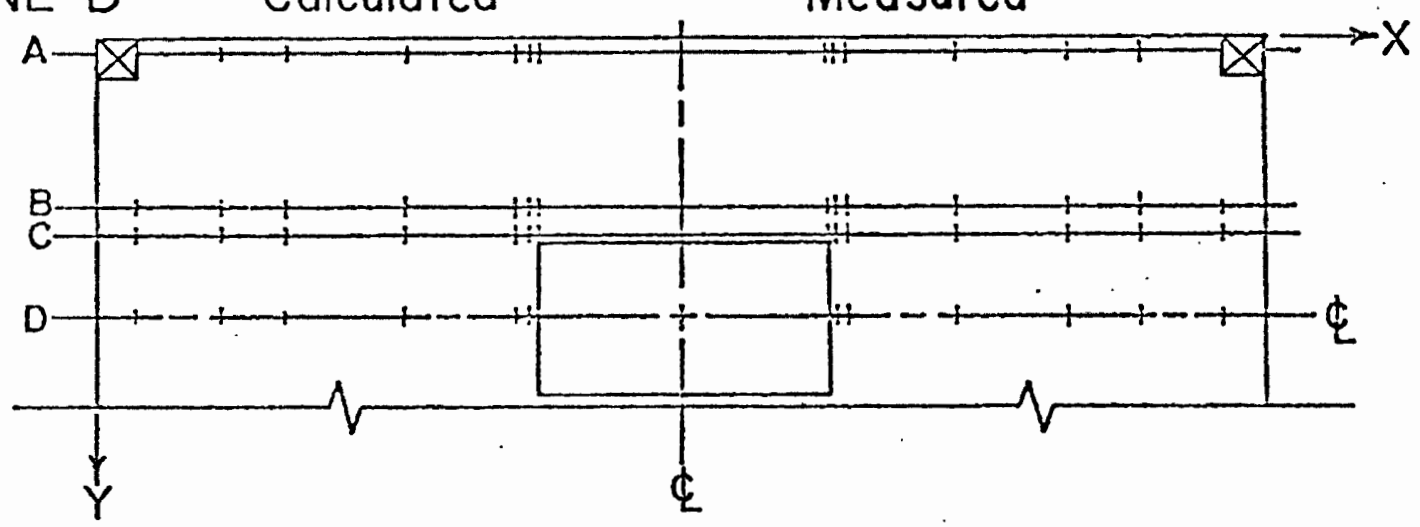

$\begin{array}{llllllllllll}\text { Station } \rightarrow 1 & 2 & 3 & 4 & 5 & 6,7,8 & 9 & 10,11,12 & 13 & 14 & 15 & 1617\end{array}$ Numbar

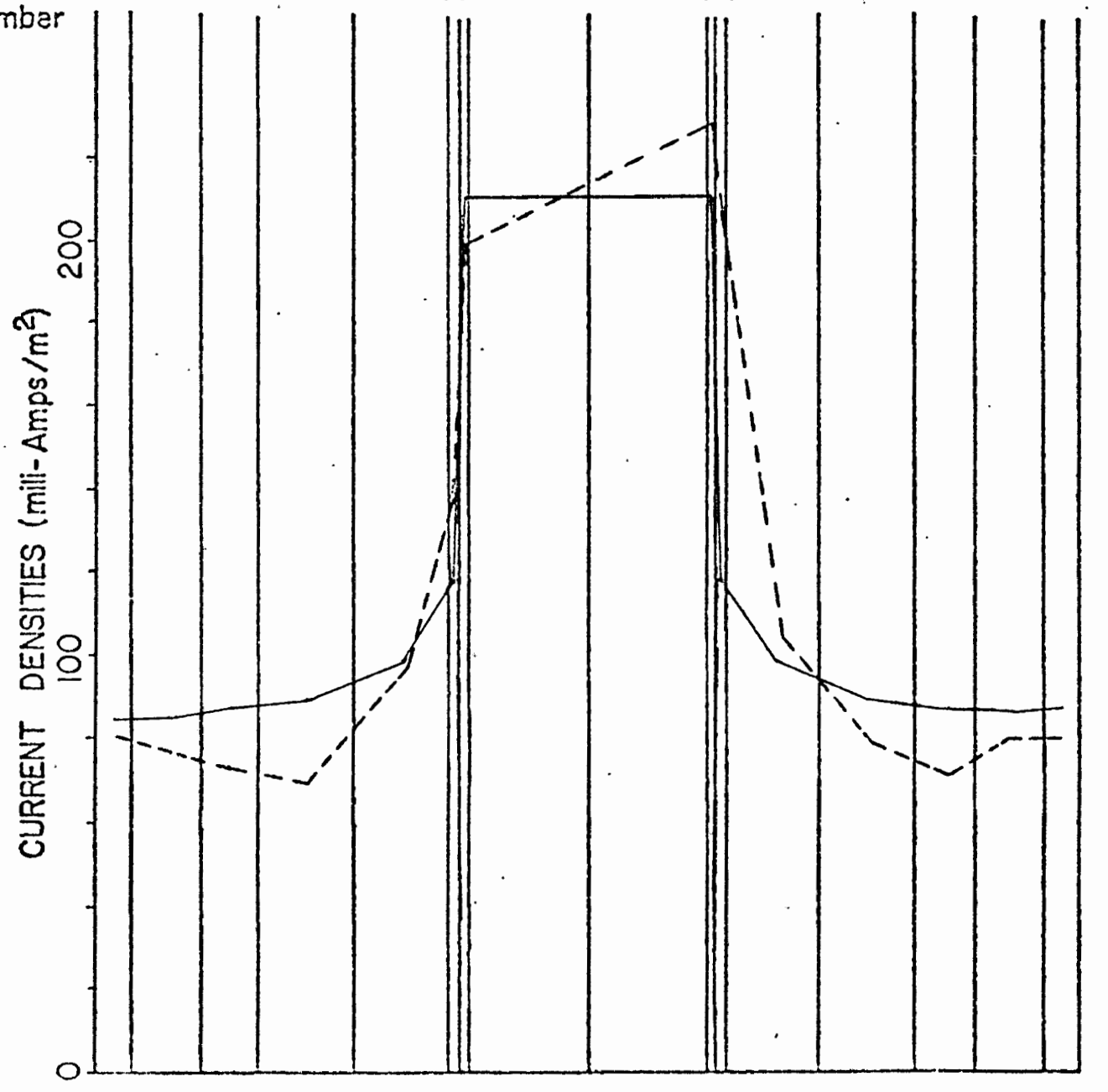

Figure 5.8 Calculated current densities. 


\subsection{POTENTIAL HAZARD TO THE HUMAN BODY}

It is known that the real measure of shock intensity lies in the amount of current (amperes) forced through the body, and not the voltage (17). Figure 5.9 shows levels of current hazards to the human body.

To define how hazardous the observed current densities are to humans, currents through the human body are calculated. The human body's resistance is in the neighborhood of $1000 \mathrm{ohm}$ (17). the human body if one is standing in the vicinity of the swimming pool. Similar calculations are done for a person who is inside the swimming pool and results are shown in Table 5.5.

In comparing the calculated currents traveling through the human body with Fig. 5.9, one concludes that hazard may exist on the edge of the swimming pool where the resistivity of the surrounding soil is very high. However, this analysis does not include the presence of a human body in the mode1. Also, the effects of short duration currents (1-10 cycles) on the human body need further investigation. 


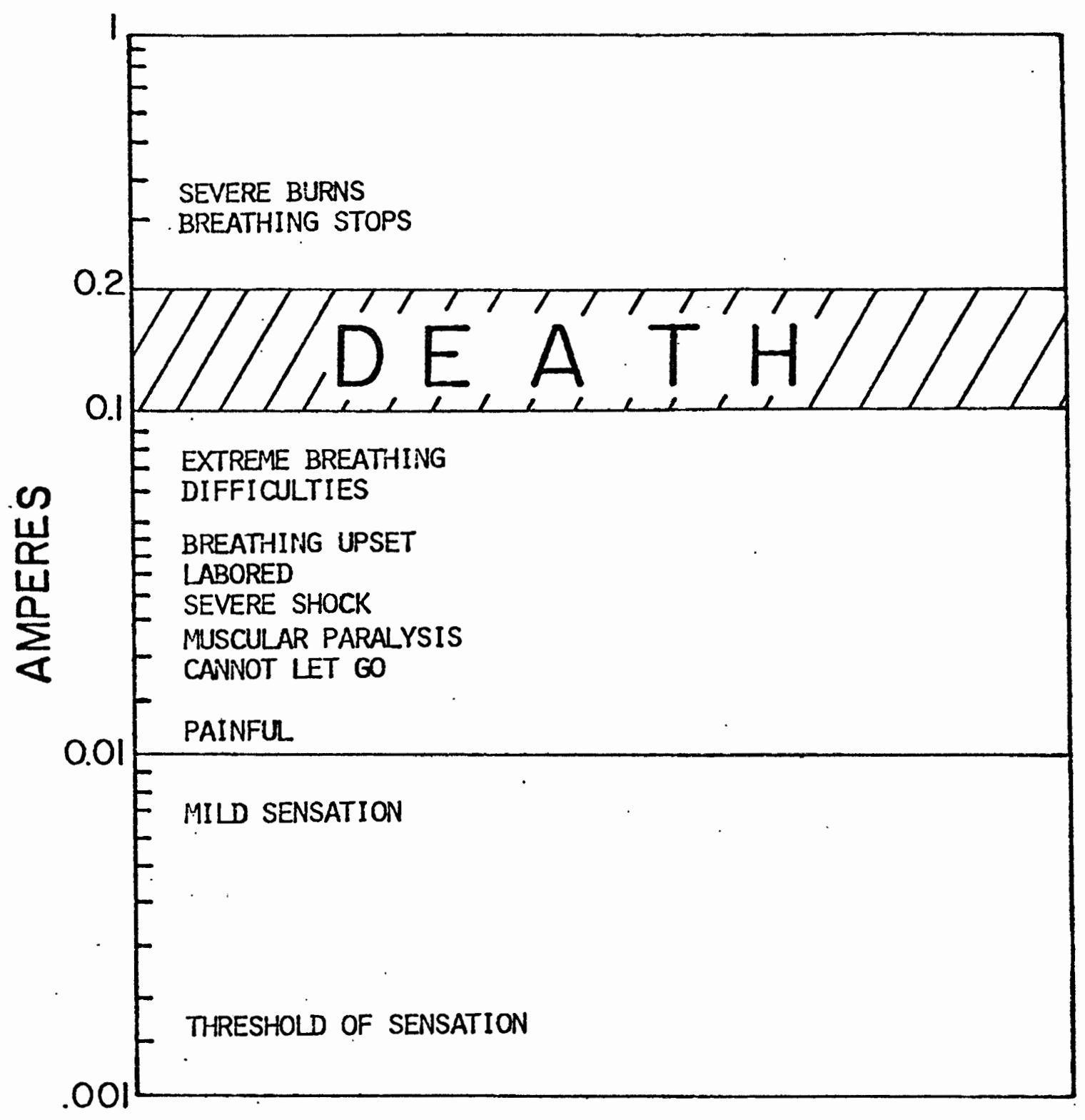

Figure 5.9 Levels of current hazards to the human body. 
TABLE 5.1

CALCULATED CURRENT TRAVELING THROUGH THE HUMAN BODY STANDING ON THE SOIL

LINE A STANDING ON THE SOIL

SOIL RESISTIVITY=1160 OHM-METER WATER CONDUCTIVITY=1500 MICRO-MOH/CM

POOL TYPE: REINFORCED

FOOT TO FOOT RESISTANCE OF HUMAN BODY $=1000$ OHM

FOOT TO FOOT DISTANCE $=50 \cdot \mathrm{CM}$.

BETWEEN VOLTAGE GRADIENT VOLTAGE ACROSS BODY CURRENT THROUGH BODY ST ST VN VOLTS/METER VOLTS AMP.

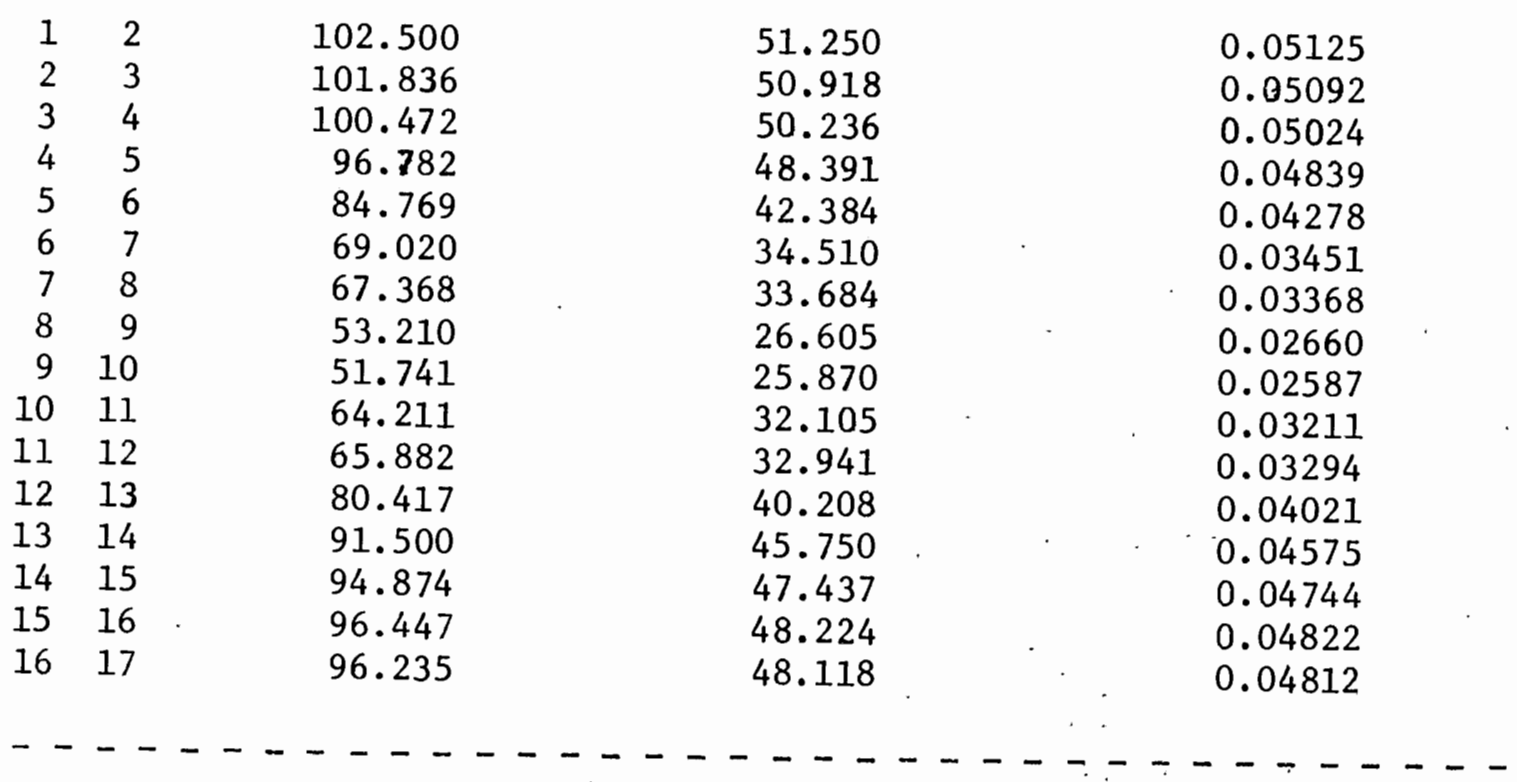


TABLE 5.2

CALCULATED CURRENT TRAVELING THROUGH THE HUMAN BODY STANDING ON THE SOIL

LINE B STANDING ON THE SOIL

SOIL RESISTIVITY=1160.00 OHM-METER WATER CONDUCTIVITY $=1500$ MICRO-MOH/CM

POOL TYPE: REINFORCED

FOOT TO FOOT RESISTANCE OF HUMAN BODY $=1000$ OHM

FOOT TO FOOT DISTANCE $=50 \mathrm{CM}$.

BETWEEN VOLTAGE GRADIENT VOLTAGE ACROSS BODY CURRENT THROUGH BODY ST非 ST非 VOLTS/METER VOLTS AMP.

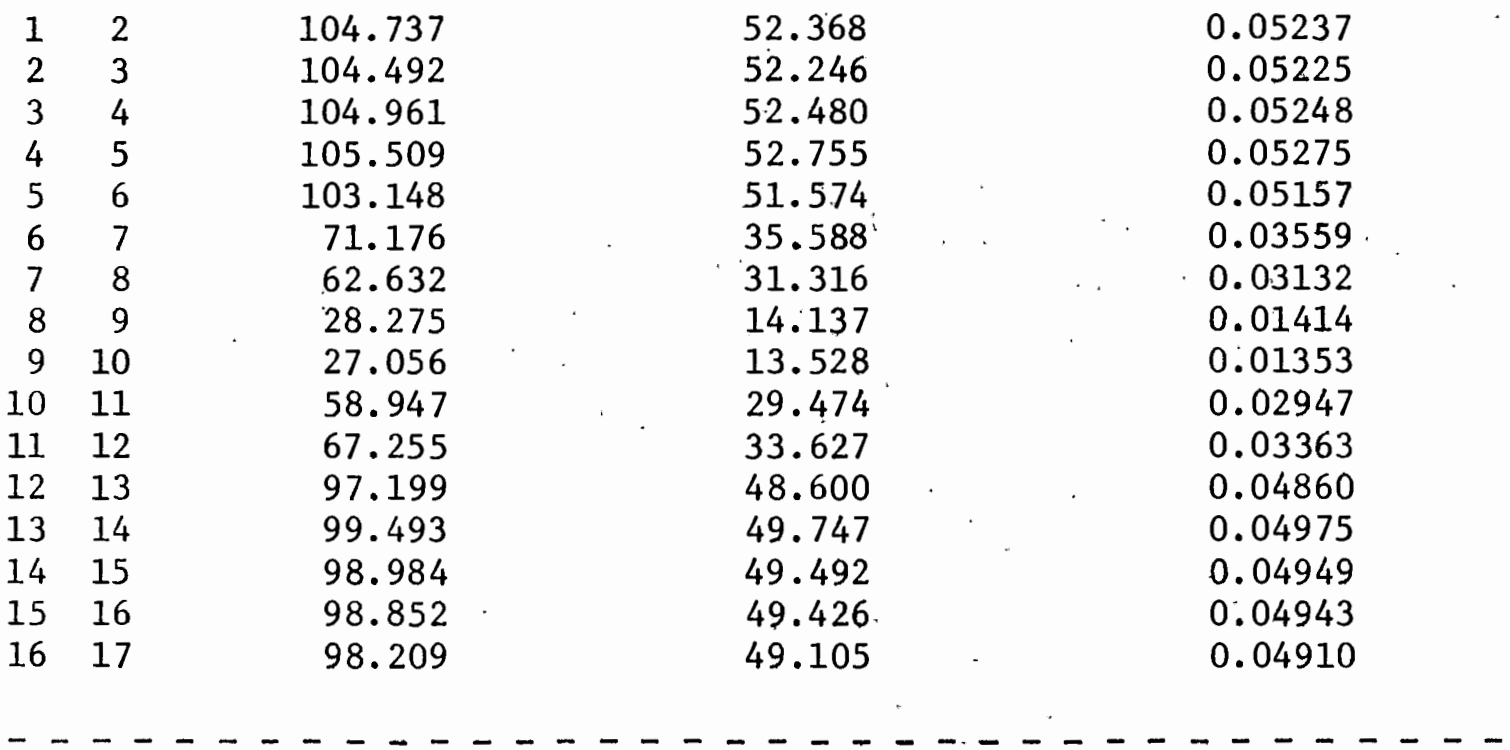


TABLE 5.3

CALCULATED CURRENT TRAVELING THROUGH THE HUMAN BODY STANDING ON THE SOIL

LINE C STANDING ON THE SOIL

SOIL RESISTIVITY=1160 OHM-METER WATER CONDUCTIVITY=1500 MICRO-MOH/CM

POOL TYPE: REINFORCED

FOOT TO FOOT RESISTANCE OF HUMAN BODY $=1000$ OHM

FOOT TO FOOT DISTANCE $=50: \mathrm{CM}$

BETWEEN VOLTAGE GRADIENT VOLTAGE ACROSS BODY CURRENT THROUGH BODY STE ST非 VOLTS/METER $\quad$ VOLTS AMP.

$\begin{array}{rrrrr}1 & 2 & 105.066 & 52.533 & 0.05253 \\ 2 & 3 & 104.951 & 52.475 & 0.05240 \\ 3 & 4 & 105.945 & 52.972 & 0.05297 \\ 4 & 5 & 108.403 & 54.201 & 0.05420 \\ 5 & 6 & 122.431 & 61.215 & 0.06122 \\ 6 & 7 & 200.980 & 100.490 & 0.10049 \\ 7 & 8 & 0.000 & 0.000 & 0.00000 \\ 8 & 9 & 0.000 & 0.000 & 0.00000 \\ 9 & 10 & 0.000 & 0.000 & 0.00000 \\ 10 & 11 & 0.000 & 0.000 & 0.00000 \\ 11 & 12 & 188.235 & 94.118 & 0.09412 \\ 12 & 13 & 115.208 & 57.604 & 0.05760 \\ 13 & 14 & 102.185 & 51.093 & 0.05109 \\ 14 & 15 & 99.882 & 49.941 & 0.04994 \\ 15 & 16 & 99.276 & 49.638 & 0.04964 \\ 16 & 17 & 98.536 & 49.268 & 0.04927\end{array}$


TABLE 5.4

CALCULATED CURRENT TRAVELING THROUGH THE HUMAN BODY STANDING ON THE SOIL

LINE D STANDING ON THE SOIL

SOIL RESISTIVITY=1160 OHM-METER WATER CONDUCTIVITY $=1500$ MICRO-MOH/CM

POOL TYPE: REINFORCED

FOOT TO FOOT RESISTANCE OF HUMAN BODY $=1000$ OHM

FOOT TO FOOT DISTANCE $=50 \mathrm{CM}$

BETWEEN VOLTAGE GRADIENT VOLTAGE ACROSS BODY CURRENT THROUGH BODY ST ST VIN VOLTS/METER VOLTS AMP.

$\begin{array}{rrrrr}1 & 2 & 105.461 & 52.730 & 0.05273 \\ 2 & 3 & 105.410 & 52.705 & 0.05270 \\ 3 & 4 & 106.929 & 53.465 & 0.05346 \\ 4 & 5 & 110.787 & 55.394 & 0.05539 \\ 5 & 6 & 127.153 & 63.576 & 0.06358 \\ 6 & 7 & 131.961 & 65.980 & 0.06598 \\ 7 & 8 & \text { IN WATER } & \text { IN WATER } & \text { IN WATER } \\ 8 & 9 & \text { IN WATER } & \text { IN WATER } & \text { IN WATER } \\ 9 & 10 & \text { IN WATER } & \text { IN WATER } & \text { IN WATER } \\ 10 & 11 & \text { IN WATER } & \text { IN WATER } & \text { IN WATER } \\ 11 & 12 & 123.922 & 61.961 & 0.06196 \\ 12 & 13 & 119.630 & 59.815 & 0.05981 \\ 13 & 14 & 104.394 & 52.197 & 0.05220 \\ 14 & 15 & 100.795 & 50.398 & 0.05040 \\ 15 & 16 & 99,717 & 49.859 & 0.04986 \\ 16 & 17 & 98.863 & 49.431 & 0.04943 \\ & & & & \end{array}$




\section{TABLE 5.5}

CALCULATED CURRENT TRAVELING THROUGH THE HUMAN BODY INSIDE THE SWIMMING POOL

SOIL RESISTIVITY $=59.50$ OHM-METER WATER CONDUCTIVITY $=3000 \mathrm{MICRO-MOH} / \mathrm{CM}$

POOL TYPE: NON-REINFORCED

FOOT TO FOOT RESISTANCE OF HUMAN BODY $=1000$ OHM

FOOT TO FOOT DISTANCE $=50 \mathrm{CM}$

BETWEEN VOLTAGE GRADIENT VOLTAGE ACROSS BODY CURRENT THROUGH BODY STE ST VOLTS/METER VOLTS AMP.

$\begin{array}{lllll}1 & 2 & 0.875 & 0.438 & 0.00044 \\ 2 & 3 & 0.800 & 0.400 & 0.00040 \\ 3 & 4 & 0.775 & 0.388 & 0.00039 \\ 4 & 5 & 0.787 & 0.394 & 0.00039 \\ 5 & 6 & 0.788 & 0.394 & 0.00039 \\ 6 & 7 & 0.788 & 0.394 & 0.00039 \\ 7 & 8 & 0.800 & 0.400 & 0.00040 \\ & & & \end{array}$


5.3 THE LIMITATIONS AND ACCURACY OF THE THEORETICAL TECHNIQUE.

The technique used in the proposed solution is called The Finite Element Method. This is a powerful numerical technique to solve problems which require a high degree of accuracy. The solution of problems solved using this technique are comparatively more accurate than those solved by other numerical methods such as the Finite Difference Method.

However, there are some limitations as described below:

(1) This program as it exists now can only handle two-dimensional problems. However, with further development, it would be possible to "solve three-dimensional complex electro-magnetic and electro-static field problems.

(2) This program uses only the triangular division of the region of interest. Rectangular or other shapes can be accommodated if the program is modified.

(3) The computer storage is another limitation. This limitation was improved by using the half-banded method. 


\section{CHAPTER VI}

\section{CONCLUSION}

In this study a computer code based on Maxwell's Equations was developed to use the Finite Element Method to calculate complex voltage gradients and current densities on the surface of any desired region.

In order to evaluate the accuracy of this program, the solution to a selected problem was compared to the solution using another computer technique. In addition, solution to several problems were compared to actual known values. In all cases close agreement between the theoretical solution and actual values was observed.

Also in order to check the validity of the program, theoretical results were compared to results obtained from experimental tests, and the comparison showed close agreement. 


\section{BIBLIOGRAPHY}

1. John R. Carson; "Wave Propagation in Overhead Wires with Ground Return", The Be11 System Technical Journal, 1926, 5, pp. 539-554.

2. L. J. Lacey; "The Mutual Impedance of Earth-Return Circuits", IEEE, Vo1. 621, 392.2, 1952 .

3. L. M. WedepohI and R. G. Wasley; "Wave Propagation in Multiconductor Overhead Lines", Proc. IEE, 1966, 113, (4).

4. M. Krakowski; "Mutual Impedance of Crossing Earth-Return Circuits", Proceedings of the IEE, Feb. 76, Vol. 114, No. 2 .

5. Mr. Nakagawa; "Earth Return Impedance of Overhead Lines Above a 3Layer Earth", Proceedings of IEE, Dec. 1973, Vo1. 120, Number 12.

6. P. Magnusson; "Wave Propagation Over Parallel Wires: The Proximity Effect", Vo1. X11, Apr. 1921.

7. H. Bateman; "Partial Differential Equations of Mathematical Physics", Cambridge University Press, 1959.

8. E. D. Sunde; "Earth Conduction Effects in Transmission Systems", Van Nostrand, 1949.

9. B. O. Pierce; "A Short Table of Integrals", Boston: Ginn and Company, 1929.

10. N. W. McLachlan, "Bessel Function for Engineers", 2nd Ed. Oxford University Press, 1955.

11. Wiley; "The Finite Element Method for Engineers", New York, 1975.

12. 0. C. Zienkiewicz, "The Finite Element Method in Engineering Science", McGraw-Hil1, 1971.

13. P. Silvester; "Finite Element Solution of Saturable Magnetic Field Problems", Transaction on Power Apparatus and Systems, Vo1. PAS89, No. 7, Oct. 1970.

14. 0. W. Andersen; "LaPlacian Electrostatic Field Calculations by Finite Elements with Automatic Grid Generations", Transaction on Power Apparatus and Systems, IEEE, Nov. 1972.

15. O. C. Zienkiewicz and Y. K. Cheung; "The Finite Element Method Instructural and Continuum Mechanics", McGraw-Hi11, 1967. 
16. 0. W. Andersen; "Finite Element Solution of Complex Potential Electric Fields", IEEE Transactions on Power, Vo1. PAS-96, No. 4, Ju1y/ August 1977.

17. E. W. Kimbark, "Direct Current Transmission", Vo1 I, Wiley-Interscience, 1948.

18. V. K. Garg, F. Rad, T. Killian; "Study of Distribution of Ground Fault Currents in Below Grade Swimming Pools Located Near Transmission Lines", Portland State University, 1978. 
APPENDIX A

\section{EULER'S THEOREM OF VARIATIONAL CALCULUS}

The transition from a variational statement to an equivalent governing differential equation is relatively simple and will be demonstrated here. The reverse process, however, is more involved and any generalized processes restrictive for the very reason that frequently on variational principle can be established.

Let us take a problem which is to be minimized.

$$
g=\int_{v} f\left(x, y, z, H, H_{x}, H_{y}, H_{z}\right) d v+\int_{c}\left(q H+p H^{2} / 2\right) d s
$$

In this equation $\mathrm{f}$ is an arbitrary function, $\mathrm{H}_{\mathrm{x}}=\frac{\partial \mathrm{H}}{\partial \mathrm{x}}$, etc., and $\mathrm{c}$ is a portion of the boundary surface on which prescribed values of $\mathrm{H}$ are not imposed. On remainder $\mathrm{H}=\mathrm{H}_{\mathrm{B}}$.

Considering an arbitrary small variation of the unknown function and its derivitives

$$
\begin{aligned}
\delta g= & \int_{v}\left(\frac{\partial f}{\partial H} \delta H+\frac{\partial f}{\partial H_{x}} \delta H_{x}+\frac{\partial f}{\partial H_{y}} \delta H_{y}+\frac{\partial f}{\partial H_{z}} \delta H_{z}\right) d v+ \\
& \int_{c}(q \delta H+p H \delta H) d s
\end{aligned}
$$

as

$$
\delta H_{x}=\delta\left(\frac{\partial H}{\partial x}\right)=\frac{\partial}{\partial x}(\delta H) \text {, etc. }
$$


Equation $\mathrm{A}-2$ can be written as;

$$
\begin{aligned}
\delta g & =\int_{v}\left[\frac{\partial f}{\partial H} \delta H+\frac{\partial f}{\partial H_{x}} \frac{\partial}{\partial x}(\delta H)+\frac{\partial f}{\partial H_{y}} \frac{\partial}{\partial y}(\delta H)+\frac{\partial f}{\partial H_{z}} \frac{\partial}{\partial z}(\delta H)\right] d v \\
& +\int_{v}(q \delta H+p H \delta H) d s=0
\end{aligned}
$$

In the above we have equated $\delta \mathrm{x}$ to zero, as at the minimum (or stationary point) the 'variation' becomes zero.

Now putting $d v=d x d y d z$ and integrating the second term of Equation A-3 by parts with respect to $\mathrm{x}$

$$
\int_{v} \frac{\partial f}{\partial H_{x}} \frac{\partial}{\partial x}(\delta H) d v=\int_{S} \frac{\partial f}{\partial H_{x}} \delta H L x d s-\int_{v} \frac{\partial}{\partial x}\left(\frac{\partial f}{\partial H_{x}}\right) \delta H d v
$$

In which $\mathrm{L}_{\mathrm{x}}$ is the direction cosine of the normal to the outer surface with the $\mathrm{x}$ axis. Performing similar operation on the other terms of Equation $\mathrm{A}-3$ and substituting, it becomes;

$$
\begin{aligned}
& \delta g=\int_{v} \delta H \frac{\partial f}{\partial H}-\frac{\partial}{\partial x}\left(\frac{\partial f}{\partial H_{x}}\right)-\frac{\partial}{\partial y}\left(\frac{\partial f}{\partial H_{y}}\right)-\frac{\partial}{\partial z}\left(\frac{\partial f}{\partial H_{z}}\right) d v+ \\
& \int_{c} \delta H \quad q+p H+L_{x} \frac{\partial f}{\partial H_{x}}+L_{y} \frac{\partial f}{\partial H_{y}}+L_{z} \frac{\partial f}{\partial H_{z}} d s
\end{aligned}
$$

The second integral is only taken over the boundary $C$ as on the remainder of surface $S$ we have prescribed values of $H$ and therefore $\delta H=0$.

For Equation $\mathrm{A}-4$ to be true for any arbitrary variation $\mathrm{H}$ first integral should be equal to zero;

$$
\frac{\partial f}{\partial H}-\frac{\partial}{\partial x}\left(\frac{\partial f}{\partial H_{x}}\right)-\frac{\partial}{\partial y}\left(\frac{\partial f}{\partial H_{y}}\right)-\frac{\partial}{\partial z}\left(\frac{\partial f}{\partial H_{z}}\right)=0
$$


Everywhere within the region $\mathrm{V}$, and on the boundary $\mathrm{C}$

$$
L_{x} \frac{\partial f}{\partial H_{x}}+L_{y} \frac{\partial f}{\partial H_{y}}+L_{z} \frac{\partial f}{\partial H_{z}}=0
$$

These two equations, if satisfied by $\mathrm{H}$, minimize $\mathrm{g}$. If the solution is unique then formulations $A-1$ and $A-5$ are equivalent. The above differential equations are known as the Euler equations of the problem. 
APPENDIX B

THE GAUSSIAN METHOD

As an example, the solution of three equations and three unknowns is described below:

$$
\begin{array}{r}
200 X-100 Y+0 Z=-8 \\
-100 X+200 Y-100 Z=-8 \\
0 X-100 Y+100 Z=-8
\end{array}
$$

In matrix form:

$$
\left[\begin{array}{rrr}
200 & -100 & 0 \\
-100 & 200 & -100 \\
0 & -100 & 100
\end{array}\right]\left[\begin{array}{l}
\mathrm{X} \\
\mathrm{Y} \\
\mathrm{Z}
\end{array}\right]=\left[\begin{array}{l}
-8 \\
-8 \\
-8
\end{array}\right]
$$

Let us first solve this problem as it is in the form of $B-2$ then reduce it to the banded form.

$$
\left[\begin{array}{rrr}
200 & -100 & 0 \\
-100 & 200 & -100 \\
0 & -100 & 100
\end{array}\right],\left[\begin{array}{l}
-8 \\
-8 \\
-8
\end{array}\right]
$$

Divide the first row by the diagonal element of the first row.

$$
\left[\begin{array}{rrr}
1 & -0.5 & 0 \\
-100 & 200 & -100 \\
0 & -100 & 100
\end{array}\right],\left[\begin{array}{r}
-0.04 \\
-8 \\
-8
\end{array}\right]
$$


Multiply the first row by the first element of the second row and subtract the first row from the second row.

$$
\left[\begin{array}{rrr}
1 & -0.5 & 0 \\
0 & 150 & 100 \\
0 & -100 & 100
\end{array}\right],\left[\begin{array}{r}
-0.04 \\
-12 \\
-8
\end{array}\right]
$$

This manipulation introduced a zero to the second row, therefore these are two unknowns in the second row. Now divide the second row by the diagonal element of the row.

$$
\left[\begin{array}{rrr}
1 & -0.5 & 0 \\
0 & 1 & -2 / 3 \\
0 & -100 & 100
\end{array}\right],\left[\begin{array}{r}
-0.04 \\
-0.08 \\
-8
\end{array}\right]
$$

Multiply the second row by the second element in the third row and subtract the second row from the third row.

$$
\left[\begin{array}{rrr}
1 & -0.5 & 0 \\
0 & 1 & -2 / 3 \\
0 & 0 & 100 / 3
\end{array}\right],\left[\begin{array}{r}
-0.04 \\
-0.08 \\
-16
\end{array}\right]
$$

This introduced two zeros to the third row and the third row contains just one unknown. The unknown may now be easily calculated. One may proceed to the second and third rows and calculate a11 the unknowns. The answer:

$$
\begin{array}{ll}
100 / 3 Z=-16 & Z=-0.48 \\
Y-2 / 3 Z=-0.08 & \\
Y-2 / 3(-0.48)=-0.08 \quad Y=-0.4
\end{array}
$$




$$
\begin{aligned}
& X-0.5 Y=-0.4 \\
& X=-0.04+0.5(-0.4)=-0.24
\end{aligned}
$$

Now put the upper half band of the coefficient matrix in a new [D] matrix and solve the problem.

D

$\begin{array}{rr}* * * * * * * * * * \\ 200 & -100 \\ 200 & -100 \\ 100 & 0\end{array}$

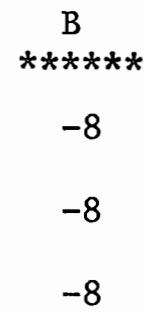

$-8$

For simplicity let us not multiply or divide the first columns by any numbers. At the end substitute 1 for all these elements. Also, due to symmetry of $[A], D(1,2)=A(2,1)$ and $D(2,2)=A(3,2)$.

First store $D(1,2)$ in $c$, because it is the same as $A(2,1)$ and there is no $A(2,1)$ in our [D] matrix.

Divide the first row by the first element of the first row.

$$
\left[\begin{array}{rr}
200 & -0.5 \\
200 & -100 \\
100 & 0
\end{array}\right] 9\left[\begin{array}{r}
-0.04 \\
-8 \\
-8
\end{array}\right]
$$

Then multiply the first row by the stored value of $c$ and subtract $D(1,2)$ from $D(2,1)$, because these two elements correspond to the same unknown in matrix [A].

$$
\left[\begin{array}{rr}
200 & -0.5 \\
150 & -100 \\
100 & 0
\end{array}\right],\left[\begin{array}{r}
-0.04 \\
-12 \\
-8
\end{array}\right]
$$


Now store $D(2,2)$ in $c$ and divide the second row by the first element of the row.

$$
\left[\begin{array}{cc}
200 & -0.05 \\
150 & -2 / 3 \\
100 & 0
\end{array}\right],\left[\begin{array}{r}
-0.04 \\
-0.08 \\
-8
\end{array}\right]
$$

Multiply the second row by the stored value of $c$ and subtract $D(2,2)$ from $D(3,1)$, because these two elements correspond to the same unknowns.

$$
\left[\begin{array}{rr}
200 & -0.5 \\
150 & -2 / 3 \\
100 / 3 & 0
\end{array}\right],\left[\begin{array}{c}
-0.04 \\
-0.08 \\
-16
\end{array}\right]
$$

Divide the third row by the first element.

$$
\left[\begin{array}{rr}
200 & -0.5 \\
150 & -2 / 3 \\
100 / 3 & 0
\end{array}\right],\left[\begin{array}{l}
-0.04 \\
-0.08 \\
-0.48
\end{array}\right]
$$

Now substitute $I$ for column one.

$$
\left[\begin{array}{rr}
1 & -0.5 \\
1 & -2 / 3 \\
1 & 0
\end{array}\right],\left[\begin{array}{l}
-0.04 \\
-0.08 \\
-0.48
\end{array}\right]
$$

This is the same result as before in banded form. Therefore, the problem has been solved by the use of a simpler method and also it saved memory space. Fig. 3.1 shows a flow chart of such a program. 


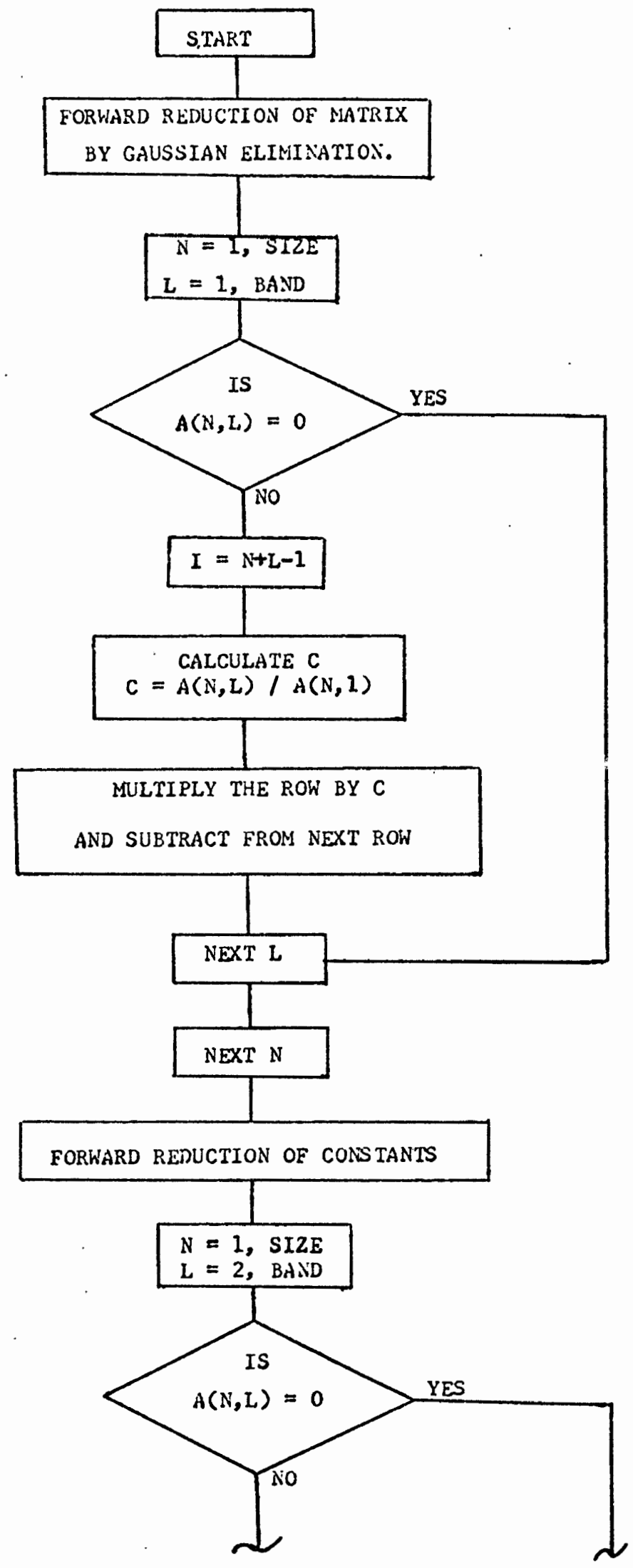

Figure B. Flow chart, subroutine "SOLVE". 


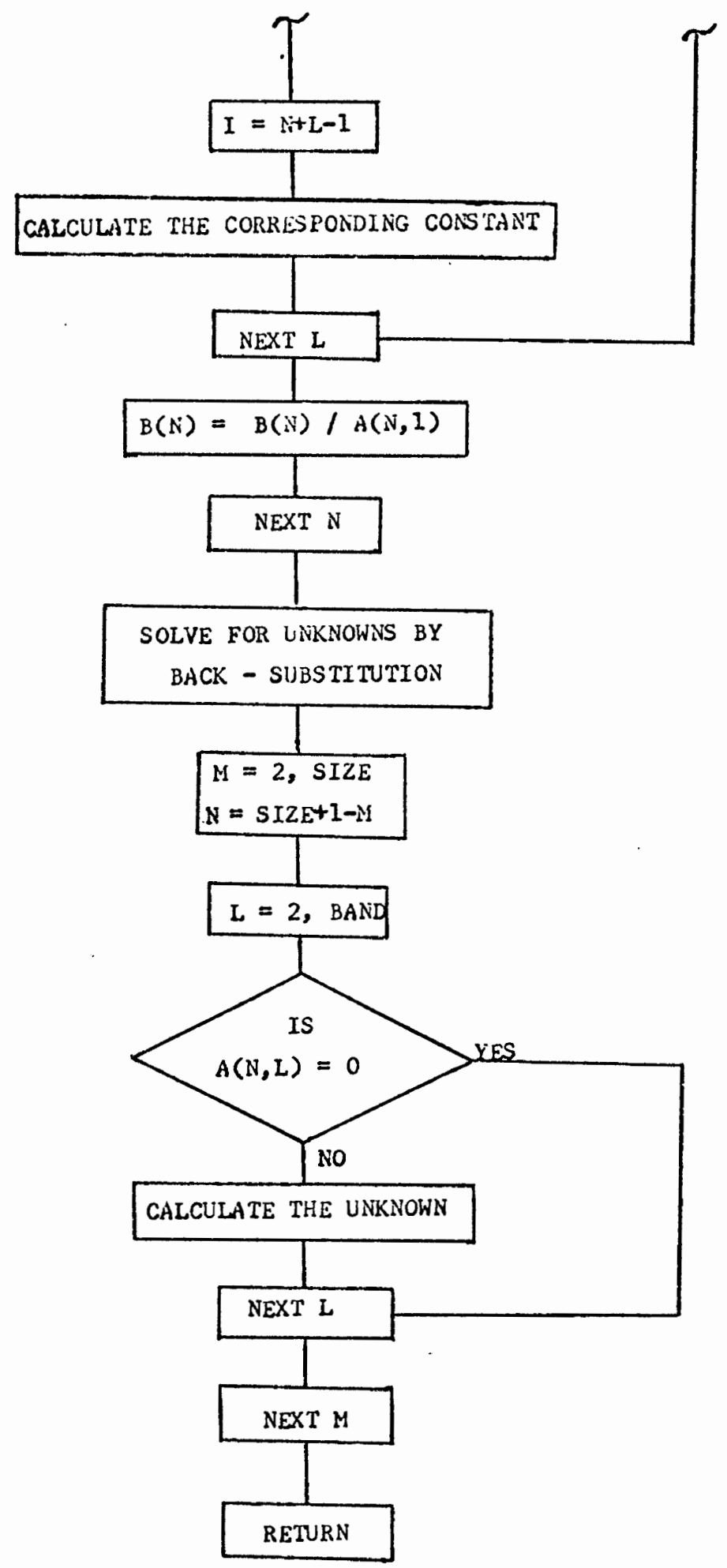

GALCULATE THE CORRESPONDING CONS'TANT 


\section{APPENDIX C}

\section{CALCULATION OF CURRENT DENSITY}

The equation for mutual impedance (6) between two infinitely long conductors, at heights $h_{1}$ and $h_{2}$ meters above the earth, and separated by a horizontal distance of $y_{1}$ meters, in the power series form is:

$$
\begin{aligned}
\mathrm{z}_{12}\left(\mathrm{~h}_{1}, 0, \mathrm{y}_{1}\right)= & \frac{j \omega \mu_{0}}{4 \pi}\left[\ln \left(\frac{4}{\mathrm{~h}_{1}^{\prime 2}+\mathrm{y}_{1}^{\prime 2}}\right)+1-2 \gamma\right]+\frac{\omega \mu_{0}}{8}- \\
& (1-j) \frac{\omega \mu_{0} h_{1}^{\prime}}{3 \sqrt{2 \pi}}-\frac{j \omega \mu_{0}\left(h_{1}^{\prime 2}-y_{1}^{\prime 2}\right)}{64}- \\
& \frac{\omega \mu_{0}\left(h_{1}^{\prime 2}-y_{1}^{\prime 2}\right)}{32 \pi}\left[\ln \left(\frac{h_{1}^{\prime 2}+y_{1}^{\prime 2}}{4}\right)+2 \gamma-5 / 2\right]
\end{aligned}
$$

Where $\gamma$ is Euler's number, 0.577216

$$
h_{1}^{\prime}=h_{1} \sqrt{ } \omega \mu_{0} \sigma_{1} \quad, \quad h_{2}^{\prime}=h_{2} \sqrt{ } \omega \mu_{0} \sigma_{1}, \quad y_{1}^{\prime}=y_{1} \sqrt{ } \omega \mu_{0} \sigma_{1}
$$

and current density equation is:

$$
J=z_{12}\left(h_{1}, 0, y_{1}\right) * \sigma * I_{s c}
$$

Based on equations $\mathrm{C}-1$ and $\mathrm{C}-2$, impedances and current densities on the surface of the earth for various values of $y$ and different values of $\rho$ are calculated and given in Tables C.1 to C.3.

The worst case is for $y=0$ and the current density for such value of $\mathrm{y}$ is 0.07 amp per square meter. 


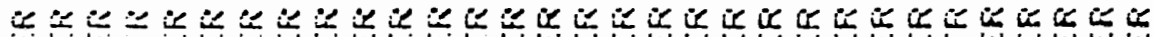

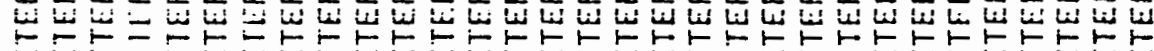

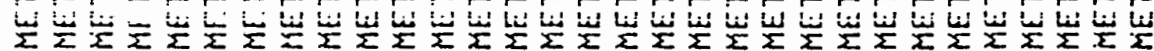

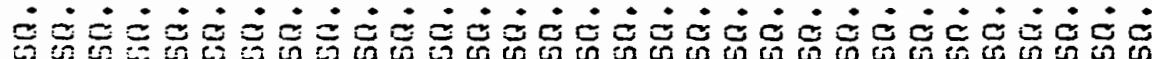

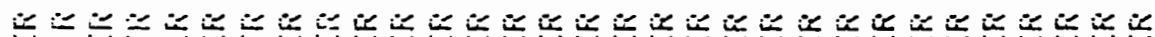

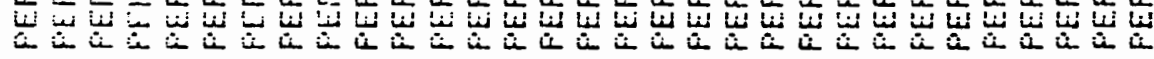

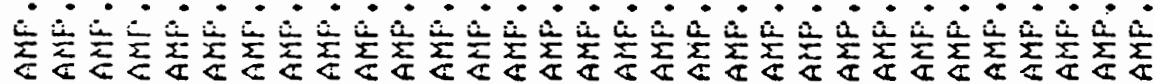

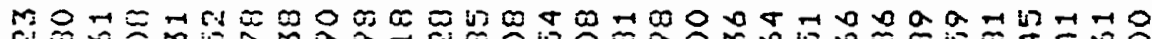
zयँ

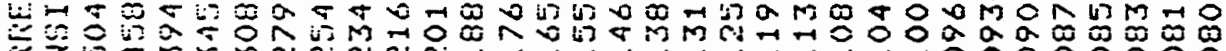

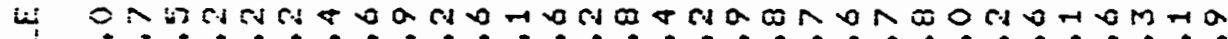

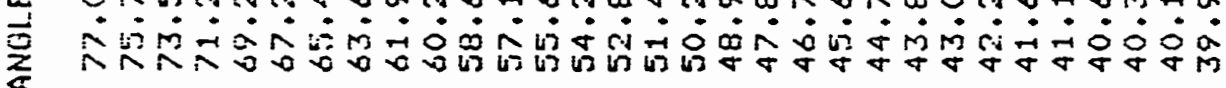

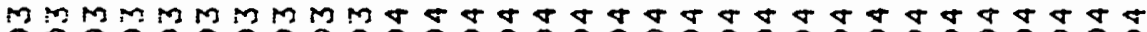

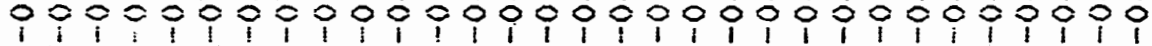

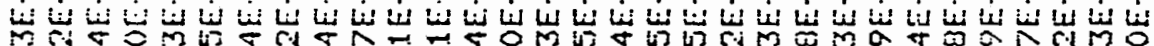
\%

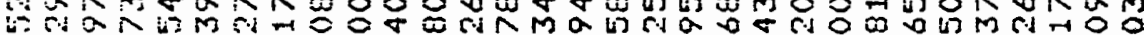

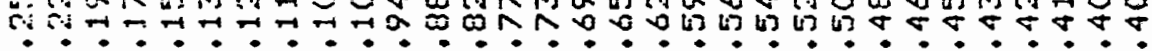

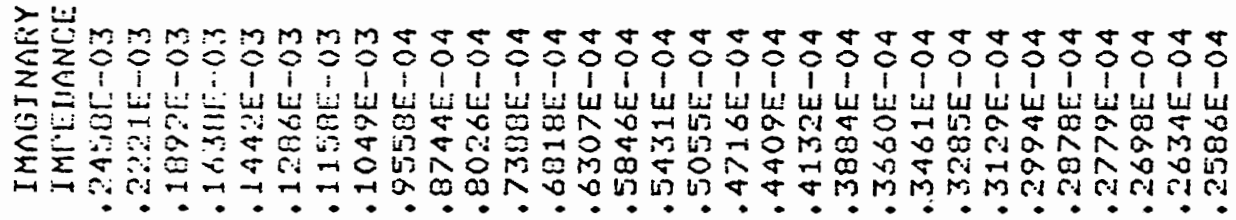

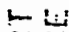

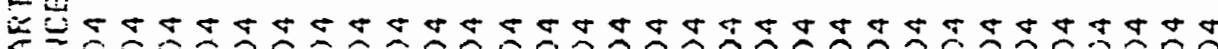

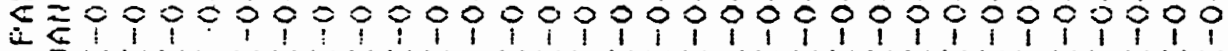

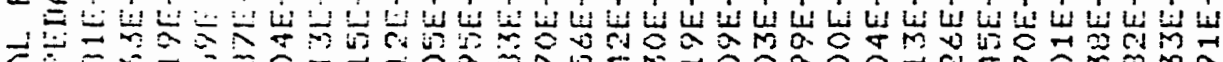

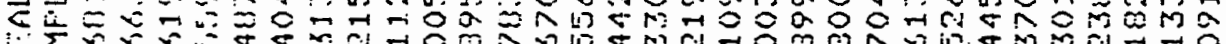

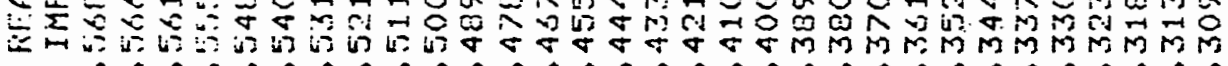

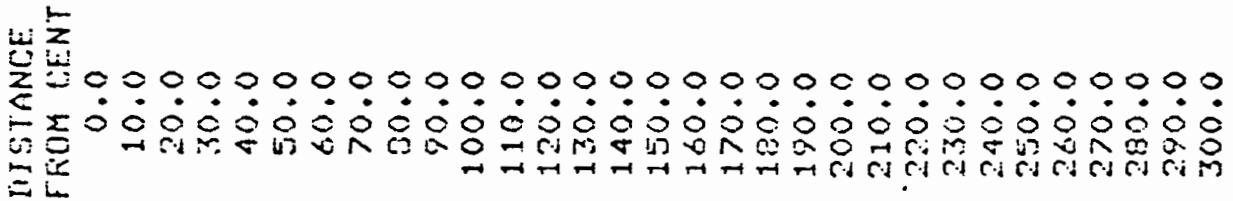




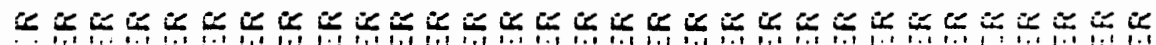

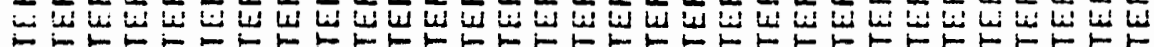

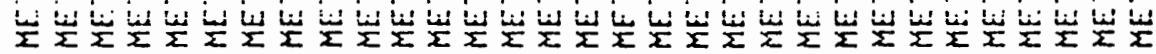

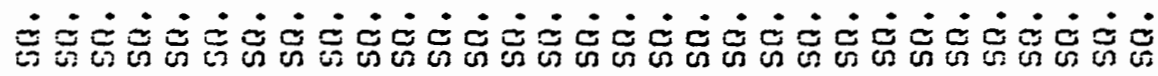

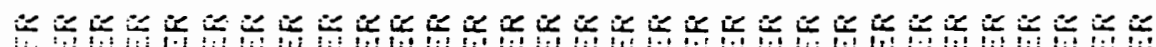

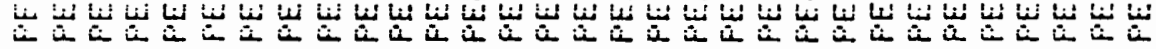

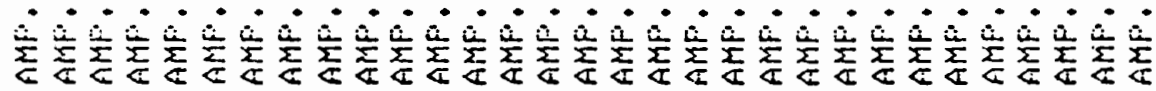

$->$ -

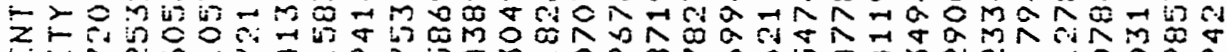

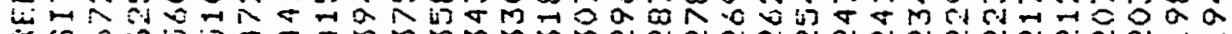

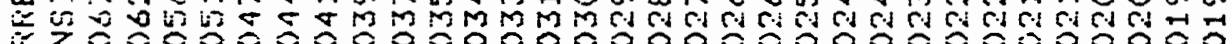

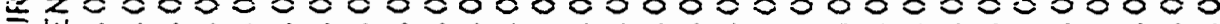
ت

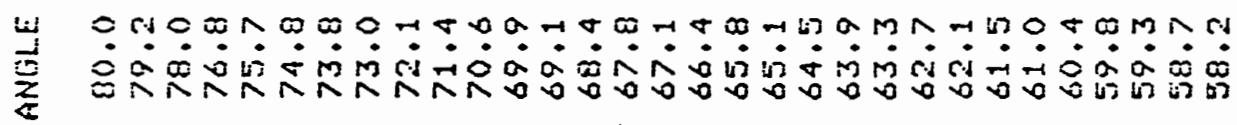

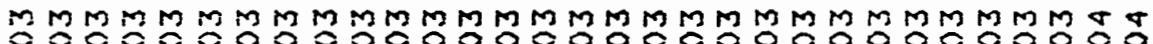
운

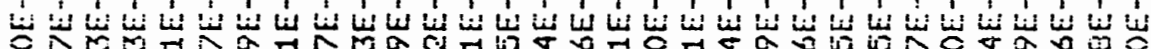
ज人

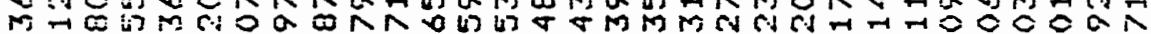
m

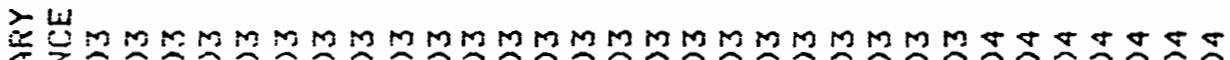

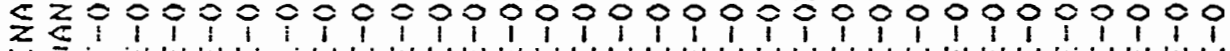

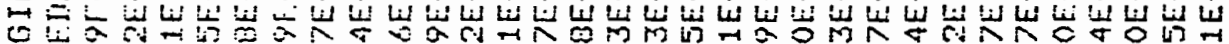

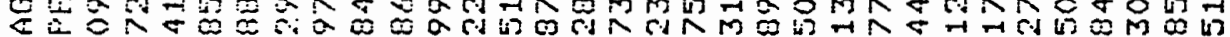

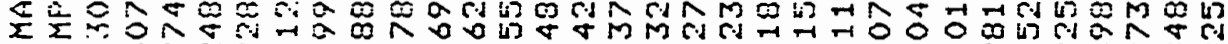

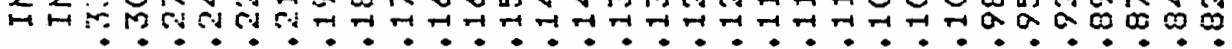

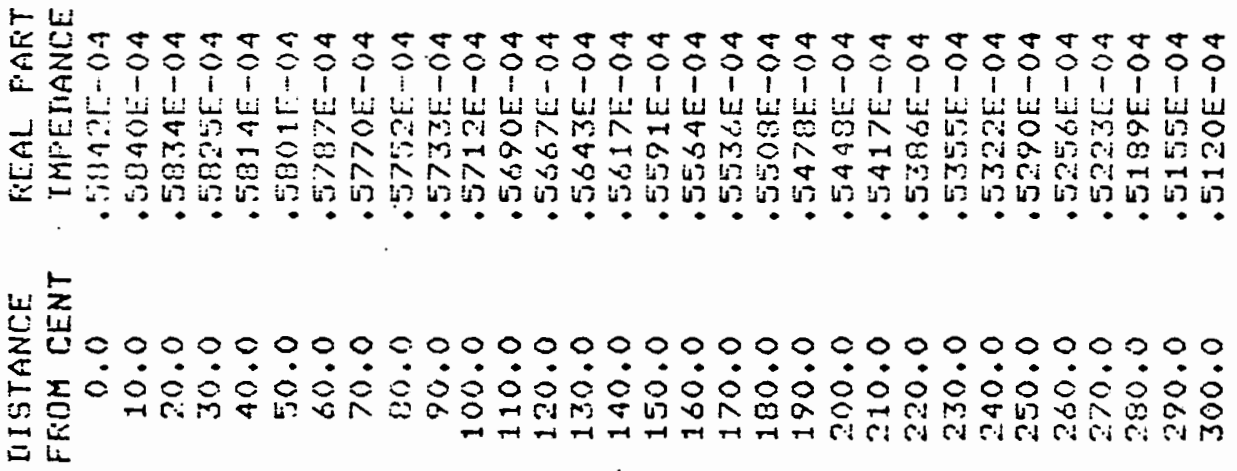


世е

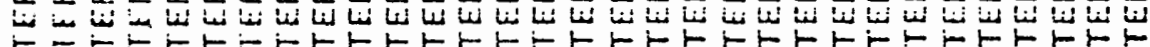

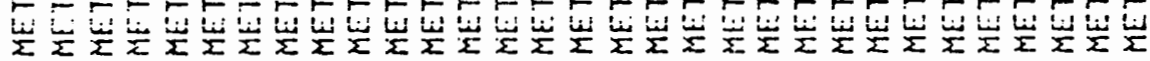

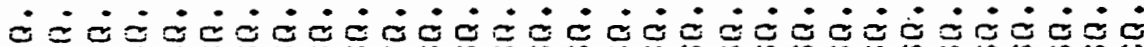

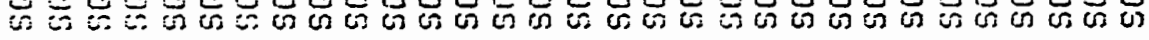

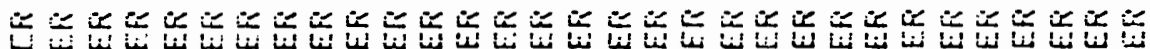

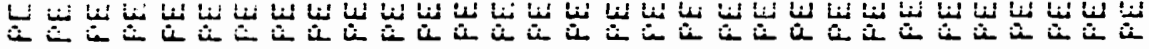

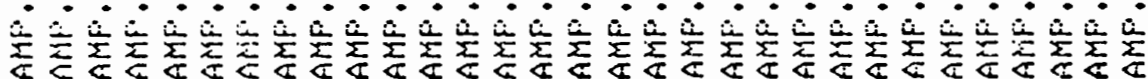

$0 \approx M \approx \alpha$ a = 2 .

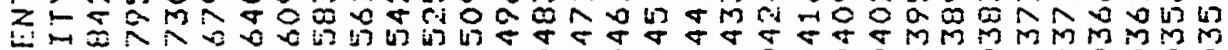

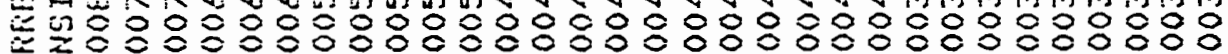
ن

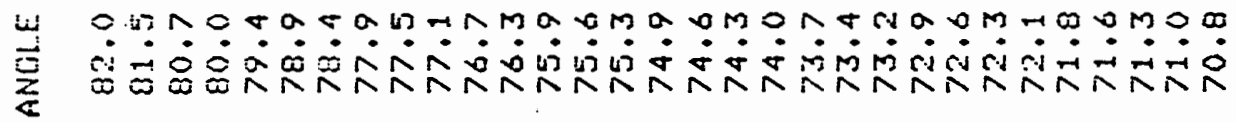

MMMMMMMMMMMMMMMMMMMMMMMMMMMMMM

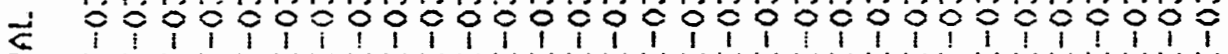

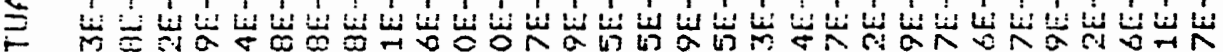
इ तล

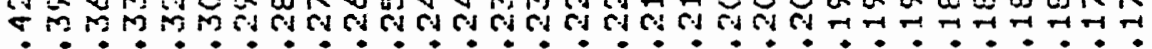

TUWMMMMMMMMMMMMMMMMMMMMMMMmMMMM $\sum \sum_{i}$ 正 1 i 心

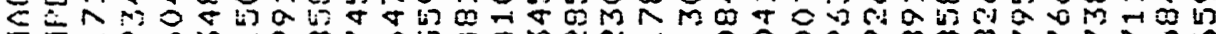

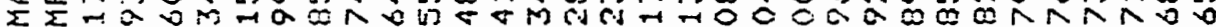

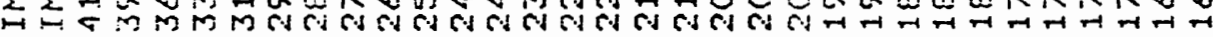

$\vdash \dot{H}$

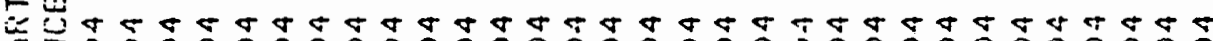

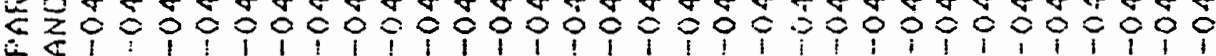
- $=\frac{1}{2}$

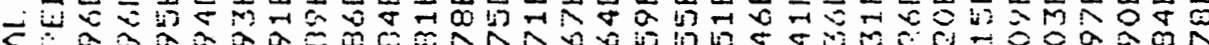

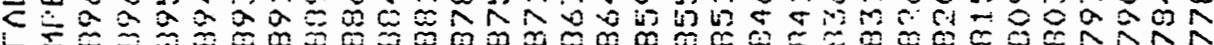

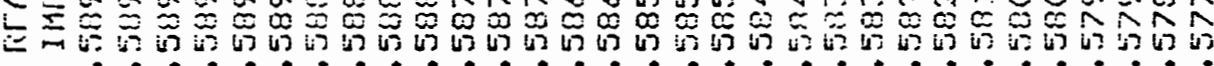

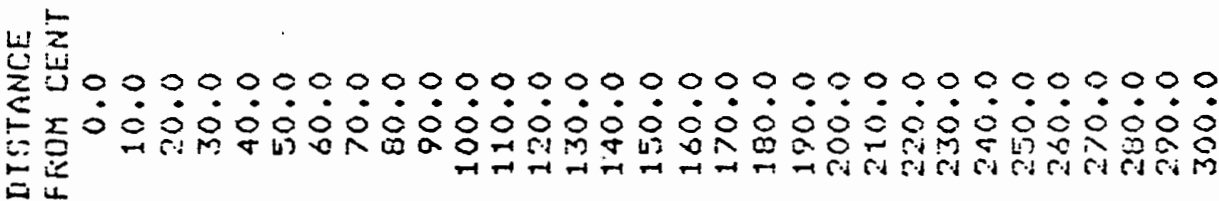


APPENDIX D

LISTING OF PROGRAMS AND SUBROUTINES

\author{
Listing of Programs: \\ MAIN \\ GOOD \\ TES \\ SEARCH
}

and Subroutines:

BAND

PROPT

FIND

SOLVE 
COMMON A(401,20),N(3,760),XN(3,760), YN $(3,760)$, MAT $(760)$, IEL $(760)$ COMMOPS $B(401), V(403)$

IPTEGEF M, NOIE, LNOLE, IEL, IELEE

c

COMFLEX A, B, FFOF, F1, F2,F3,U,ECV

$F^{\prime} 1=(1.8182 E-04,3.542 E-11)$

$F \cdot=(30.0 E-00 \cdot 0.00 E+01)$

$F \cdot 3=(3.0 E-03,7.4374 E-10)$

c

$\mathrm{C}$

IEW - BAPII-WIUTH OF THE COEFFICIENT MATFIX

MOLIF - NUMEER OF NOTES

LNOCIE- NUMEEF OF LAST NOME EEFORE THE NOLE WITH EOUNUFAY CONI.

IEL - NAME OF MATRIX WHICH STOFES ELEMENTS NUMEER

IELE - NUMREF OF ELEMENTS

FEAII (15, 1 ) NOJE - IELE, LNOIE, BCV

FOFMAT $(13,1 X, 13,1 X, 13,2(1 X, F 7,3))$

WFITE $(66,69) \mathrm{F} 1$

WFITE $(66,69) F 2$

WFITE $(36,69) F 3$

69

FDFMAT $(2(1 X, E 14,6))$

$\mathrm{C}$

$I E W=0$

IU $20 \quad I=1$, TELE

FEA II $(15,2) I E L(I), N(1, I), N(2, I), N(3, I), X N(1, I), Y N(1, I), X N(2, I), Y N(2$

c

$C, I), X N(3, I), Y N(3, I), \operatorname{MAT}(I)$

C

2

C

20

C

FORMAT $(I 3,3(1 X, I 3), 6(1 X, F 8,3), 1 X, I 1)$

CONT INUE

nO $22 I=1$, IELE

c

C

THIS SUBROUTTNE FINISS THE BAND-WIITH OF THE MATRIX

C

CALL BANIIN, I, LNOEE, IEW)

i.

[10 $50 \quad I=1, L$. NOLIE

no $60 \quad J=1$, IBL

f, $\quad h(I, J)=(0.0,0.0)$

riU $199 K K=1$. LNORE

$199 \quad U(N)=(0,0,0.0)$

(U) (LIONF+1 $)=(0.0,0.0)$

$U(L N O L E+2)=E C U$

c

OO $190 k=1$, IELE

C

SURROUTINE FROFT FINUS THE FROFEFT OF MATERIALS ANI AREA UF IHE C ELEMENT. 
FROGRAM MAIN (COONT.)

CALL FHOFT(MAT, KH, FFOF, F3,F1, F2, S, XN, YN)

C

c

c

c

c

$c$

190 CONTTNUE

c.

c

$\mathrm{c}$

$\mathrm{C}$

c

$\mathrm{C}$

i

c.

1000 CONTINIJE

STOF:

ENII
THIS SUBROUTINE CALCULATES THE VOLTAGES AT EACH NONES.

CALL. SOLUE (LNONE , IEU, A, B)

CALLL. FEESULT (BCU,B) 
IITENSION $X(401), Y(401), X X(17), Y Y(17)$ REATI (15, 2)L, M,NX,NY

2 FOFITAT (AIB)

no $10 \quad I=1, N X$

LO FEAT $(15,1) X X(I)$

I.O 20 (I.: $=1, N Y$

$20 \quad R E A O H(15,1) Y Y(I)$

1 FORMAT $(F B, 3)$

$J=0$

$\operatorname{Lin}=1$.

$0030 \quad I=L, M$

$J=\sqrt{2}+1$

$X(I)=X X(1)$

$Y(I)=Y Y(L I)$

$I I=I-L+1$

$I F(T 1, L T, N X)$ SO TO 30

$F=I 1 / F \operatorname{LOAT}(N X)$

$L 1=\operatorname{IFIX}(F)$

$F=F-1$

IF $(F, F Q, 0.0) \quad 90$ TO 35

(30 ro 36

$35 \quad J=0$

$36 \quad$ L. $1=1.1+1$

30 CONTTNUE

Do $50 \quad I=\mathrm{L} ., \mathrm{M}$

50) WRTtE $(16,3) \mathrm{I}, X(I), Y(I)$

3 FORAAT $(3 X, 13,2(2 X, F B .3))$ 
IIMENSION NM(3,760), XN $(3,760), Y N(3,760), \operatorname{MAT}(760), \operatorname{IEL}(760), X(401)$ DIMEUSION $Y(401)$

$5 I:=1,401$

$5 \quad \operatorname{REAII}(13,1) K K, X(I), Y(I)$

1 FOSHAT $(3 X, 13,2(2 X, F 8,3))$

III? $10 \quad I=17,744$

FEA II $(14,2) I E L(I), N(1, I), N(2, I), N(3, I), \operatorname{MAT}(I)$

2 FOFMAR I I , 3(1X,IZ), 1X,I1)

$L=U(1, I)$

$J:=R:(2, I)$

$K=r(3, I)$

$X Y(1, I)=X(L)$

$Y\}(1, I)=Y(L)$

$X+1 ; 2, I)=X(J)$

$Y:\{(2, I)=Y(J)$

$X(i)(Z, I)=X(K)$

$Y+(3, I)=Y(K)$

10 CONTIRUE

110 $20 \quad I=1,16$

$20 \quad K E \dot{R}[(16,3) \operatorname{IEL}(I), H(1, I), N(2, I), N(3, I), X N(1, I), Y N(1, I), X N(2, I), Y N(2$ $C, I), X Y(3, I), Y N(3, I), M A T(I)$

3 FOAMAT $(I 3,3(1 X, I 3), B(1 X, F B, 3), 1 X, I 1)$ I10 $40 \quad I=745,760$

$40 \quad F C A D(16,3) I E L(I), N(1, I), N(2, I), N(3, I), X N(1, I), Y N(1, I), X N(2, I), Y N(2$ $C, I), X Y(3, I), Y N(3, I), \operatorname{MAT}(I)$ IID $100 \quad I=1,760$

100 LFITE $(17,4) \operatorname{IEL}(I), N(1, I), N(2, I), N(3, I), X N(1, I), Y N(1, I), X N(2, I), Y N($ $C 2, I), X N(3, I), Y N(3, I), M A T(I)$

END 
FIE $=3,1415926$

W $=377.0$

$X M U=4$ *F TE* $(10 E-8)$

ZEEMA $=0,1$

GAMA $=0.577216$

$H 1=10.68$

HWHLWSQFT (WWXMU*ZEGMA)

WRTT TE $(15, \mathrm{~L})$

WFITE $(15,2)$

1. FOFMAT (2X, "IISTANCE" 4X, "REAL FAFT", EX, "IMATINAFY", EX, " MUTUAL. " C, EX, "ANGLE", $3 X$, "CUREENT")

2 FOFRAT ( $2 X$, "FFOM CENT", 3X, "IMFELANCE", 5X, "IMFELANCE", 26X, "IIENSITY")

$11099 \quad N=0,30$

$Y 1=\Gamma \times 10.0$

$Y=Y 1 * S Q R T$ (WWXMU*ZEGMA)

$A=H+N_{2} 2+Y * * 2$

$[B=H *+\cdots 2-Y * * 2$

C.:- $A L O(B(A / A)$

VI: $=A \operatorname{LOG}(A / A)$

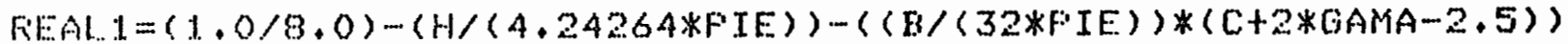

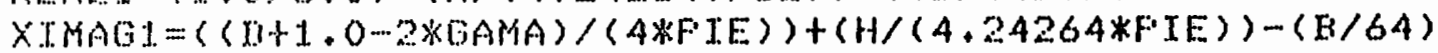

FEAL... =W*XMUKFEAL 1

XIMAG=WWXIUWXIMAGI

$Z=6 O F T$ (FEAL**2+XTYAG**2)

FHT =:-ATAN (XTMAG/FEAL..)

FHI $=F H T$ F $(100,0 / F$ IE $)$

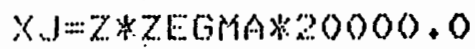

WRTTE $(1 S, 3) Y \perp$, REAL, XTMAG, Z, FHI, XJ

3 FOFMAT $2 X, F 6,1,5 X, E 9,4,5 X, E 9,4,5 X, E=9,4,5 X, F 5,1,3 X, F 8,6,2 X$, C"AMF" + FEF SQ, METEF")

CONTINUE

STOF

ENA 
SUBFOUTTNE BANII $N, I, L N O M E$, ISW

IITENSTON $N(3,760)$

$I F(N(1, T) \cdot G T \cdot L N O C E)$ GO ro 60

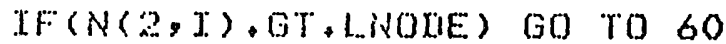

$I F(\lambda(3, T), O T \cdot L N O D E)$ GO TO 60

IXI $=A B S(N(1, I) \cdots N(2, I))$

$I X 2=\cdots \operatorname{ABS}(N(2, x) \cdots N(3, x))$

$[B]=\cdots \operatorname{Rs}(N(1, I) \cdots N(3, I))$

$T F(T B L+L T+T B 2) \quad 00$ TO 40

IF (IXI.L.T.IBB) (GO TO 45

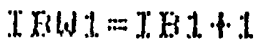

40 IF $(T E 2+1 . T+I B 3) 60$ TO 45

Q0 9050

IXU $1:=\operatorname{Lx} 2+1$

(50 ro 50

$45 \quad T$ TSW $1:=\operatorname{TS} 3+1$

$50 \quad T F(T K W \cdot L . T . I B W 1) \quad 60$ T0 55 00 ro 60

53 T. THW:TSWL

J. HW $1:=0$

so RETURN

END 


\section{SURFOUTINE FFOFT}

SURFOUTINE FFOFT (MAT, K゙, FROF, F3,F1, F2, S, XN, YN)

IITMENSION MAT $(760)$, XN $(3,760), Y N(3,760)$

COMFLEX FFOF, FI. "F.2, FB

IF (MAT (KE) +EQ + 1) GO TO 10

IF (MAT $(K)+E R+2)$ G0 TO 20

$P F O F=: F$

$00 \mathrm{TO} 30$

1. $0 \quad F F F=F 1$.

$60 \mathrm{TO} \quad 30$

FPOF=:F?

20
30

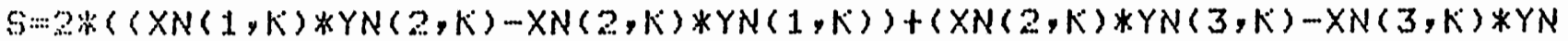

$(2(2, k))+(X N(3, K) * Y N(1, K)-X N(1, K) * Y N(3, K)))$

FEETUFN

ENDI 
SURFOUTINE FINII(N,K,LNOHE, YN,XN,G, FFOF, $\mathrm{H}, U, A)$

DITMENSION $A(401,20), V(40.3), E(401), N(3,760), X N(3,760), Y N(3,760)$

COMF'LEX F'FOF, A,E,X,U

no $89 \quad K=1,3$

[10 $90 \quad I=1,3$

IF (M.EQ.I) 90 TO 80

$\operatorname{IF}((M(M, K)-N(I, K)), G T .0)$ GO TO 90

IF $(M . E Q .1)$ QO TO 68

IF (M.EQ.2) 50 TO 85

IF (I, EQ.1) GO TO 82

00 T 03

68 IF (I.E. T. 2) GO TO 81

GO $\mathrm{ro} 82$

85 IF (I.EQ.1) G0 TO 81

GO TO 83

81 IF (N (K,K) . LE.LNONE) GO TO 181

GO TO 90

$181 \operatorname{IF}(N(I, K), L E, L N O I E)$ GO TO 281

$X=(((Y N(2, K)-Y N(3, K)) *(Y N(3, K)-Y N(1, K))+(X N(2, K)-X N(3, K)) *(X N(3, K)$

$C-X N(1, K i))>(S) * F \cdot R O F$

$M M=N(I, K)$

$A l l=N(M, K)$

$B(N N)=-X * U(M M)+E(N N)$

82 IF (MH (M,K).LE.LNOLE) GO TO 182

GO TO 90

182 IF $(N(I, K)$. LE. LHOIIE) GD TO 282

$X=(((Y N(2, K)-Y N(3, K)) *(Y N(1, K)-Y N(2, K))+(X N(2, K)-X N(3, K)) *(X N(1, K)$

$(-X N(2, K))) / S) * F R O F$

$M M=N(I, K)$

$N N=N(M, K)$

$B(N N)=-X * V(M M)+B(N N)$

GO TO 90

83 IF (N(M,K).LE.LNOIE) GO TO 183 GO TO 90

183 IF $(N(I, K) \cdot L E+L N O I E)$ GO TO 283

$X=(((Y N(3, K)-Y N(1, K)) *(Y N(1, K)-Y N(2, K))+(X N(3, K)-X N(1, K)) *(X N(1, K)$

$C-X N(2, K))>/ S) * F F O F$

$M M=N(I, K)$

$N N=N(M, K)$

$B(N N)=-X * V(M M)+B(N N)$

(B) TO 90

$231 \quad M M=N(I, K)-N(M, K)+1$

$N N=N(M, K)$

$A(N N, K M)=(((Y N(2, K)-Y N(3, K)) *(Y N(3, K)-Y N(1, K))+(X N(2, K)-X N(3, K)) *($

$C X N(3, K)-X N(1, K))) / S) * F F D P+A(N N, M M)$

GO TO 90

$282 \quad M M=N(I, K)-\lambda(M, K)+1$

$N N=N\left(M_{i} \cdot K\right)$

$A(N N, M H)=(((Y N(2, K)-Y N(3, K)) *(Y N(1, K)-Y N(2, K))+(X N(2, K)-X N(3, K)) *($

$C X N(1, K)-X N(2, K))) / S) * P F(O F+A(N N, M M)$ 


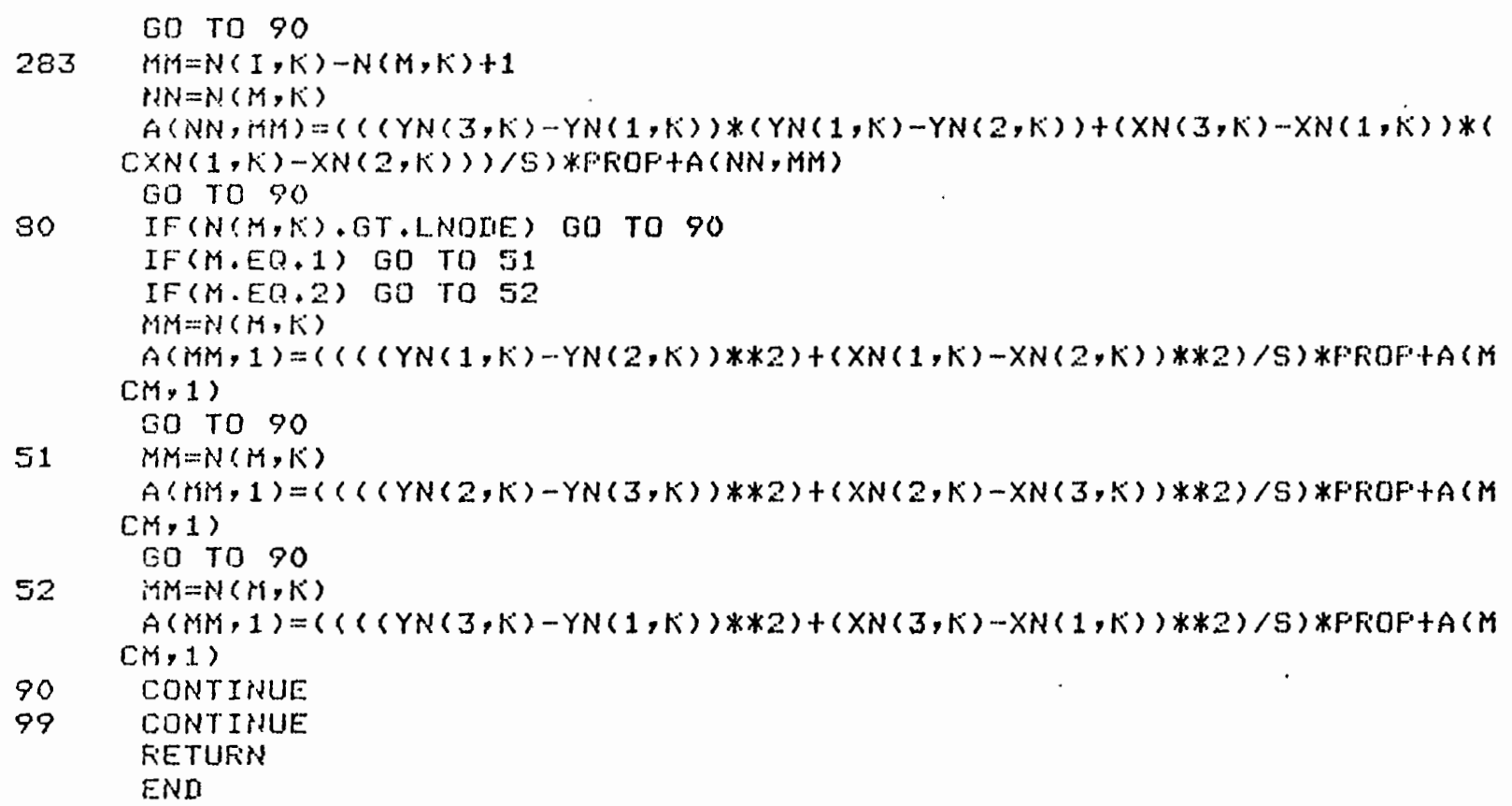


SUEROUTINE SOLUE (NSIZE, MEANH, A, B)

DTMENSTON A(AO1, 20), B(401)

COMFLEX $A, B, C$

C

FORWARIU FERUCTTON OF MATEIX(GAUSS ELIMINATION)

IIO $1.00 \mathrm{~N}=1$, NSTZE

IIO $200 \quad L=2$ Y MBANO

$\operatorname{IF}(A(N, 1), E Q,(0.0,0.0))$ GO TO 200

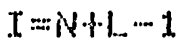

$C=A(N, L) / A(N, 1)$

$J=0$

XIO $30 k=L$, MBAND

$J=j+1$

$30 \quad A(I, J)=A(I, J)-C * A(N, K)$

$A(N, L)=C$

200 CONTTNUE

100 CONTINUE

C FOFWAFI FERUCTION OF CONSTANTS

NO $10 \mathrm{~N}=1$, NSIZE

WO $20 \quad L=2$, TKBAND

$\operatorname{IF}(A(N, L)+E Q+(0,0,0.0))$ GO TO 20

$I=N+L-1$

$B(I)=B(I)-A(N, L) * E(N)$

20 CONTINUE

$10 \quad B(N)=B(N) / A(N, 1)$

C SOLUE FOF UNKOWNS EY BACK-SUESTITUTION

nO $40 \quad M=2, N S I Z E$

N=NST T.E+1 $\cdots$ N

$1050 \mathrm{~L}=2$, MBAND

$\operatorname{IF}(A(N, L), E Q,(0,0,0,0))$ GO TO 50

$K=N+1 .+-1$

$B(N)=B(N)-A(N, L) * B(K)$

50 CONTTNUE

4O CONTTNUE

RETURN

ENII 
APPENDIX E

COMPUTER RESULTS 


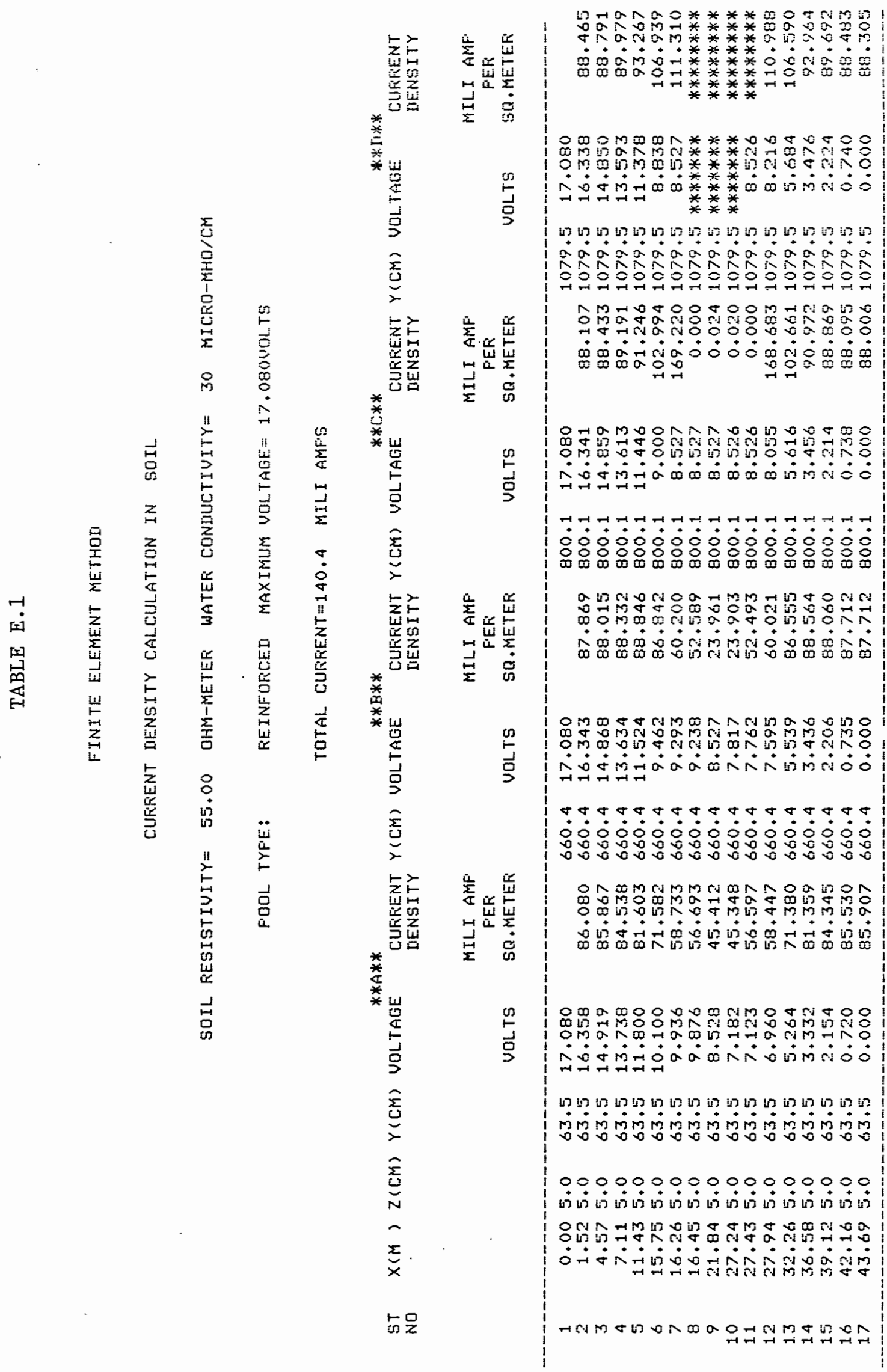




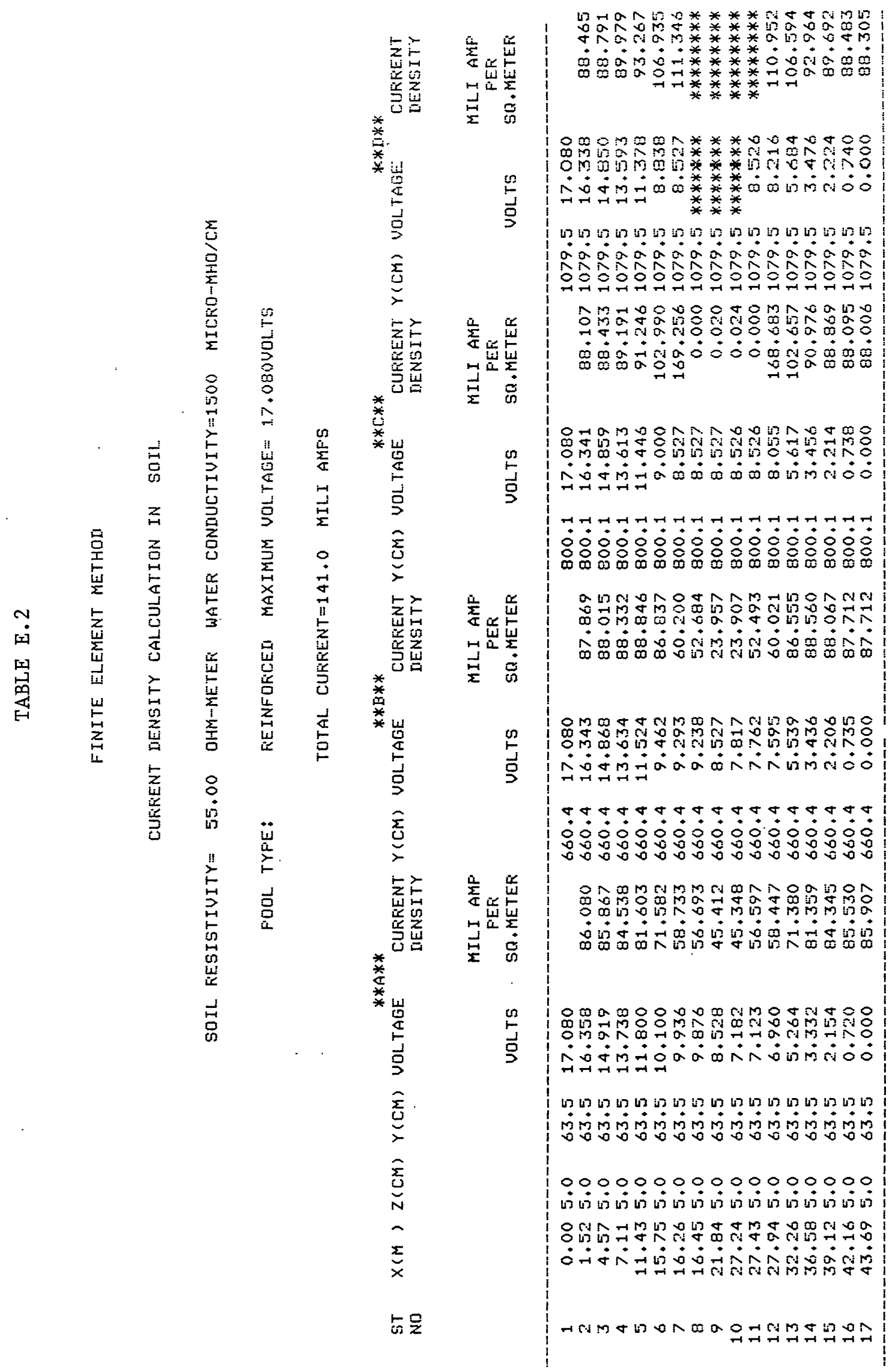




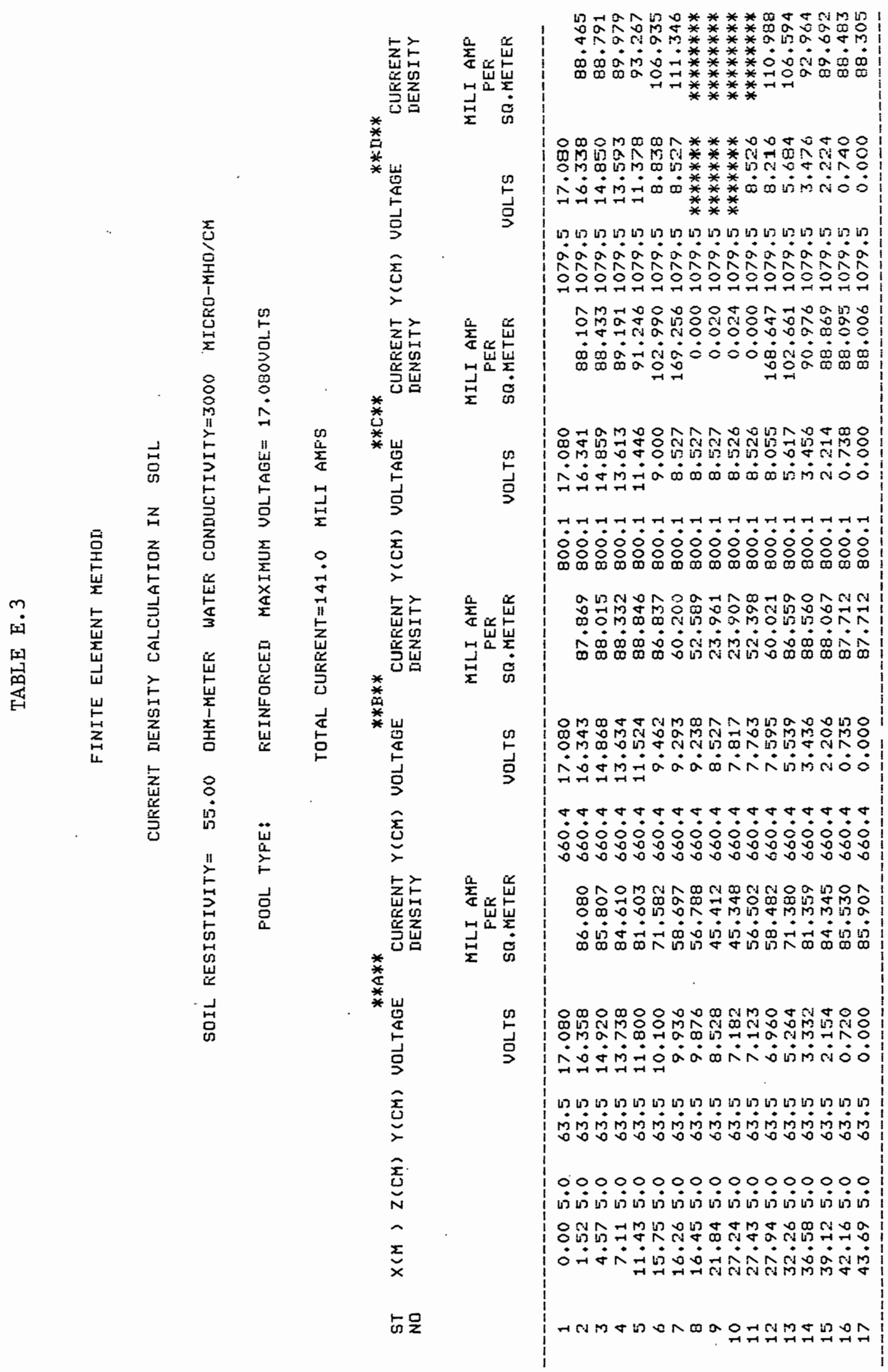




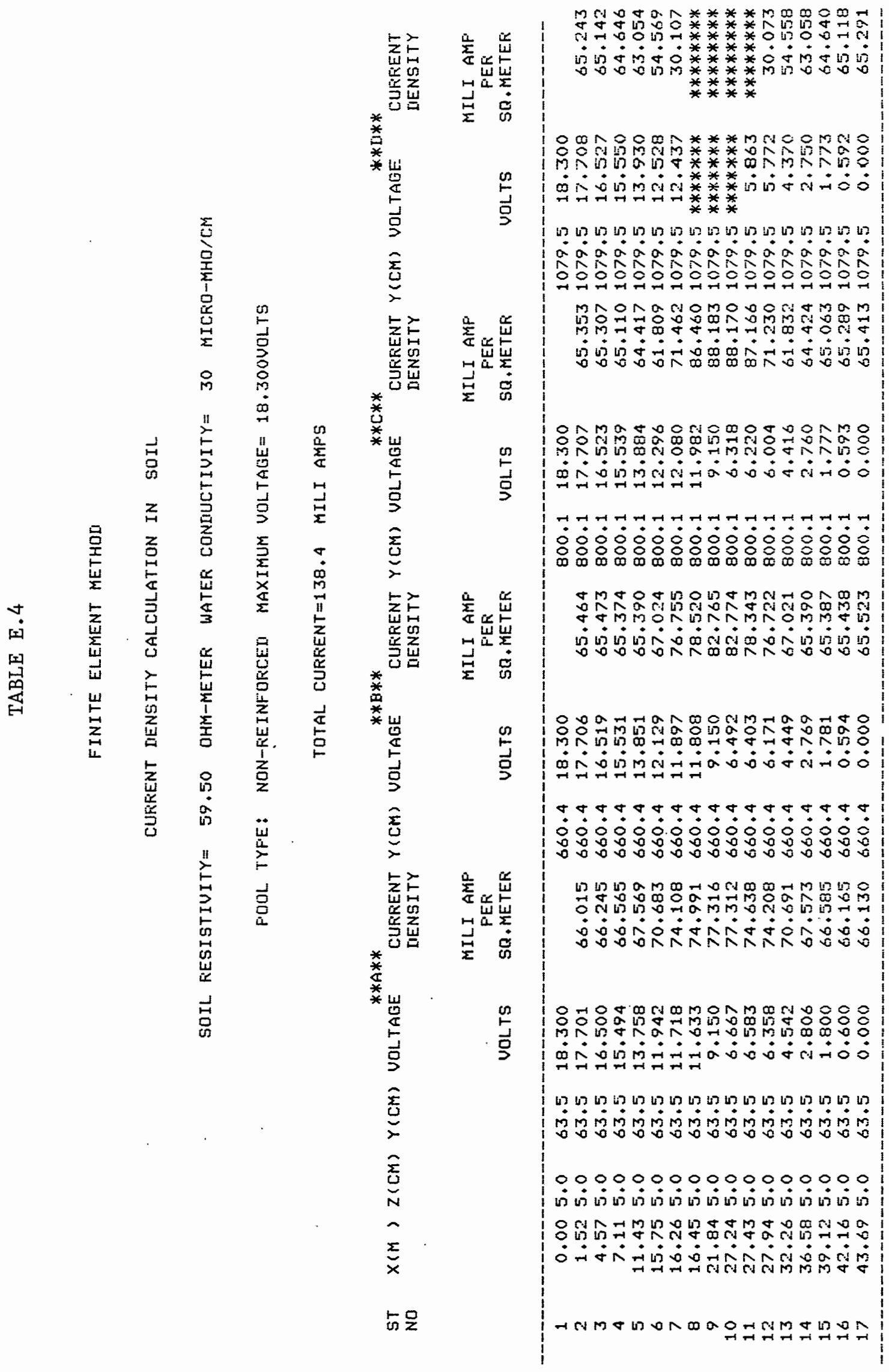




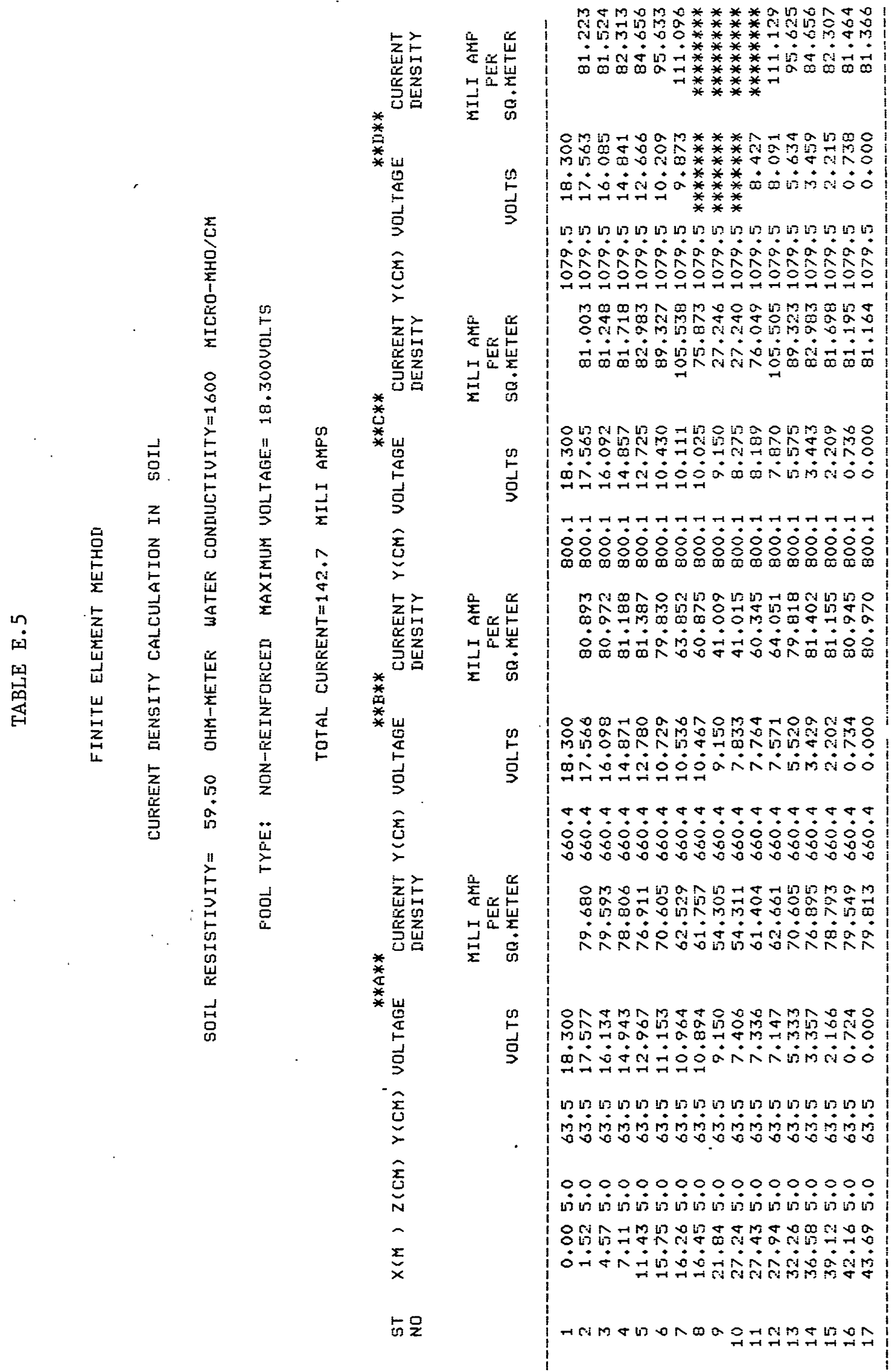




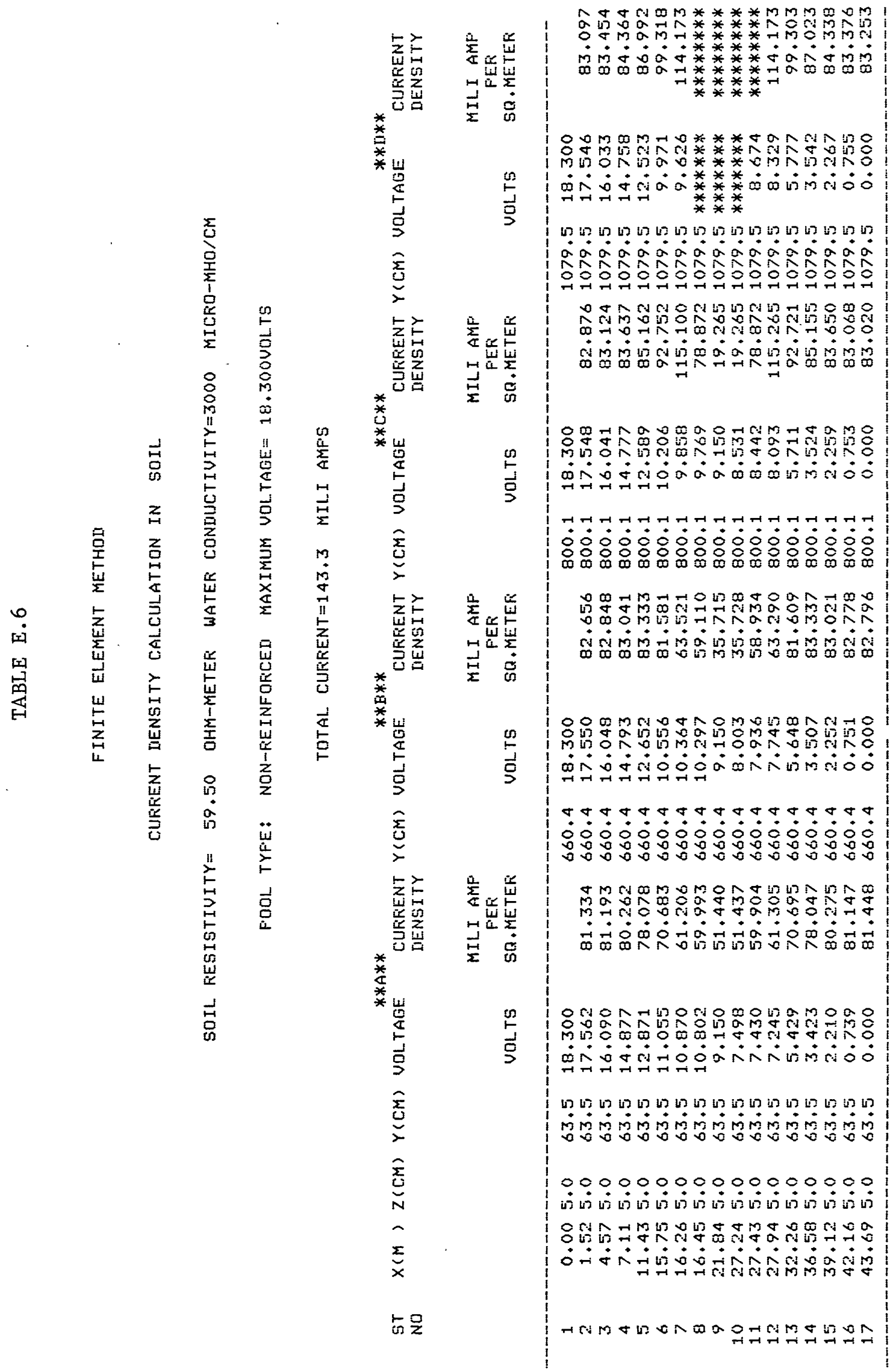




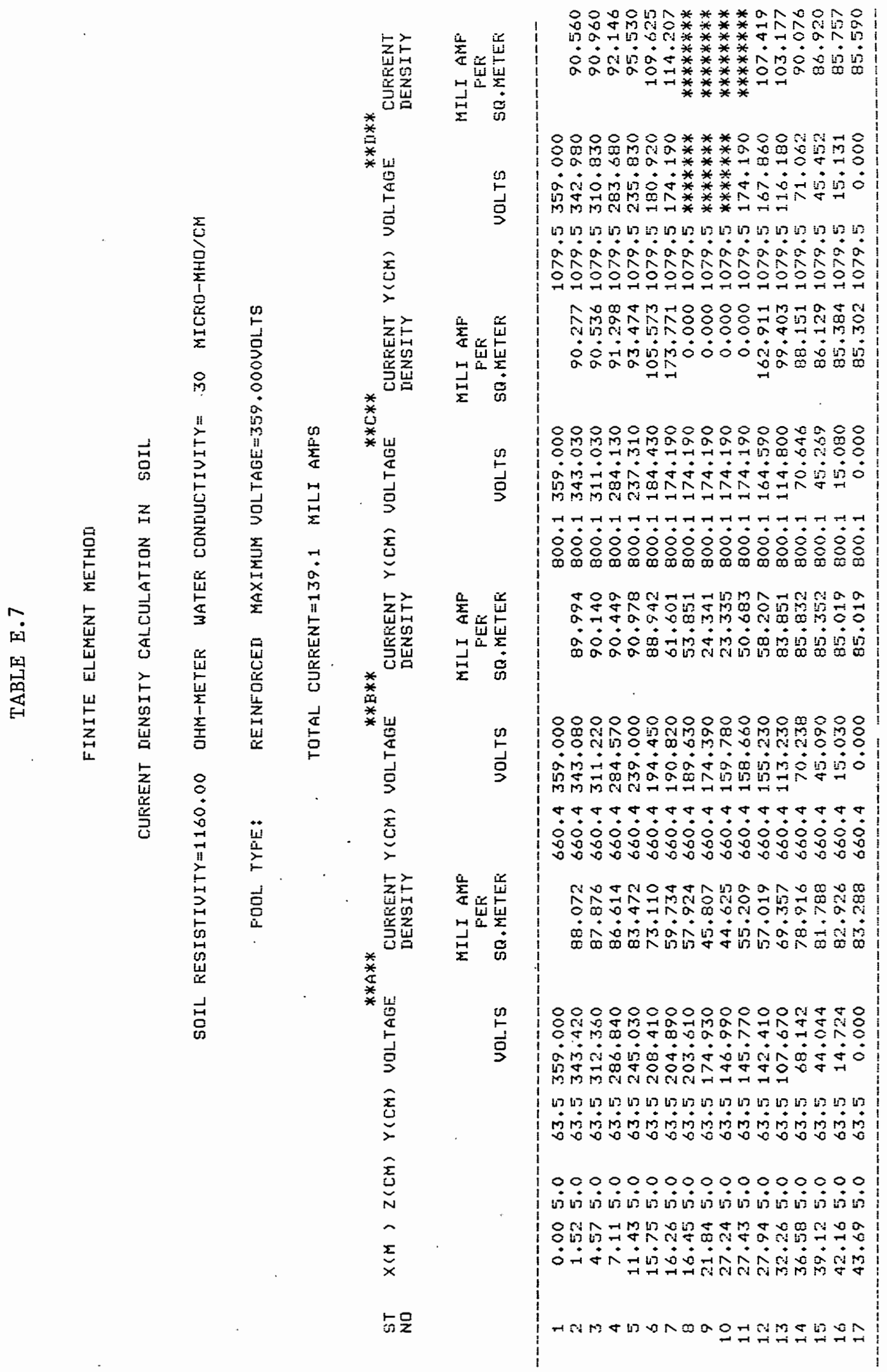




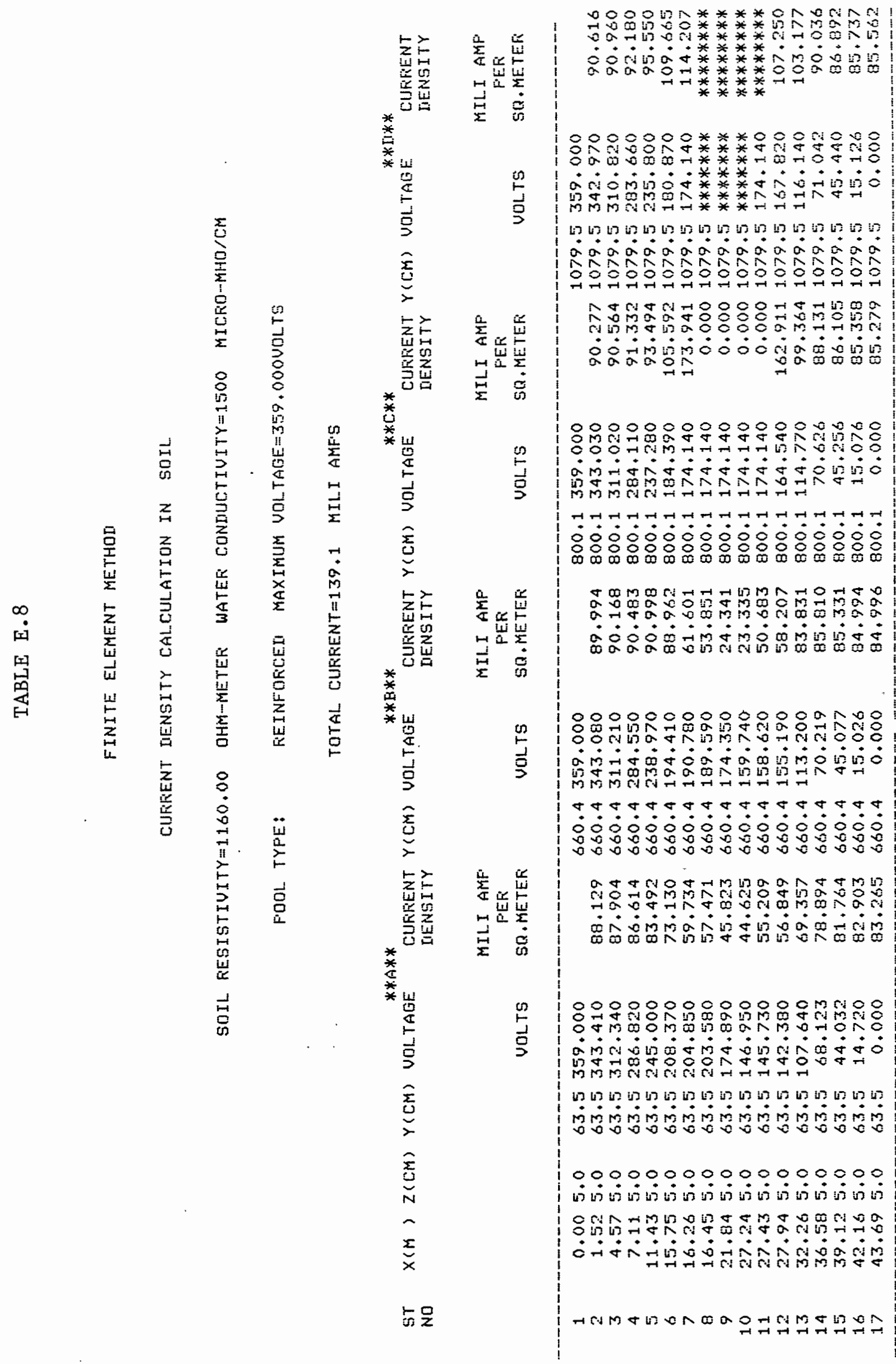




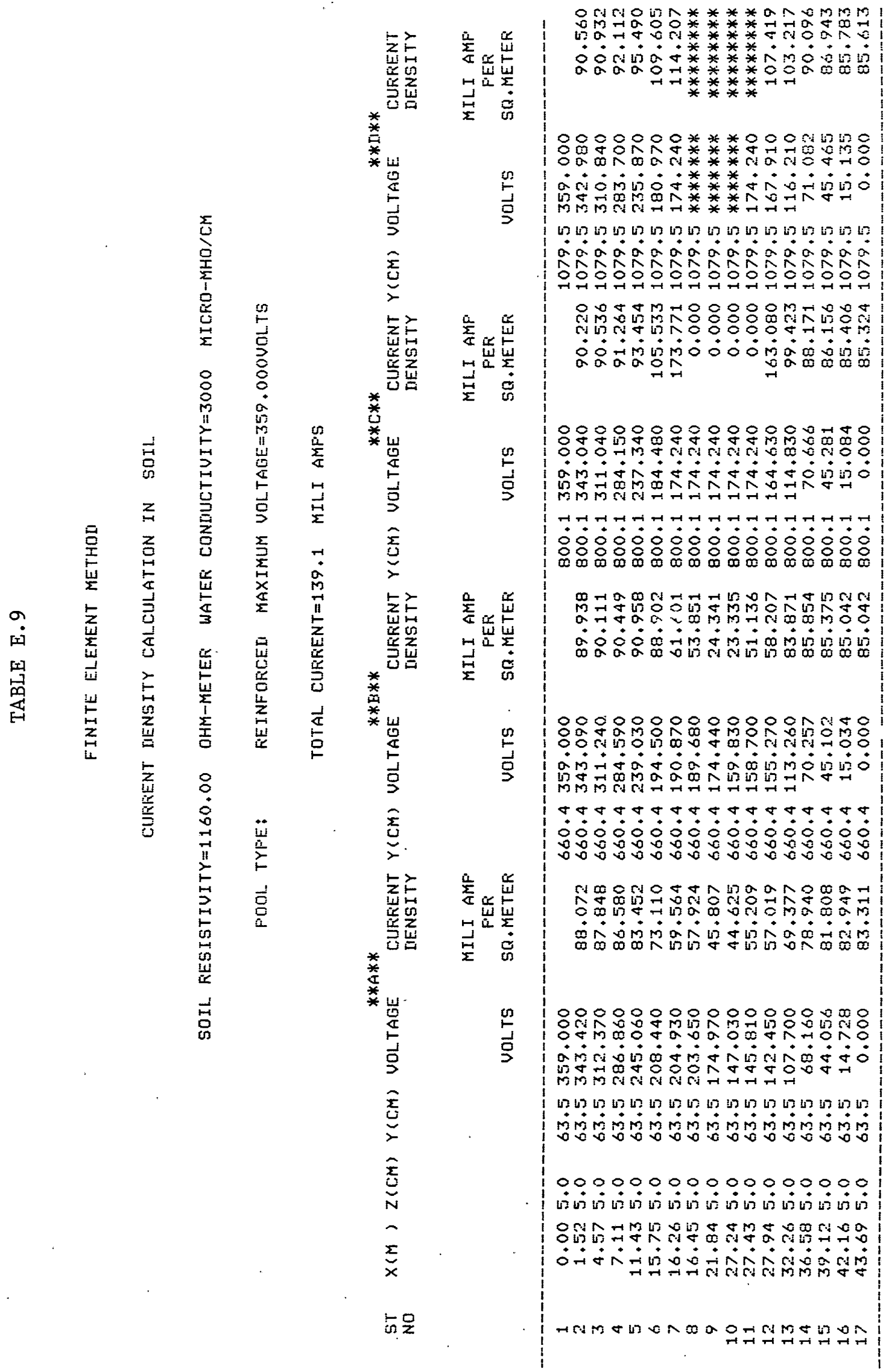




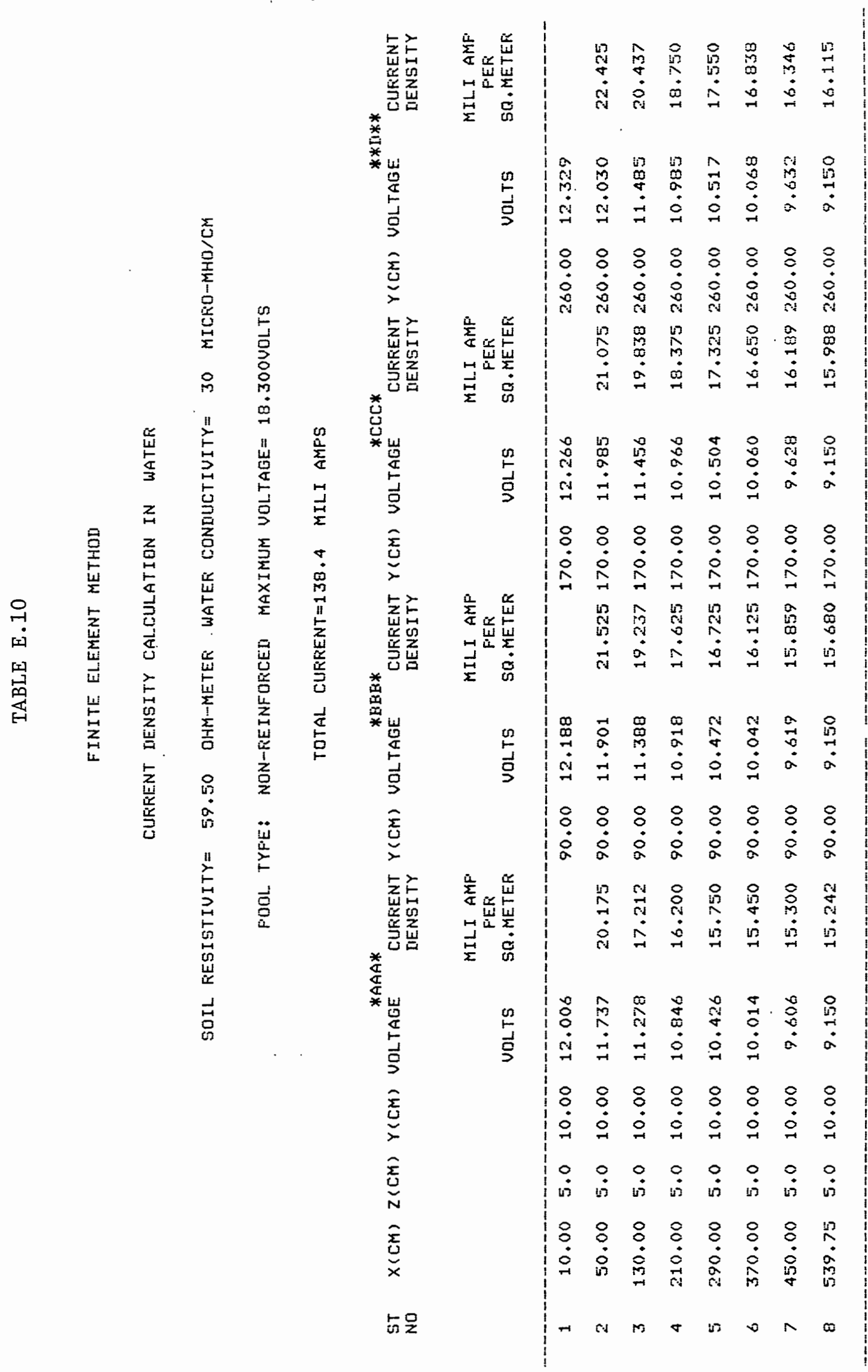




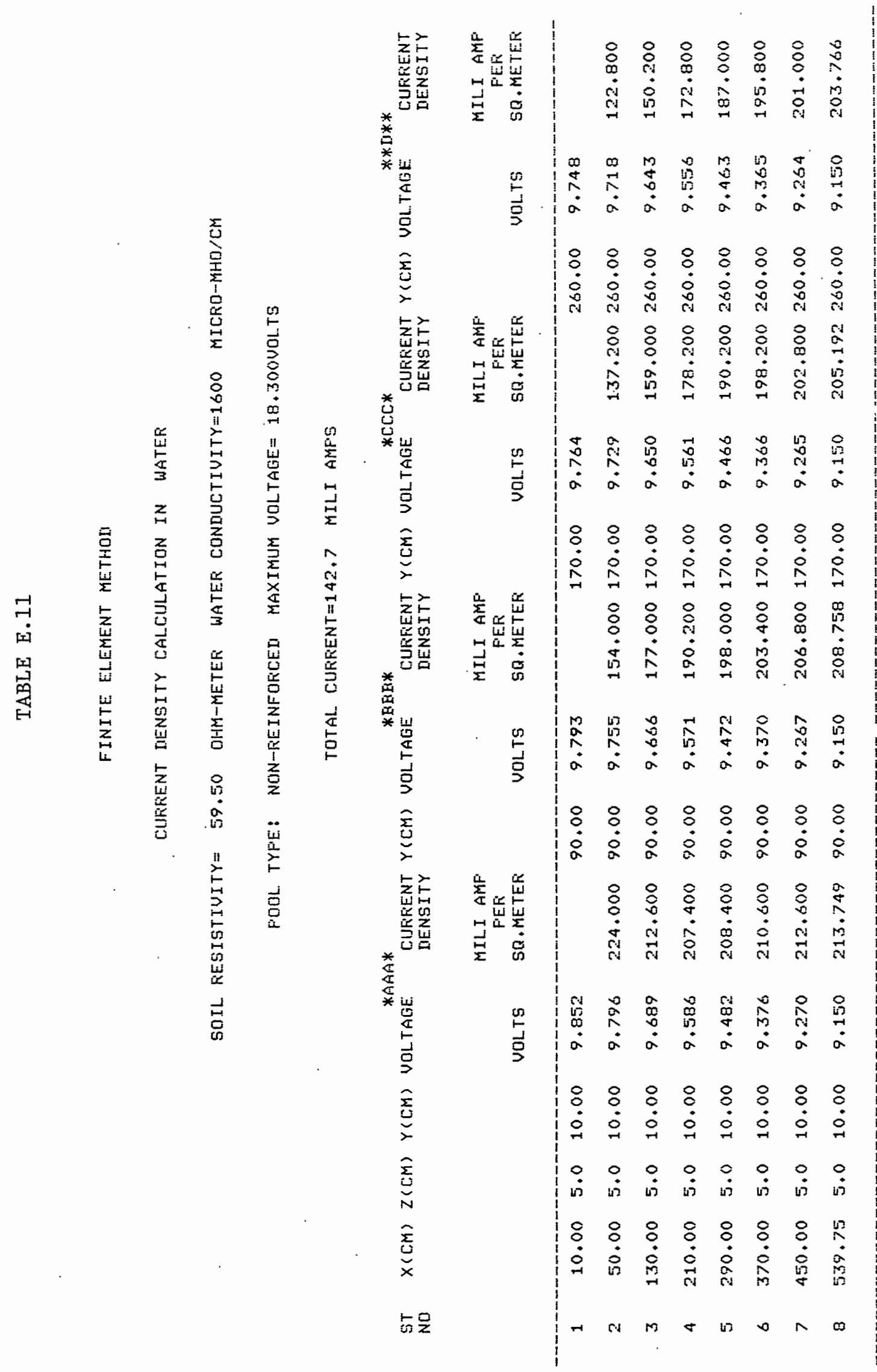




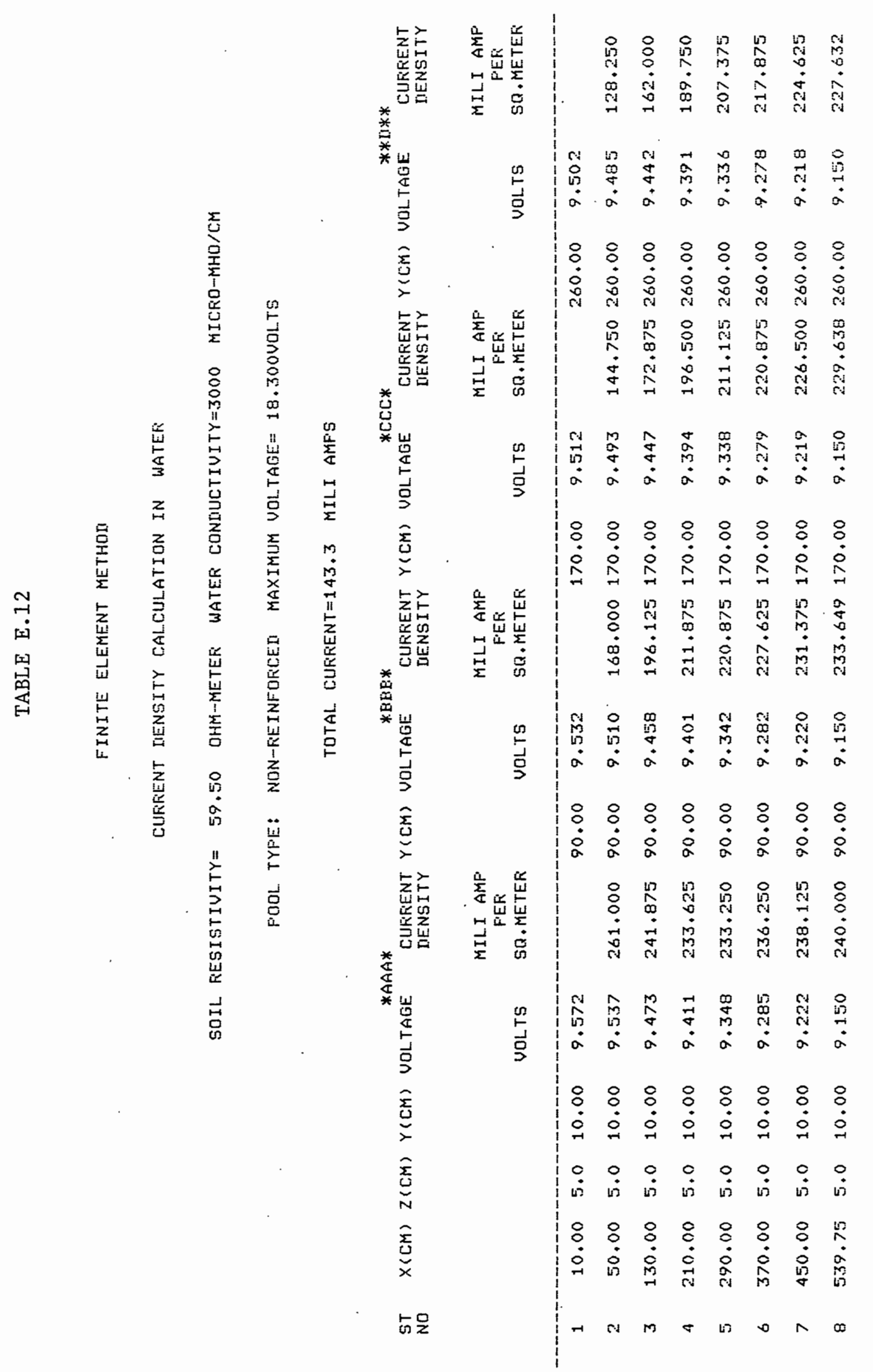




\section{APPENDIX F}

EXPERIMENTAL RESULTS 


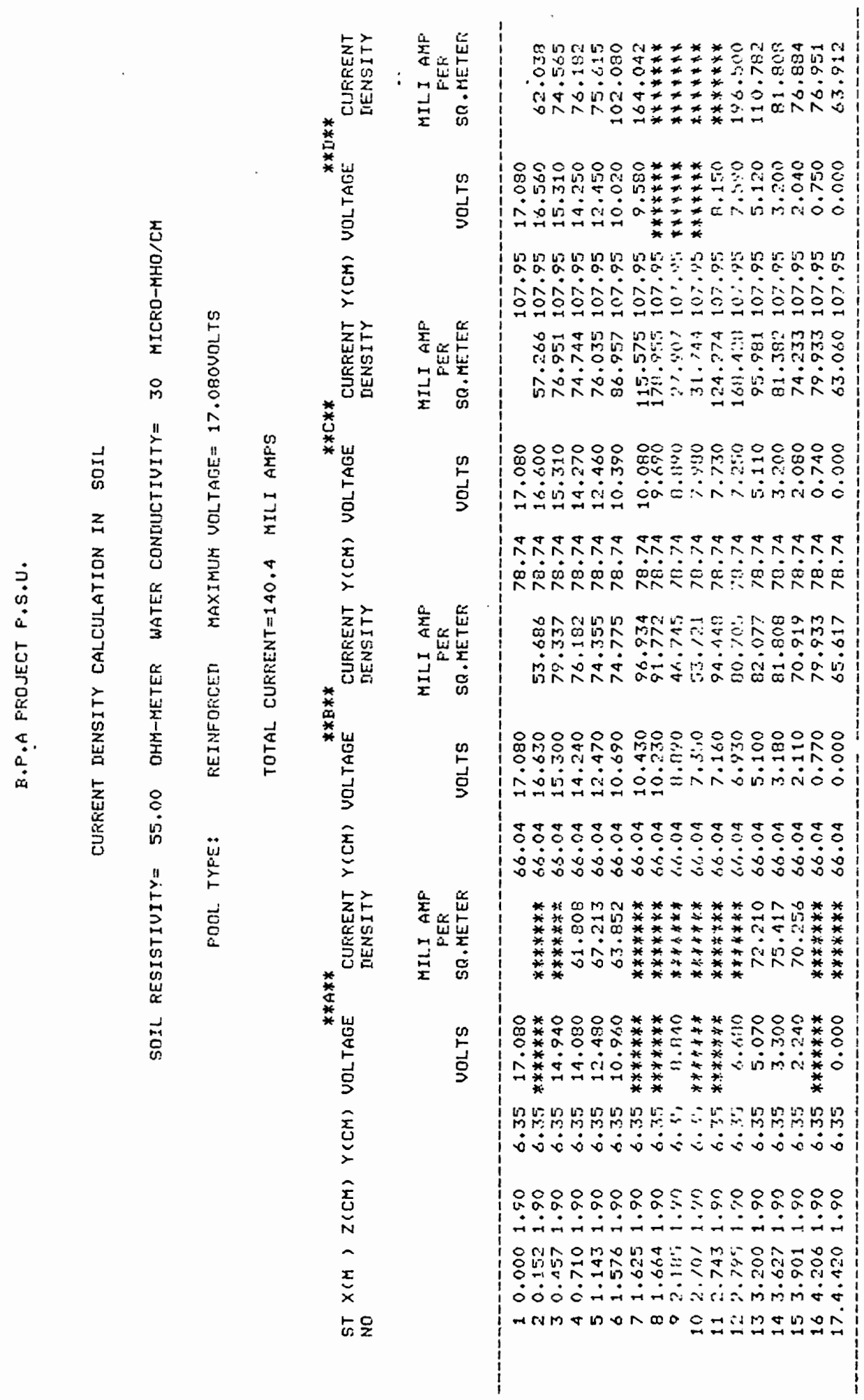


도

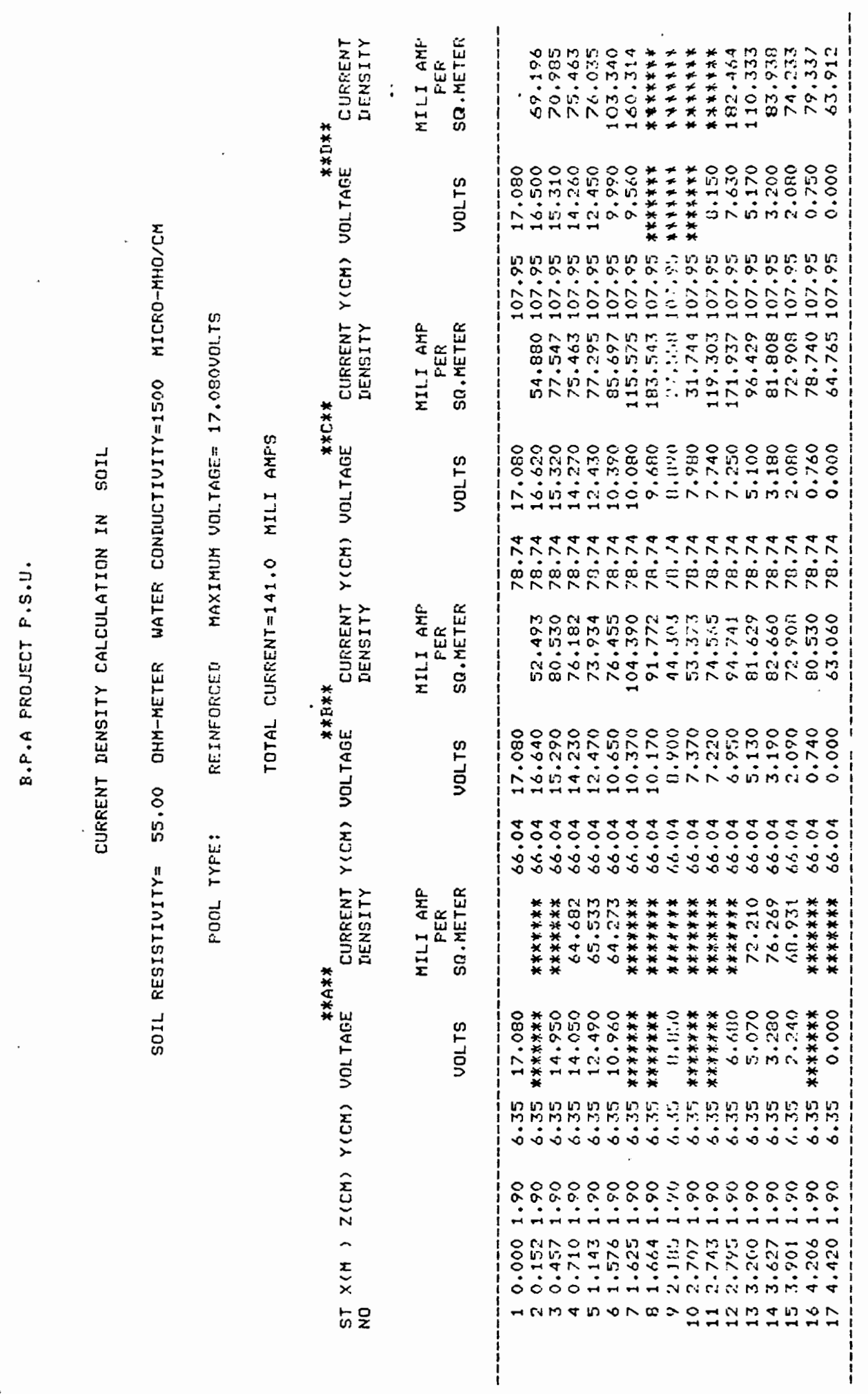


m

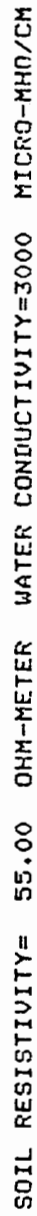

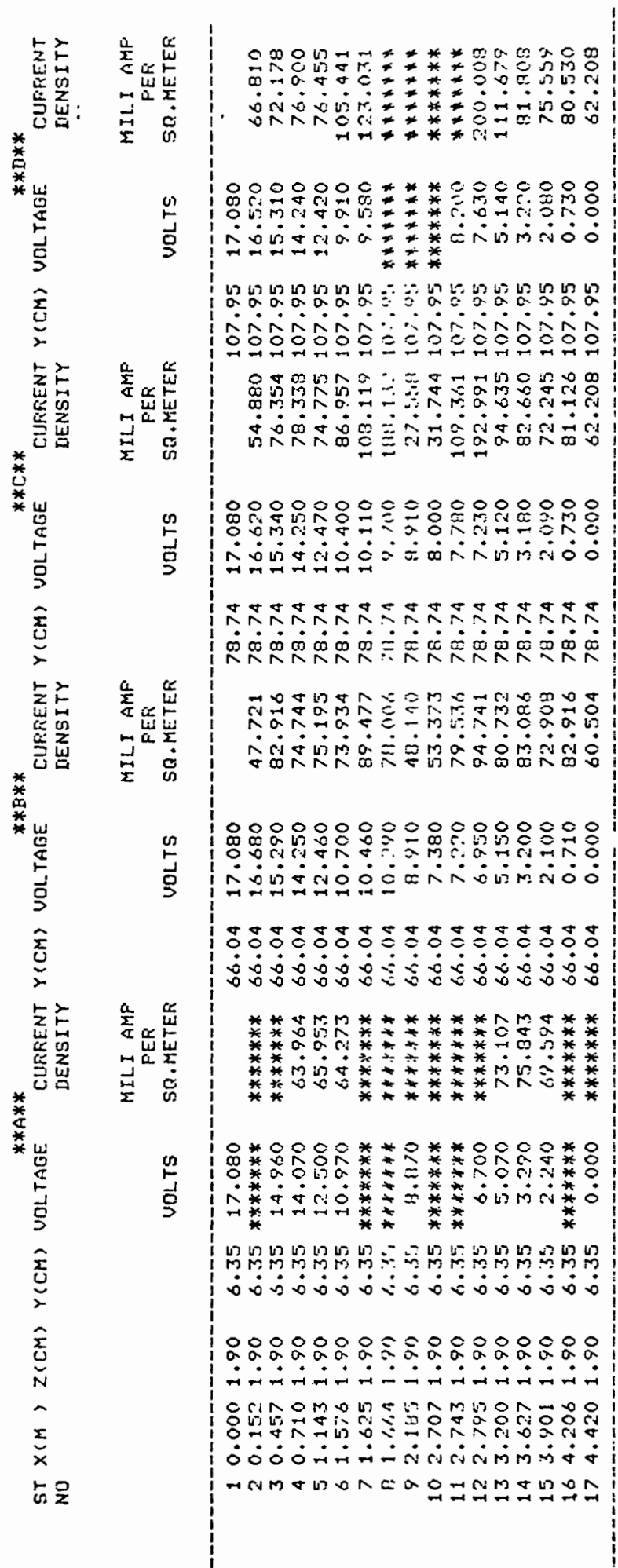


돈

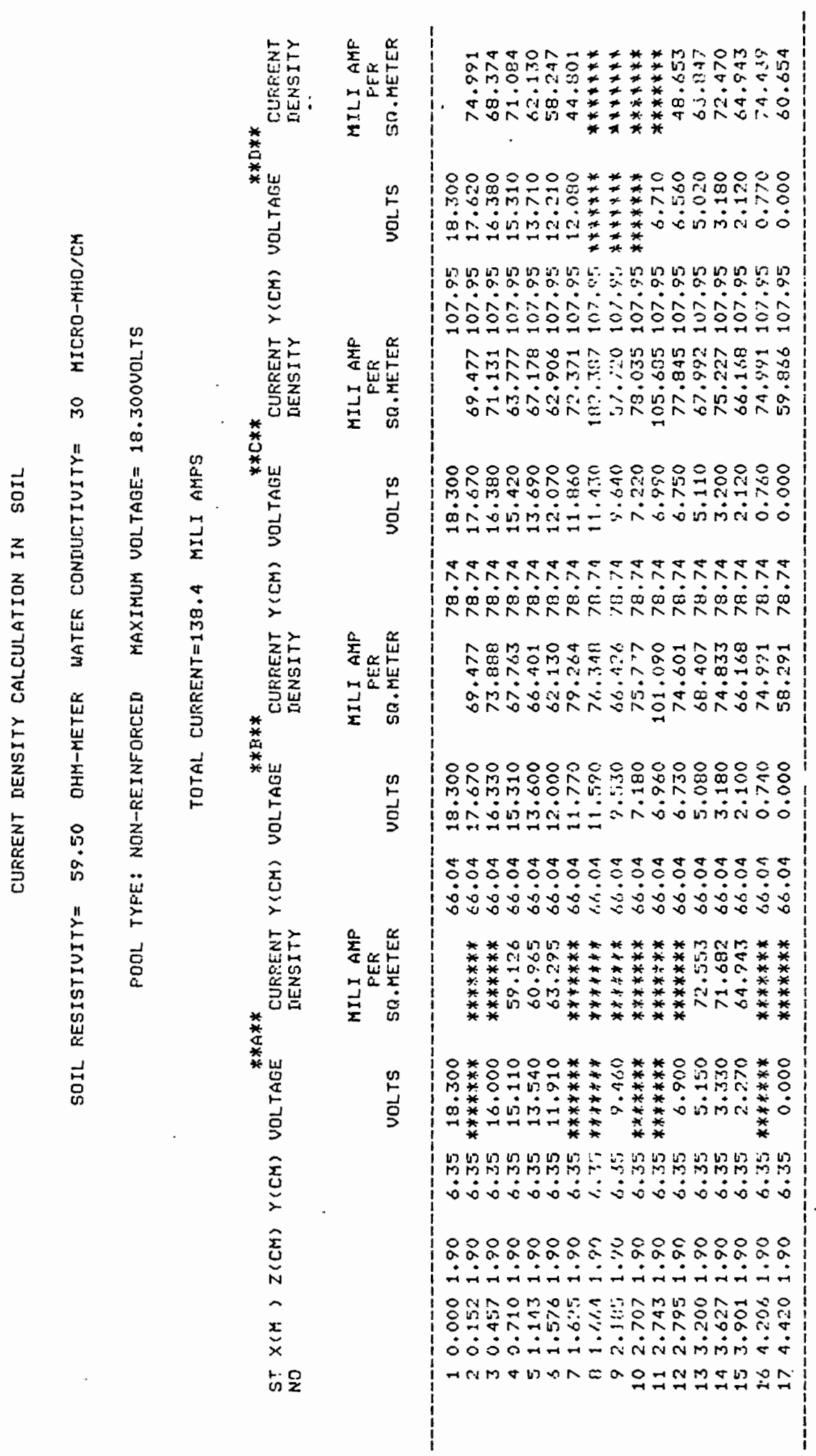


的

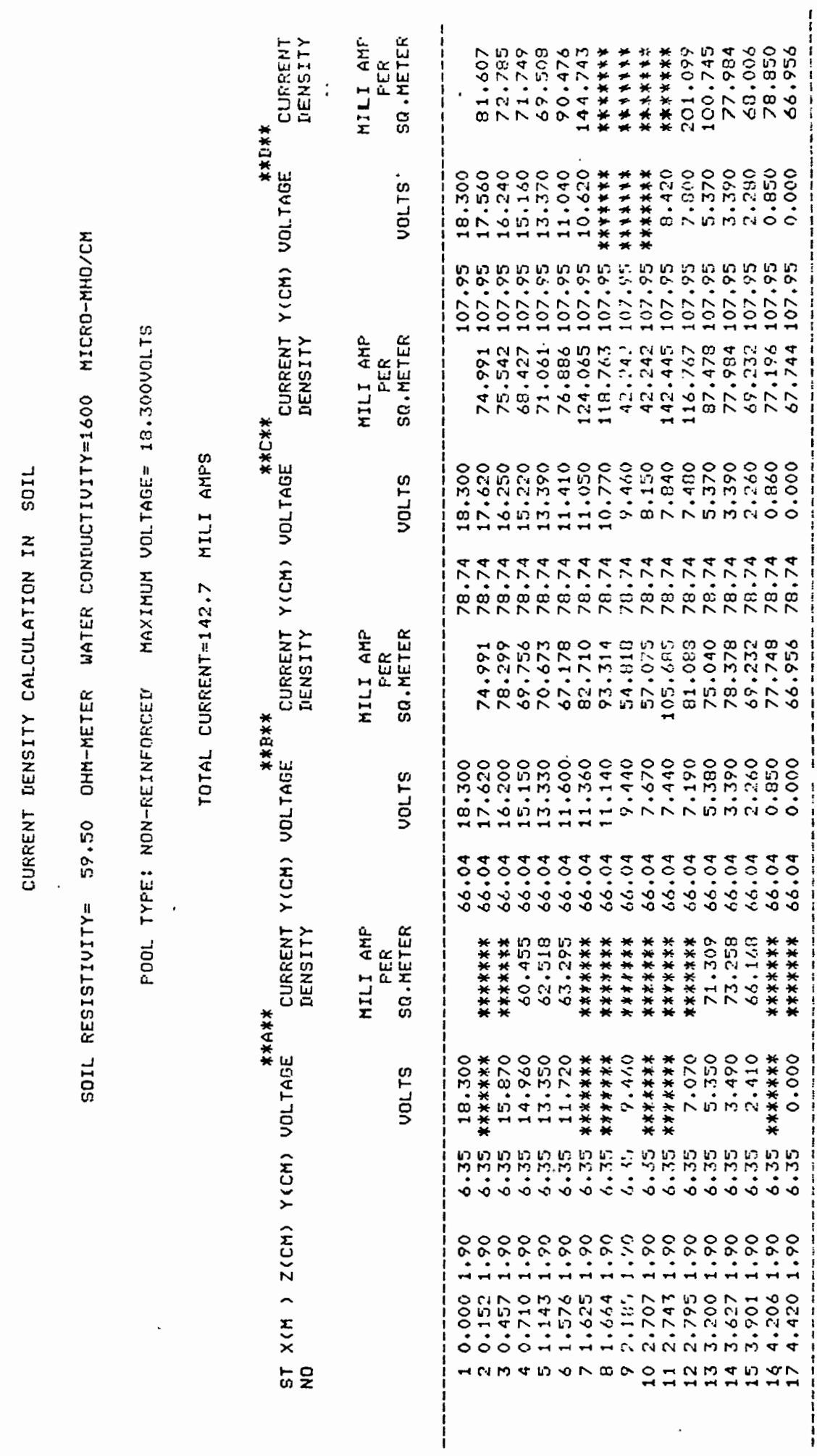


孚

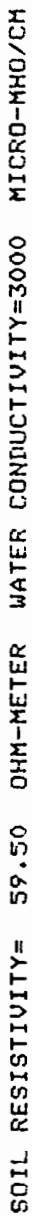

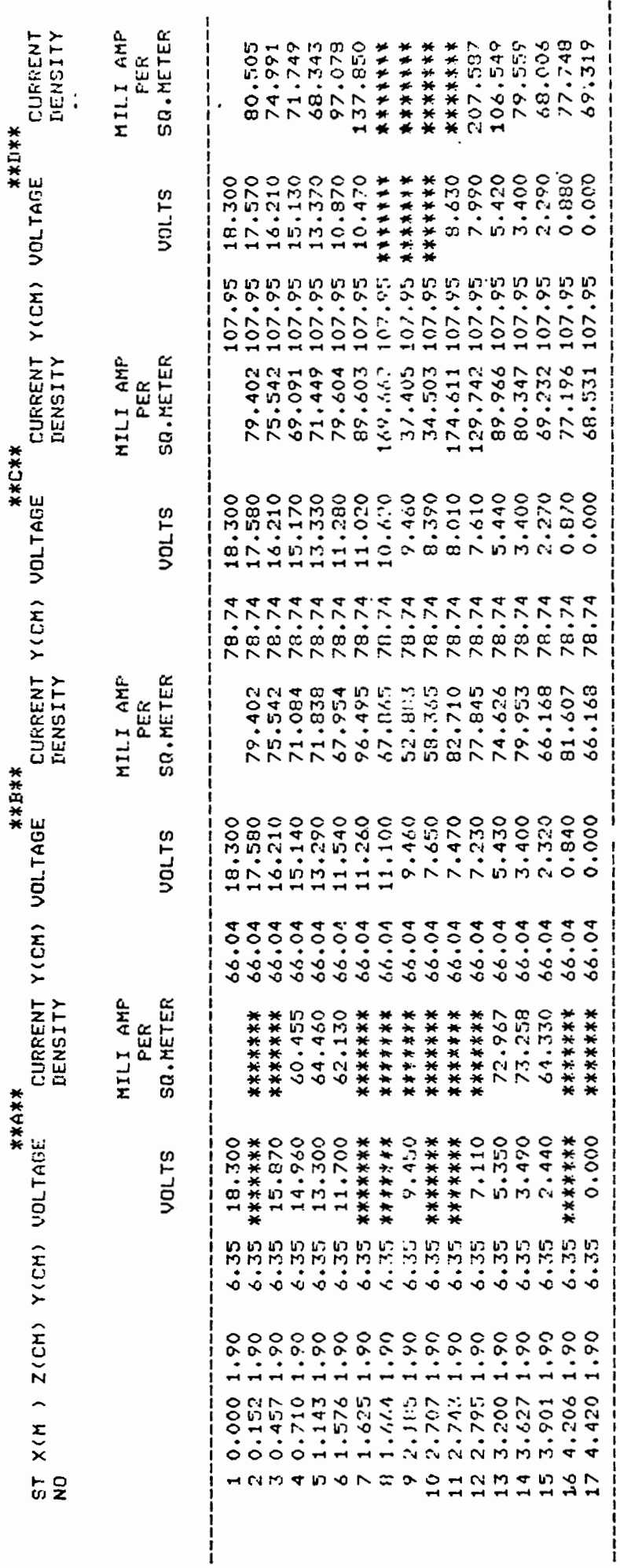


品

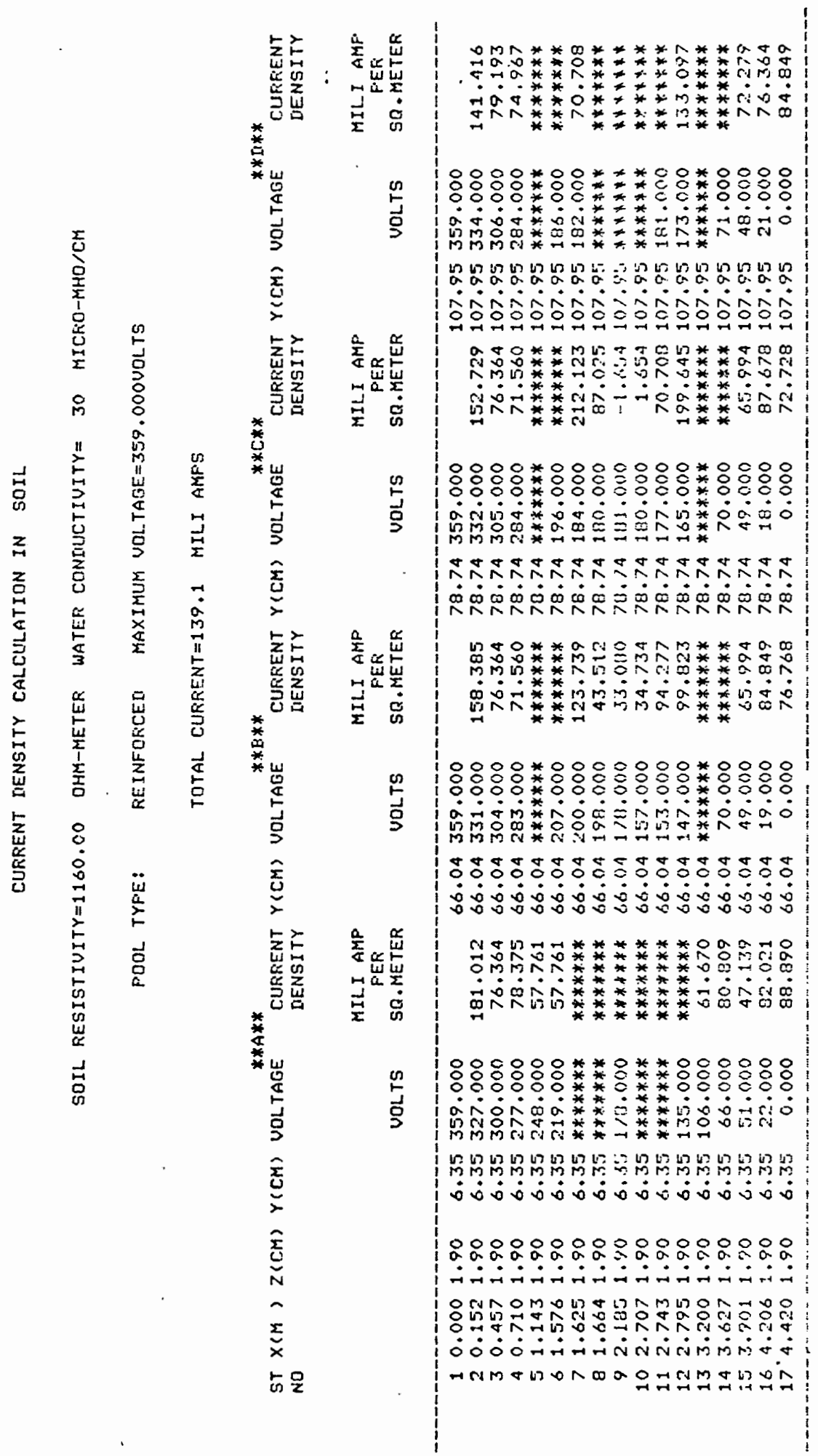




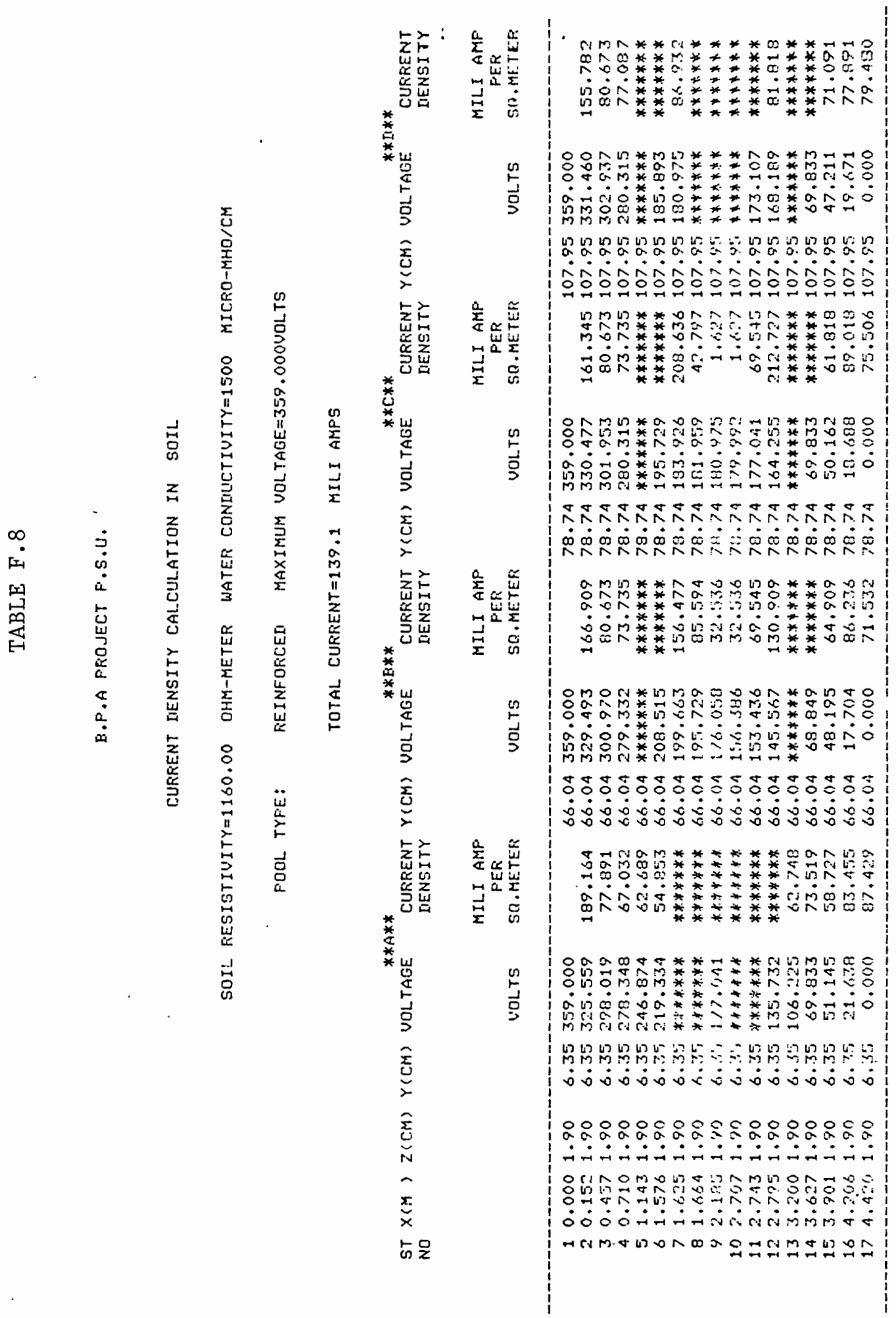




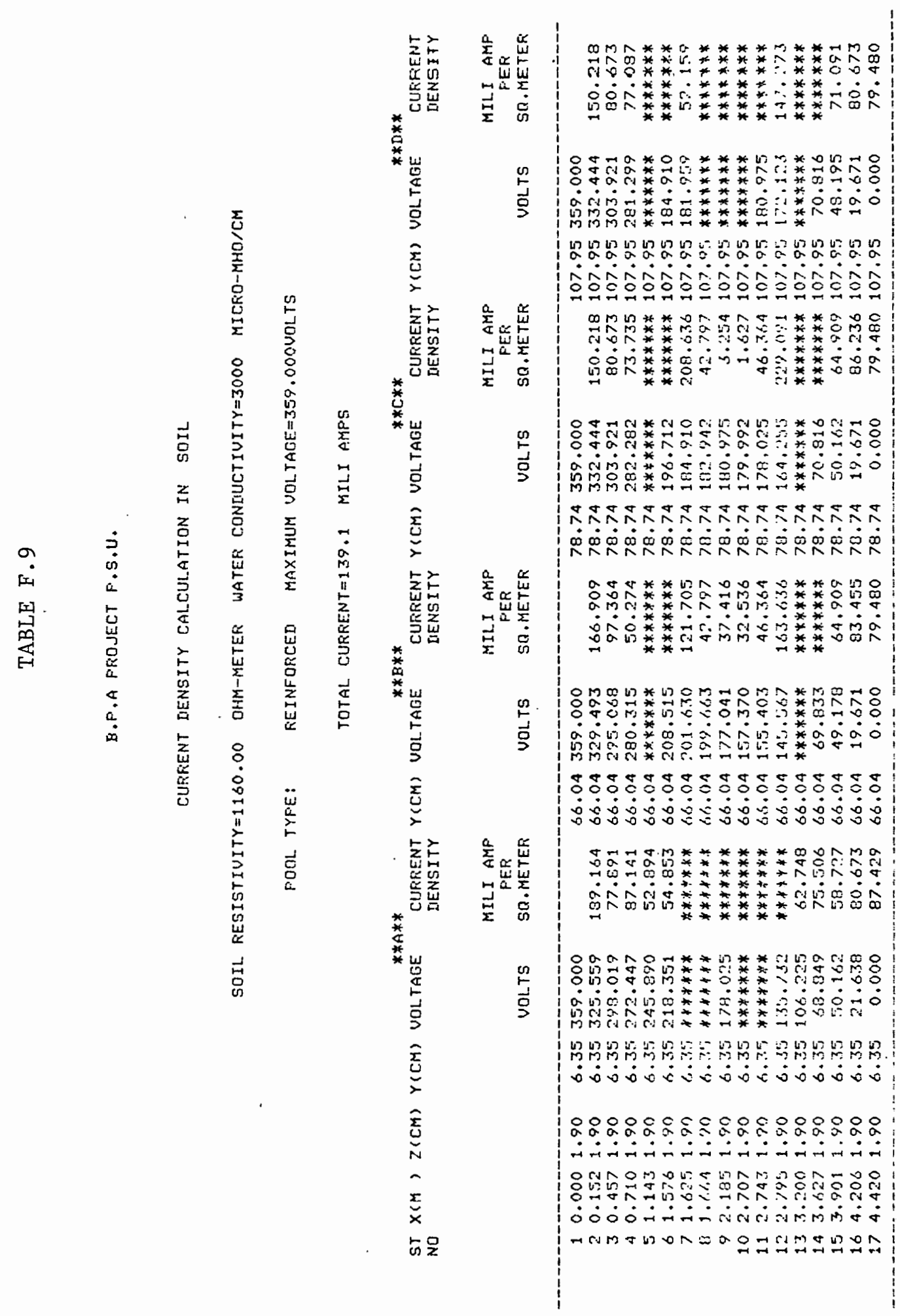




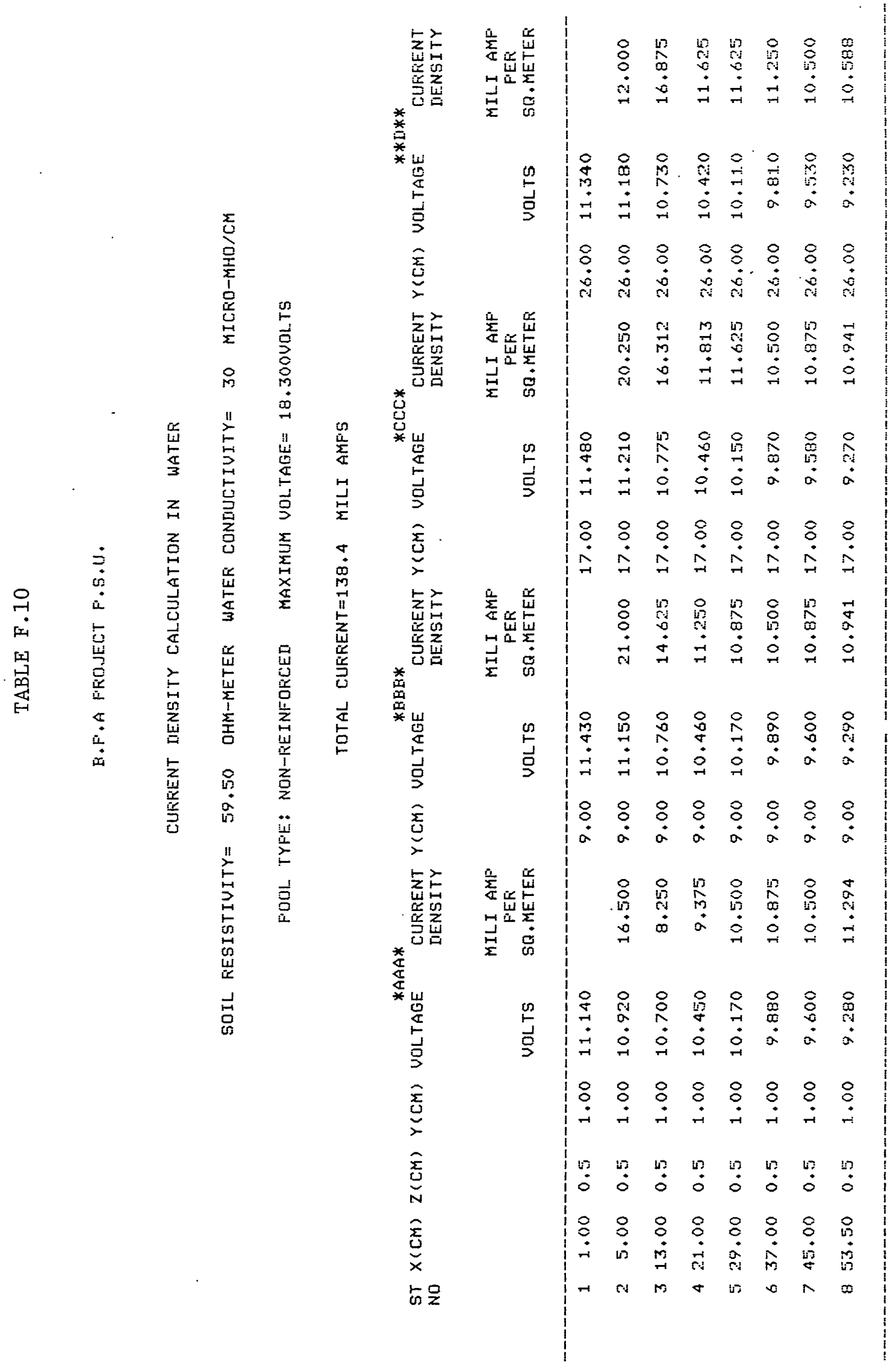




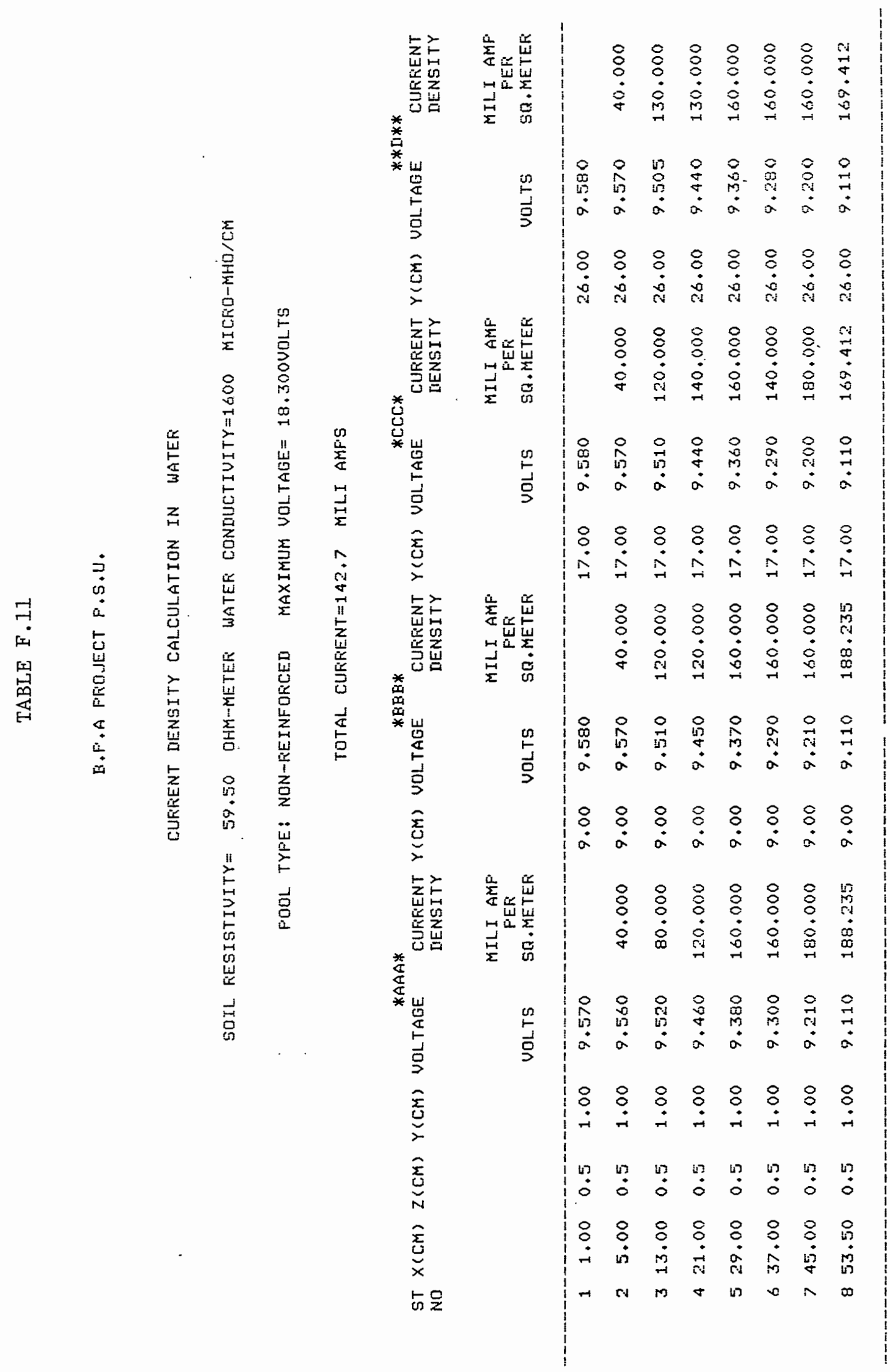




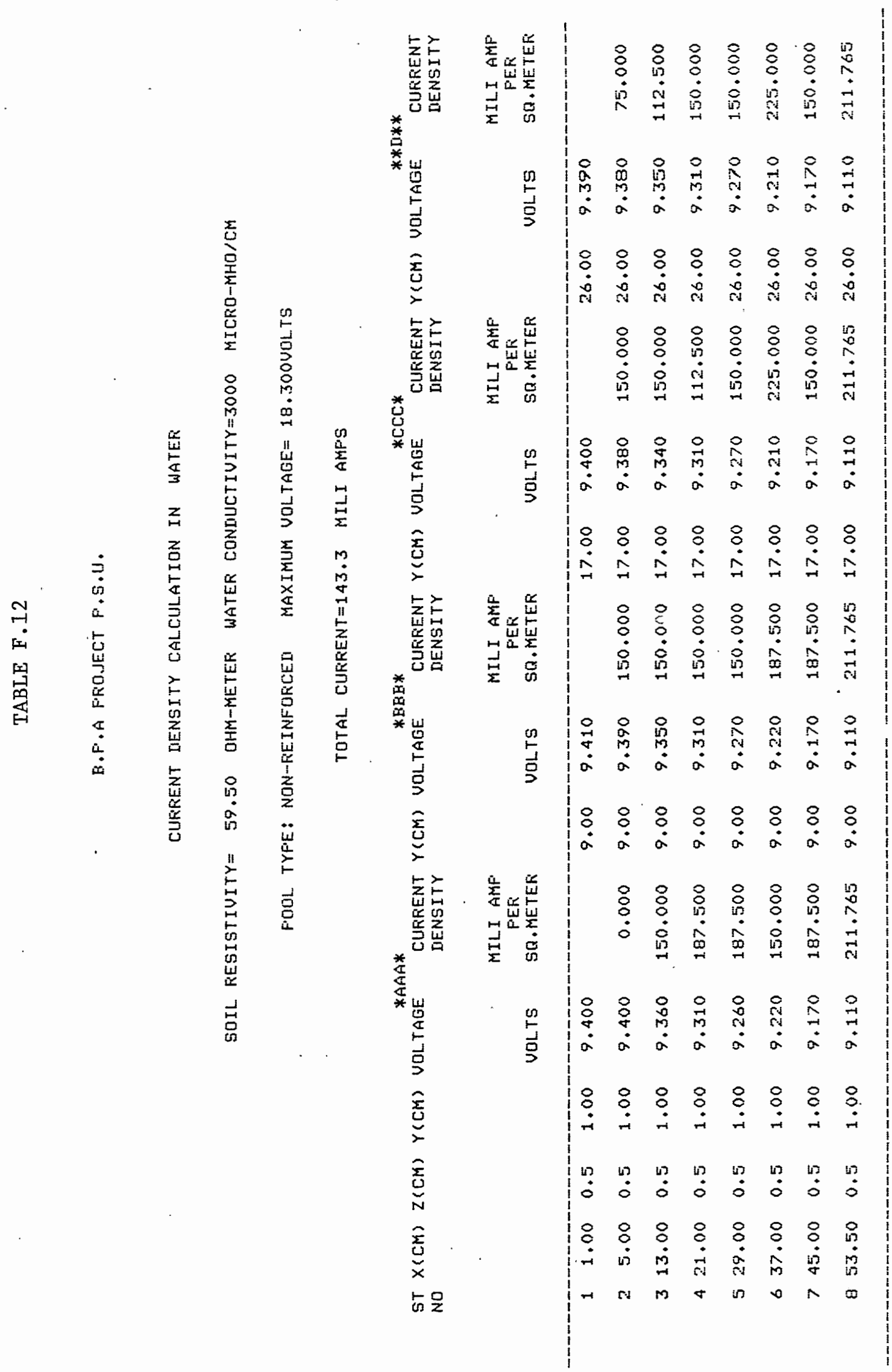

